University of Louisville

ThinkIR: The University of Louisville's Institutional Repository

Electronic Theses and Dissertations

$5-2014$

\title{
Effectiveness of chronic obstructive pulmonary disease (COPD) management program at the University of Louisville.
}

Malhar Anantbhai Jhaveri

University of Louisville

Follow this and additional works at: https://ir.library.louisville.edu/etd

Part of the Epidemiology Commons

\section{Recommended Citation}

Jhaveri, Malhar Anantbhai, "Effectiveness of chronic obstructive pulmonary disease (COPD) management program at the University of Louisville." (2014). Electronic Theses and Dissertations. Paper 686.

https://doi.org/10.18297/etd/686

This Doctoral Dissertation is brought to you for free and open access by ThinkIR: The University of Louisville's Institutional Repository. It has been accepted for inclusion in Electronic Theses and Dissertations by an authorized administrator of ThinkIR: The University of Louisville's Institutional Repository. This title appears here courtesy of the author, who has retained all other copyrights. For more information, please contact thinkir@louisville.edu. 


\title{
EFFECTIVENESS OF CHRONIC OBSTRUCTIVE PULMONARY DISEASE (COPD) MANAGEMENT PROGRAM AT THE UNIVERSITY OF LOUISVILLE
}

\author{
By \\ Malhar Anantbhai Jhaveri \\ M.B.B.S., Sardar Patel University, March 2005 \\ M.P.H., University of Kentucky, May 2009 \\ A Dissertation \\ Submitted to the Faculty of the \\ School of Public Health and Information Sciences of the University of Louisville \\ in Partial Fulfillment of the Requirements \\ for the Degree of \\ Doctor of Philosophy \\ Department of Epidemiology \\ University of Louisville \\ Louisville, Kentucky
}

May 2014 
Copyright 2014 by Student Malhar A Jhaveri

All Rights Reserved 

EFFECTIVENESS OF CHRONIC OBSTRUCTIVE PULMONARY DISEASE (COPD) MANAGEMENT PROGRAM AT THE UNIVERSITY OF LOUISVILLE

\author{
By

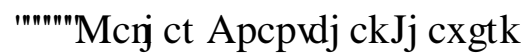 \\ M.P.H., University of Kentucky \\ M.B.B.S., Sardar Patel University \\ A ' issertation approved on \\ April $18^{\text {th }} 2014$
}

By the following Dissertation Committee:
Frank $\overline{\text { Groves, MD, MPH (Committee }}$ Chair)
Rodney J Folz, MD, PhD

Richard N. Baumgartner, PhD

Susan Muldoon, $\mathrm{PhD}$

Guy Brock, PhD 


\section{' ( ' ,\&\$ 7,210}

I dedicate this dissertation to my parents

Mr. Anantbhai C Jhaveri and Mrs. Sulataben A Jhaveri, who has always been source of my inspiration and hard work. 


\section{\$\&. $12: /(' *(0)(176$}

I would like to gratefully and sincerely thank Dr. Frank Groves for his guidance, understanding, patience, and most importantly, his mentorship during my graduate studies at the University of Louisville. His mentorship was paramount in providing a well-rounded experience consistent with my long-term career goals. He encouraged me to not only grow as an epidemiologist but also as an instructor and an independent thinker. I would also like to thank Dr. Rodney Folz for his assistance and guidance in getting my graduate career started on the right foot and providing me with the foundation for becoming an independent researcher. I would specially thank him for allowing me to use his data for my dissertation. I would also like to thank my dissertation committee members: Drs. Richard Baumgartner, Guy Brock, and Susan Muldoon, who gave me their valuable time whenever I needed and advise me during the time of doctoral program. I would also like to thank the entire team of researchers at the University of Louisville COPD management program team who were actively involved in the program.

Finally, and most importantly, I would like to thank my wife and my best friend Aanal Shah. Her support, encouragement, quiet patience and unwavering love were undeniably the bedrock upon which the past three years of my life have been built. Her tolerance of my occasional tantrum moods is a witness in itself of her unyielding devotion and love. I thank my parents Mr. Anantbhai Jhaveri and Mrs. Sulataben Jhaveri for their 
faith in me and allowing me to be as ambitious as I wanted. Even though they live very far from me they are always a phone call away whenever I needed them. Also, I thank Aanal's parents, Mr. Ashitbhai Shah and Mrs. Sonalben Shah for their encouragement and support during my time in $\mathrm{PhD}$. I would also like to thank all my three brothers (Jinal Jhaveri, Viral Jhaveri, and Manan Jhaveri) and only sister (Bijal Jhaveri) for their valuable support throughout my whole journey and always stood by my side in every step of my life. 
\$\%675\$\&7

\title{
EFFECTIVENESS OF CHRONIC OBSTRUCTIVE PULMONARY DISEASE (COPD) MANAGEMENT PROGRAM AT THE UNIVERSITY OF LOUISVILLE
}

\author{
Malhar A Jhaveri
}

April $18^{\text {th }} 2014$

Background: Chronic obstructive pulmonary disease (COPD) is a progressive disease of the respiratory system characterized by airflow limitation that is not completely reversible and is associated with systemic effects especially of the cardiovascular system. COPD is frequently complicated by acute exacerbations that contribute to physical impairment and increased health care use. As COPD is a chronic lung disease with significant systemic manifestations, it is important to have chronic disease management programs specifically targeting individuals with COPD designed to improve their overall quality of life, reduce the burden of disease and decrease the impact of COPD on daily life. Chronic disease management encompasses a multidisciplinary approach designed to enhance the quality and cost-effectiveness of health care for chronic conditions and has been defined as "an approach to patient care that emphasizes coordinated, comprehensive care along the continuum of disease and across health care delivery systems". The purpose of this present study is to evaluate the effectiveness of a chronic obstructive 
pulmonary disease management program implemented at the University of Louisville in 2011.

Methods: We conducted a retrospective observational cohort study of COPD subjects using clinical data from medical records and cost data from a claims dataset. Respiratory health was assessed by pulmonary function testing, St. George Respiratory questionnaire, COPD Assessment Test (CAT), 6 minute walk test (6MWT), Modified Medical Research Council (mMRC) dyspnea scale, and BODE index. General measures include Duke Profile for assessing overall health and Patient Health Questionnaire (PHQ-9) for assessing depression. At baseline, chi-square test for categorical variable and t-test for continuous variable was used to check for any difference between the two groups. To check for any longitudinal significant change in quality of life measures like SGRQ, CAT score, mMRC scale, BODE index, six minute walk distance and PFT measures from baseline paired t-test was performed. For each subject, the baseline probability of participation in the disease management program was calculated by the propensity score method using logistic regression analysis. Multiple linear regression analysis was performed to assess the rate of deterioration of various clinical parameters like $\mathrm{FEV}_{1}$ and FVC between two groups. Cost analysis was done by comparing the cost related to COPD among subjects in DMP group versus those under usual care. These costs includes total COPD cost, and also sub-categories of cost like office visit cost, in-patient hospitalization (IPH) cost, out-patient hospitalization (OPH) cost, pharmacy cost, cost related to home care and laboratory cost.

Results: A total of 52 subjects were enrolled in the disease management program between February $1^{\text {st }} 2011$ and December $31^{\text {st }} 2013: 37$ in 2011, 11 in 2012 and 4 in 
2013. The usual care group consists of 662 subjects diagnosed with COPD. There is a significant difference in average age of subjects between the two groups (54.2 in DMP versus 58.3 in usual care; $\mathrm{P}$ value 0.0094$)$. Subjects who suffered from asthma, rhinitis and arthritis were significantly more likely to enroll in the disease management program. At baseline, the average PHQ9 was 6.3 which improved at the end of 12 months (mean = 4) and at 24 months (mean = 3.1). At baseline, the average duke score was 64.1 which were improved at the end of 12 months (mean $=71.6)$ and 24 months $($ mean $=68.3)$. At baseline average SGRQ score was 37.1 which were improved at the end of 12 months $($ mean $=28.4, \mathrm{P}=0.02)$ and 24 months from $($ mean $=30.2, \mathrm{P}=0.21)$. We found that not only did those subjects enrolled in the COPD program decrease their rate of loss of lung function, but remarkably showed a significant improvement in $\mathrm{FEV}_{1}$ from baseline to 12 months (mean difference: $140 \mathrm{ml}$, P value $=0.0046$ ) and from baseline to 24 months (mean difference: $30 \mathrm{ml}, \mathrm{P}$ value 0.55 ). Average cost per person per year among subjects in DMP group in first year is $\$ 3693$, which decreased to $\$ 3608.8$ in second year and to \$2934 in third year. Pharmacy cost contributes majority of total COPD cost followed by office cost and out-patient hospitalization. There is a significant decline in cost related to all major diseases like arthritis, hypertension, hyperlipidemia, diabetes, and osteoporosis after enrollment of COPD subjects into disease management program comparing to cost before enrollment into program. Average cost per person per year for in-patient hospitalization is significantly high for subjects in usual care (\$5578.7) versus subjects in DMP group (\$250.9).

Conclusion: The University of Louisville COPD disease management program appears to be effective in improving lung health and reducing airflow limitations among COPD 
subjects as evidence by significant improvement in objective measures like $\mathrm{FEV}_{1}$.

Program is also effective in reducing the impact of COPD on daily activities as evident by significant improvement in subjective measures for health related quality of life like $\mathrm{St}$ George Respiratory Questionnaire, COPD assessment test, PHQ9 and Duke Profile. Notwithstanding subjects in DMP had higher COPD related cost, they had significantly low in-patient hospitalization cost and also significant reduction in cost associated with major co-morbidities after enrollment in the disease management program. 


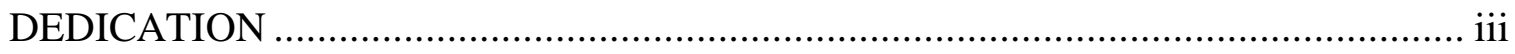

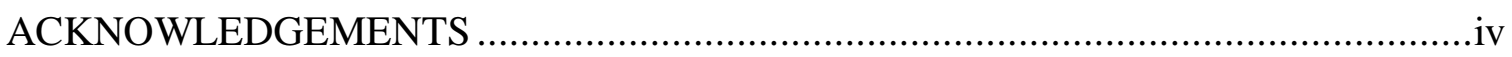

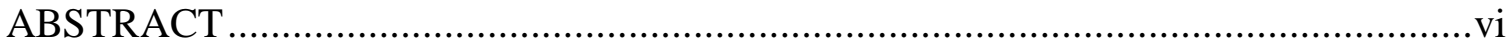

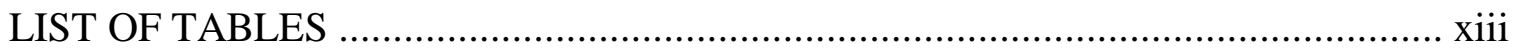

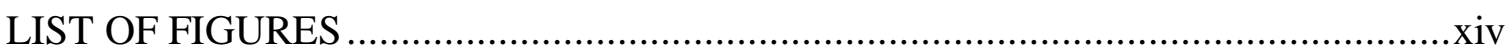

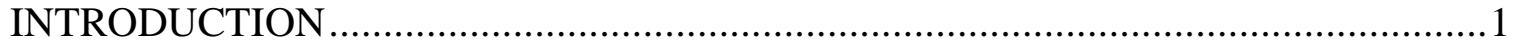

BACKGROUND

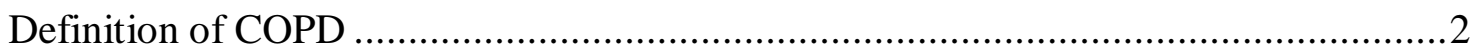

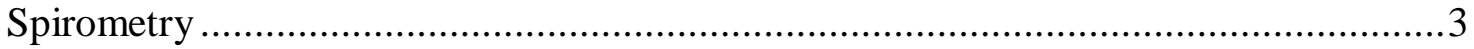

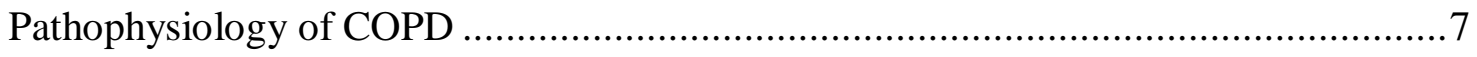

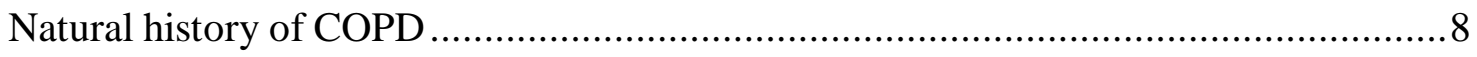

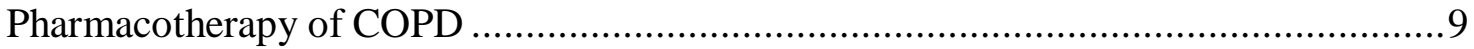

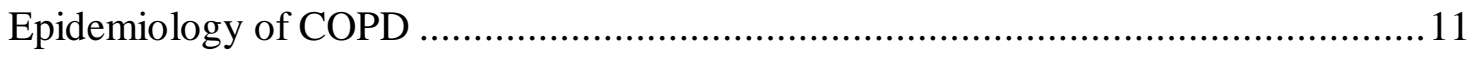

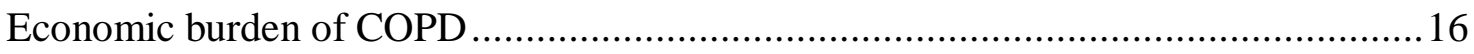

Chronic Disease Management .............................................................................18

Definition of chronic disease management ...........................................................18

Disease management Program (DMP) ………………...................................19

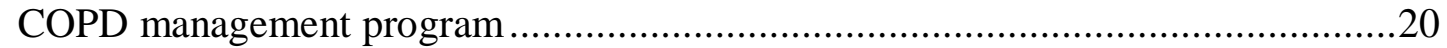

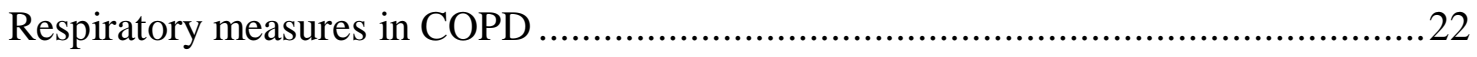

Six Minute Walk Test (6 MWT) .....................................................................22

MMRC Dyspnea Scale ………………….....................................................24

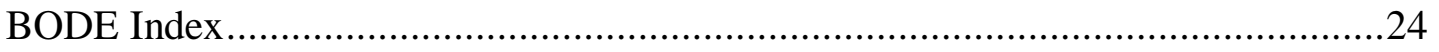

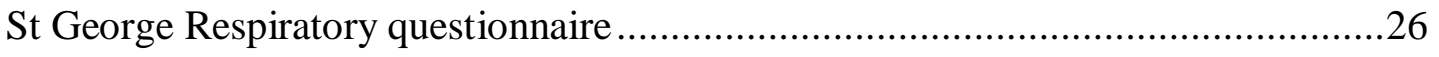

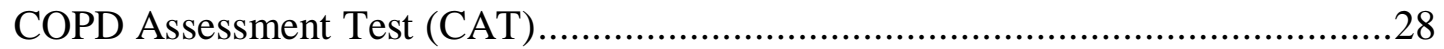

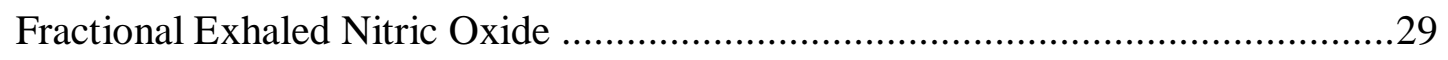

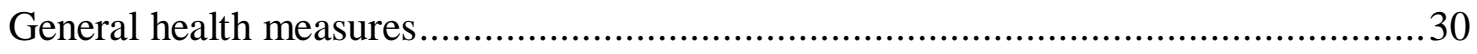

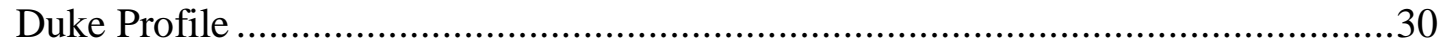

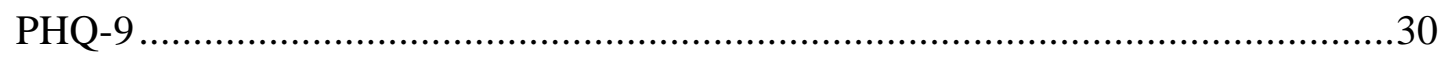




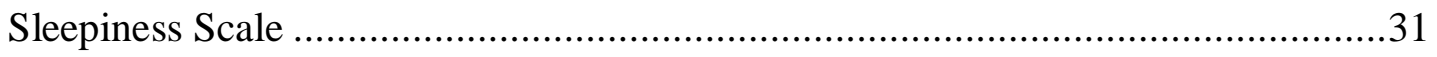

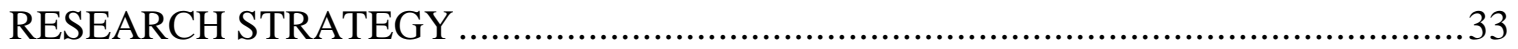

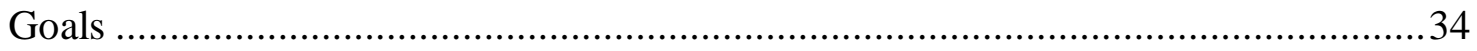

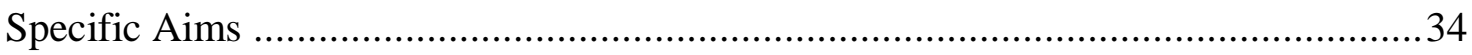

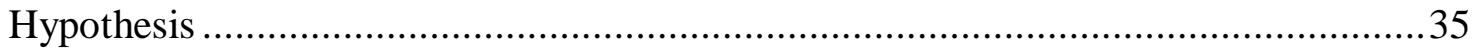

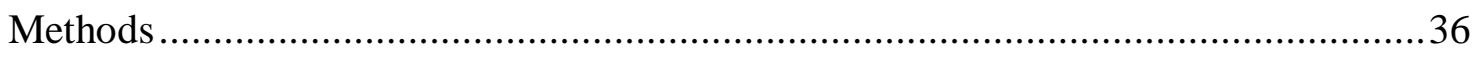

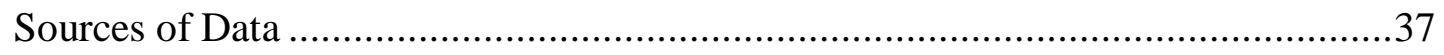

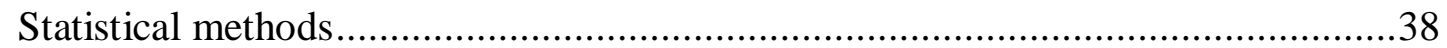

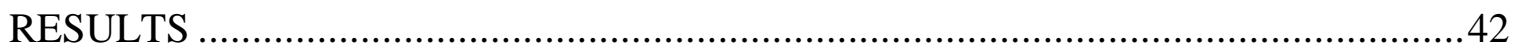

Descriptive statistics and baseline characteristics of the study subjects ......................42

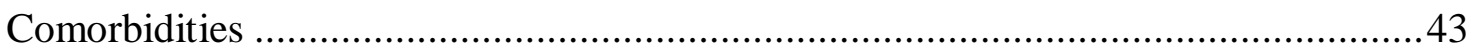

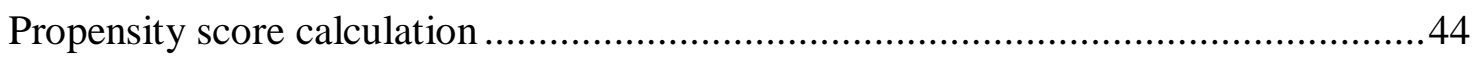

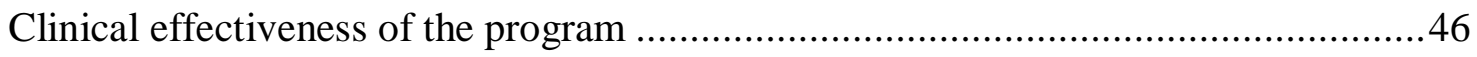

Longitudinal changes of General Measures in DMP group ....................................46

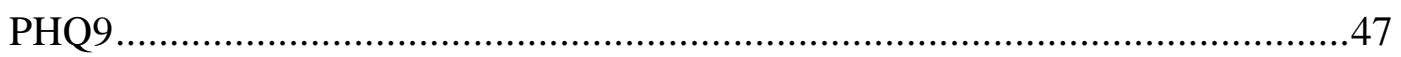

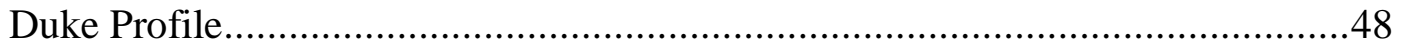

Longitudinal changes of Respiratory Measures in DMP group................................49

St George Respiratory Questionnaire (SGRQ) ...................................................50

COPD Assessment Test (CAT) .................................................................

Modified Medical Research Council (mMRC) Dyspnea Scale ...........................52

Longitudinal changes of Pulmonary Function Test in DMP Group and Usual Care

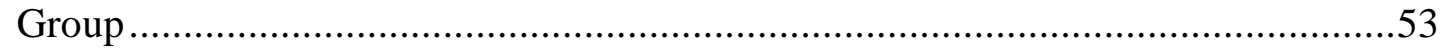

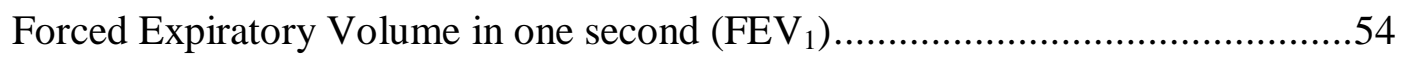

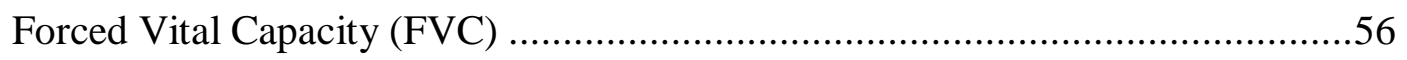

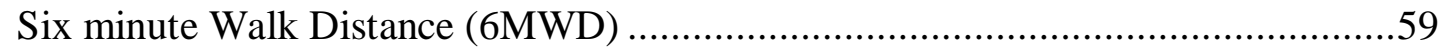

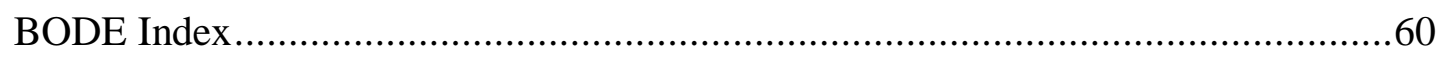

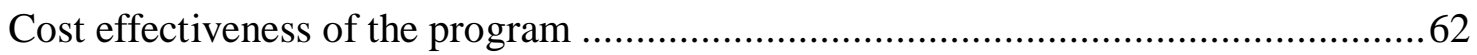

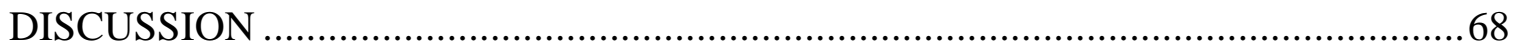

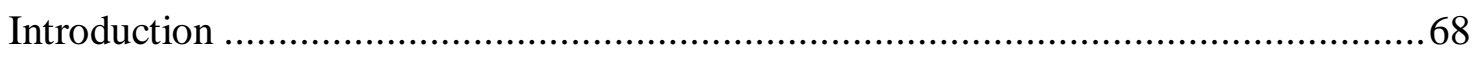

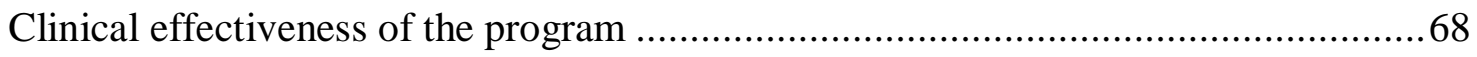

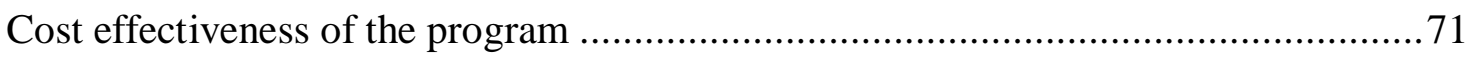




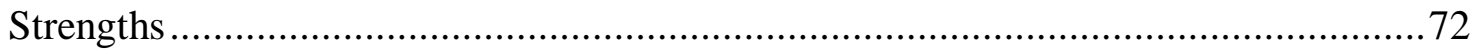

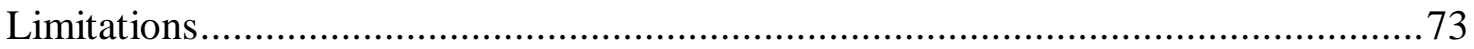

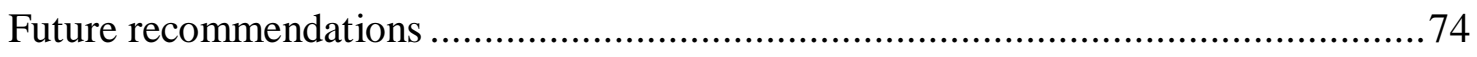

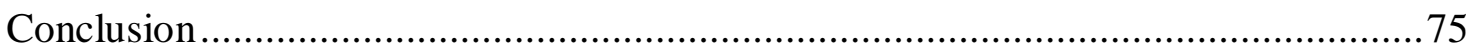

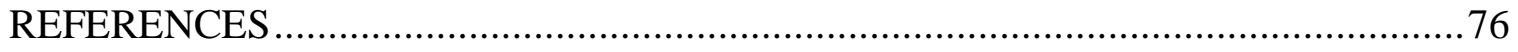

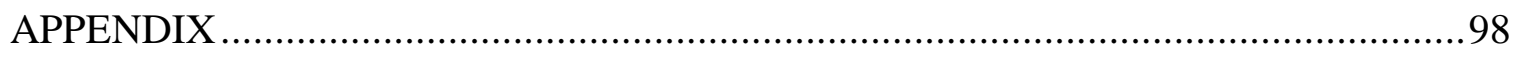

Appendix 1: NHANES Spirometry references graphs....................................98

Appendix 2: Natural Decline of FEV1 by Age ..................................................99

Appendix 3: University of Louisville COPD Disease Management Program ............ 100

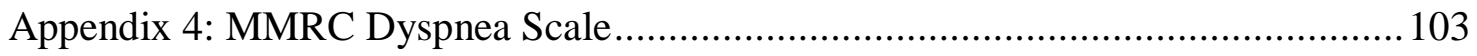

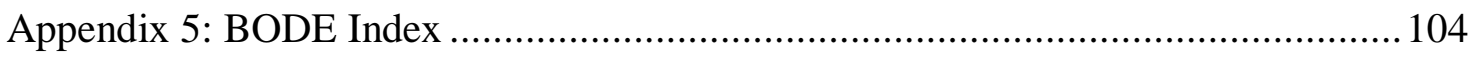

Appendix 6: St George Respiratory Questionnaire ........................................... 105

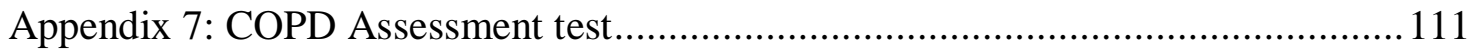

Appendix 8: Duke Health Profile ..................................................................... 112

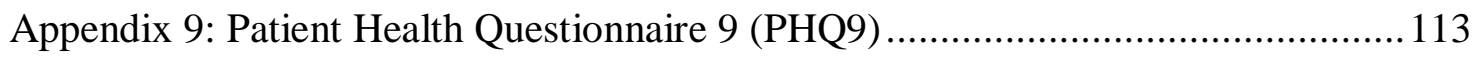

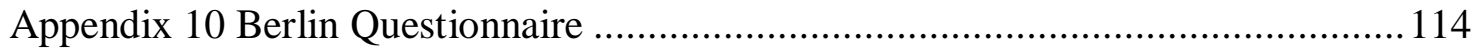

Appendix 11 Epworth Sleepiness Scale ...................................................... 116

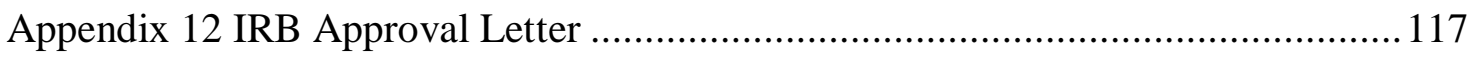

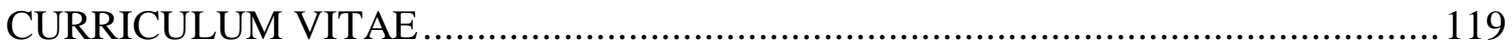




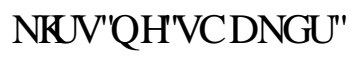

Table 1 Pulmonary Function test findings in different lung disease .............................4

Table 2 Epidemiological studies of Smoking and COPD .......................................15

Table 3 Summary of Respiratory and General Measures in COPD ..............................32

Table 4 Baseline characteristics of study subjects ...................................................42

Table 5 Prevalence of Co-morbidities among the study subjects .................................44

Table 6 Logistics regression model for propensity score calculation ...........................44

Table 7 Longitudinal changes of general measures in DMP group .............................46

Table 8 Longitudinal changes of Respiratory measures in DMP group.........................49

Table 9 Longitudinal comparison of mMRC Dyspnea Scale ...................................52

Table 10 Longitudinal changes in Pulmonary Function test measures in DMP and Usual

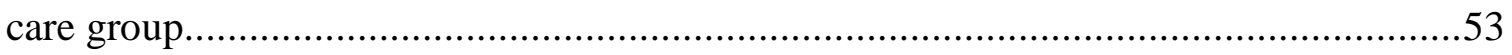

Table 11 Longitudinal comparison of changes in absolute $\mathrm{FEV}_{1}(\mathrm{ml})$.........................54

Table 12 Estimates from Linear regression Models for examining changes in absolute

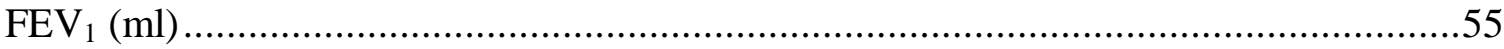

Table 13 Longitudinal comparison of changes in absolute FVC $(\mathrm{ml})$............................56

Table 14 Estimates from linear regression models for examining change in absolute .....57

Table 15 Longitudinal changes in 6 MWD (meter) in DMP and Usual care group .........59

Table 16 Longitudinal comparison of changes in 6 MWD ......................................60

Table 17 Longitudinal comparison of changes in BODE index in DMP Group .............61

Table 18 COPD related cost in DMP Group.............................................................62

Table 19 Comparison of COPD related cost between two groups from 2009-2013........63

Table 20 Regression model for COPD related cost ...............................................65

Table 21 Health Care Utilizations and Average number of claims ...............................65

Table 22 Co-morbidities related cost in Usual Care Group and Disease management

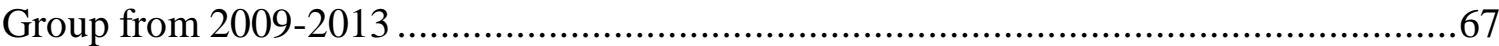




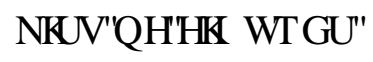

Figure 1 Age specific prevalence of COPD among US adults aged $\geq 25$ years (BRFSS) ..13

Figure 2 Distribution of Propensity score in DMP group and Usual care group .............45

Figure 3 Longitudinal changes in PHQ9 in DMP group ..........................................47

Figure 4 Longitudinal changes in Duke score in DMP group ..................................48

Figure 5 Longitudinal changes in SGRQ score in DMP group ...............................50

Figure 6 Longitudinal changes in CAT score in DMP group ................................51

Figure 7 Longitudinal changes in mMRC scale in DMP Group...............................52

Figure 8 Longitudinal $\mathrm{FEV}_{1}$ and FVC changes in DMP Group and Usual Care Group (by

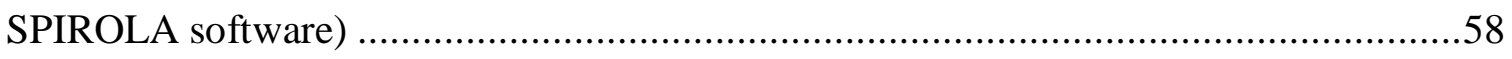

Figure 9 Longitudinal changes in BODE index in DMP Group ...............................61

Figure 10 Histogram of COPD related cost .....................................................64

Figure 11-Categories of COPD cost in DMP and Usual Care Group ..........................64

Figure 12 Co-morbidities cost before and after enrollment into disease management

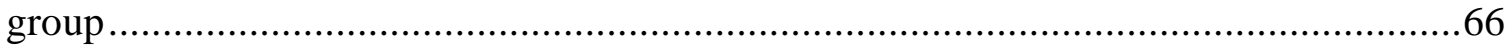




\section{$, 1752^{\prime} 8 \& 7,210$}

Chronic obstructive pulmonary disease (COPD) is a progressive disease of the respiratory system characterized by airflow limitation that is not completely reversible

and is associated with systemic effects especially of the cardiovascular system ${ }^{1,2}$. COPD is frequently complicated by acute exacerbations that contribute to physical impairment and increased health care use ${ }^{2}$. The COPD GOLD (Global Initiative for Obstructive Lung Disease) stage directly correlates with both severity and frequency of acute exacerbations $^{3}$. COPD is a major public health burden whose current prevalence is estimated to be approximately $8-10 \%$ in adults aged 40 years or more in developed countries like the USA. However, in developing countries, the prevalence varies widely and is difficult to estimate because of different definitions used to identify cases of $\mathrm{COPD}^{4}$. Regardless of the burden that COPD places on health care systems and the availability of recommendations for its management ${ }^{1}$, COPD remains a condition that is all too often sub-optimally managed. As COPD is a chronic lung disease with significant systemic manifestations, it is important to have chronic disease management programs specifically targeting individuals with COPD designed to improve their overall quality of life, reduce the burden of disease and decrease the impact of COPD on daily life. The University of Louisville implemented a chronic disease management program (DMP) for COPD in 2011. We evaluate here the clinical and cost effectiveness of the DMP for individuals with COPD at the University of Louisville. 
$\% \$ \& 5281^{\prime}$

\section{Definition of COPD}

COPD is a disease characterized by the combination of two conditions: chronic bronchitis and pulmonary emphysema ${ }^{5,6}$. Chronic bronchitis is best characterized as chronic inflammation of the bronchial airways and is defined clinically "as cough with sputum production every day for at least three months in a year for two or more consecutive years ${ }^{\$ 7,8}$. Pulmonary emphysema, on the other hand, is defined pathologically as "a dilation of alveoli distal to the terminal bronchioles along with destruction of the lining of the air sacs" ${ }^{\prime 6}$. There are many ways of defining COPD but the widely accepted definitions of COPD are from the American Thoracic Society (ATS), the European Respiratory Society (ERS) and the Global Initiative for chronic Obstructive Lung Disease (GOLD).

According to the ATS definition ${ }^{9}$ COPD is "a disease state characterized by the presence of airflow limitation due to chronic bronchitis or emphysema; the airflow obstruction is generally progressive, may be accompanied by airway hyperreactivity, and may be partially reversible". As per ERS, COPD is defined as 10 "reduced maximum expiratory flow and slow forced emptying of the lungs, which is slowly progressive and mostly irreversible to present medical treatment". GOLD defines COPD as 11 "a disease state characterized by airflow limitation that is not fully reversible and the airway limitation is gradually progressive". More recently ATS/ERS jointly defined COPD as 
"a preventable and treatable disease state characterized by airflow limitation that is not fully reversible" and is the most common definition being used now ${ }^{1}$. COPD is classified into four stages based on $\mathrm{FEV}_{1} / \mathrm{FVC}$ ratio and $\%$ predicted $\mathrm{FEV}_{1}$. In all four stages $\mathrm{FEV}_{1} / \mathrm{FVC}$ ratio is $<0.7$ and severity is further classified based on $\%$ predicted $\mathrm{FEV}_{1}$. In Stage 1 (mild) $\%$ predicted $\mathrm{FEV}_{1}$ is $\geq 80$, Stage-II (moderate) it is $50-79$, Stage III (severe) it is $30-49$ and Stage IV (very severe) it is $\leq 30^{11}$. The prevalence of COPD varies depending on the type of definition and national surveys used to estimate the prevalence of $\mathrm{COPD}^{12}$.

\section{Spirometry}

Spirometry is a routinely performed pulmonary function test ${ }^{13}$ and, as the name suggests, is a measurement of the amount of air you breathe. This includes measurements of both the volume and rate of air that can be inhaled and exhaled as a function of time. Both $\mathrm{ATS}^{14}$ and $\mathrm{ERS}^{15}$ publish guidelines for performing and interpreting pulmonary function tests in respiratory diseases like COPD and Asthma. Based on spirometry testing results, patient can be classified further into an obstructive or restrictive pattern of pulmonary disease (See Table 1).

Important spirometry measurements of the pulmonary function test ${ }^{16}$ are forced vital capacity (FVC), forced expiratory volume (FEV), peak expiratory flow (PEF), maximum voluntary ventilation (MVV), total lung capacity (TLC), functional residual capacity (FRC), and residual volume (RV) ${ }^{16}$. FVC is the maximum volume of air exhaled forcefully following a maximal inspiratory effort. FEV is the volume of air 
exhaled with force in one breath. The volume of air exhaled measured after 1 second is called the $\mathrm{FEV}_{1} . \mathrm{FEV}_{1}$ is one of the important spirometry measures in COPD subjects. PEF measures how quickly one can exhale and is the highest airflow rate measured during the FVC procedure. MVV is the greatest amount of air that one can breathe in and out during a one minute interval. TLC is the amount of air contained in the lungs after a full inspiration. FRC is the amount of air in lungs at the end of a normal exhaled breath. Residual volume is the amount of air remained in lungs after full expiration.

The primary pulmonary function parameters that distinguish obstructive versus restrictive lung disease are $\mathrm{FEV}_{1}, \mathrm{FVC}$ and the ratio of $\mathrm{FEV}_{1}$ to $\mathrm{FVC}$ expressed as a percentage $\left(\mathrm{FEV}_{1} / \mathrm{FVC} \%\right)$. Table 1 summarizes the different findings of pulmonary function tests in individuals who are normal and those with obstructive lung disease and restrictive lung disease ${ }^{17}$. The rates of decline of $\mathrm{FEV}_{1}$ with age in different ethnic groups are shown in Appendix 1 and 2.

Table 1 Pulmonary Function test findings in different lung disease

\begin{tabular}{|l|l|l|l|}
\hline & Normal Lung & $\begin{array}{l}\text { Obstructive } \\
\text { Lung disease }\end{array}$ & $\begin{array}{l}\text { Restrictive } \\
\text { Lung disease }\end{array}$ \\
\hline$\%$ predicted $\mathrm{FEV}_{1}$ & Normal $(80-120 \%)$ & Low & Low \\
\hline$\%$ predicted $\mathrm{FVC}$ & Normal $(80-120 \%)$ & Low or normal & Low \\
\hline $\mathrm{FEV}_{1} / \mathrm{FVC}$ & $\begin{array}{l}\text { Normal }(>0.70 \text { of } \\
\text { predicted ratio) }\end{array}$ & Low & Normal \\
\hline
\end{tabular}




\section{Spirometry measurements in NHANES}

National Health and Nutritional Examination Survey (NHANES) is a series of complex surveys started in 1960 to assess the health and nutritional status of adults and children in USA ${ }^{18}$. The survey includes history, personal interview and physical exam of the participant. Spirometry was done in NHANES with a primary focus to assess the burden of respiratory diseases, like asthma and COPD, among the US general population and also to calculate estimated prevalence of COPD. NHANES III data was used to calculate reference standards for spirometry ${ }^{19}$. NHANES III was a stratified multistage probability sample of the U.S. population and the survey was conducted nationally by the National Center for Health Statistics (NCHS) from 1988 to $1994^{20}$. Hankinson (1999) ${ }^{19}$ conducted a detailed analysis of NHANES III spirometry data to generate reference equations for describing pulmonary function in three major ethnic groups namely Caucasians, African-Americans and Mexican-Americans. Comparing FEV ${ }_{1}$ against age for different ethnic groups (See Appendix 1) it can be seen that both Mexican-Americans and African-Americans, irrespective of gender, have lower $\mathrm{FEV}_{1}$ values than do Caucasians for all age groups ${ }^{19}$. Whereas comparing $\mathrm{FEV}_{1}$ against height, only AfricanAmericans had lower $\mathrm{FEV}_{1}$ values while Caucasians and Mexican-Americans had similar values ${ }^{19}$. Along with absolute $\mathrm{FEV}_{1}$ and $\mathrm{FVC}$ values, $\%$ predicted values are calculated by comparing the values of similar age, gender and body composition. NHANES III standards are routinely used in clinical practice to diagnose and monitor the severity of $\mathrm{COPD}^{21}$. 
The rate of decline of $\mathrm{FEV}_{1}$ by age is directly related to the severity of airway inflammation $^{13}$. Several studies have sought to model the association of $\mathrm{FEV}_{1}$ decline with COPD mortality ${ }^{22}$, recurrent exacerbations ${ }^{2}$, and COPD prognosis ${ }^{2}$. COPD patients with frequent exacerbations have faster decline in $\mathrm{FEV}_{1}(-40 \mathrm{ml} / \mathrm{year})$ versus those with infrequent exacerbations $(-32 \mathrm{ml} / \text { year })^{2}$.

The Spirometry Longitudinal data Analysis (SPIROLA) software designed and developed by $\mathrm{CDC}$ has been used to estimate the decline in slope of pulmonary function (e.g. $\mathrm{FEV}_{1}$ ) and can be used to compare to a normal decline in people of the same age, gender and height ${ }^{23}$. SPIROLA software uses the NHANES III standard developed by Hankinson et. al. in 1999 to calculate the slope and compare it to normal individuals. This software is being widely used in workplace settings to monitor $\mathrm{FEV}_{1}$ and FVC longitudinally over time among occupational workers ${ }^{24}$. Longitudinal monitoring in the work place settings is very important for the identification of individuals who are at high risk of developing COPD based on their excessive loss of lung function ${ }^{24}$. SPIROLA will be useful in this setting by allowing for the implementation of proper treatment or prevention strategies for high risk workers that may delay or reduce the loss of lung function. SPIROLA can perform individual or group evaluation of longitudinal changes in pulmonary function. At the individual level it can monitor $\mathrm{FEV}_{1}$ change over time in relation to the limit of longitudinal decline (LLD). It can be downloaded free from Center for Disease Control and Prevention (CDC) website ${ }^{23}$. 


\section{Pathophysiology of COPD}

COPD is a disease characterized by airflow limitation which is poorly reversible. The basic pathogenesis occurring in COPD patients involves damage to lung tissue due to chronic inflammation aggravated by smoking and other toxins ${ }^{25}$. The detailed pathophysiology of COPD has been discussed in many articles ${ }^{25-28}$. Exposure to airway irritants causes accumulation of inflammatory cells, including neutrophils, lymphocytes and macrophages and initiates the release of various inflammatory mediators such as tumor necrosis factor, $\mathrm{C}$ - reactive protein, and interleukins resulting in structural damage to lung parenchyma ${ }^{14}$. A detailed role of chronic inflammation was studied by Denterer et. al. with the aim to test the hypothesis that chronic inflammation in COPD is due to defective anti-inflammatory mechanism(s). This study concluded that in patients with stable COPD, there is a significantly higher level of leukocyte counts, C-reactive protein (CRP), and lipopolysaccharide binding protein (LBP). They showed that effective COPD treatment significantly reduces levels of CRP and LBP in comparison to baseline levels ${ }^{28}$.

Apart from inflammation, other pathological factors involved in COPD include increased levels of proteases ${ }^{27}$, decreased levels of anti-proteases and oxidative stress. The above pathogenic mechanisms leads to a series of physiological abnormalities in COPD including airflow obstruction due to mucosal hyper-secretion and mucosal edema, airway hyperresponsiveness, hyperinflation of lung, dysfunction of cilia, loss of elasticity of lung due to proteolysis by elastase, and abnormalities in gas exchange due to destruction of alveoli ${ }^{26}$. 


\section{Natural history of COPD}

As discussed in the above definitions, COPD is a chronic progressive disease with airway limitation not completely reversible. The most important parameter that measures airflow limitation is $\mathrm{FEV}_{1}$. Hence the natural history of the disease strongly correlates with the level of $\mathrm{FEV}_{1}$ from birth. Appendix 2 displays the normal decline of $\mathrm{FEV}_{1}$ by age (Curve D) alongside impaired lung growth (Curve A), early decline (Curve B) and rapid decline (Curve C $)^{29}$. Subject A has impaired lung growth with a lower plateau phase but the rate of decline in $\mathrm{FEV}_{1}$ is normal. Subject B has normal lung growth (i.e. normal plateau) and a rapid decline in initial years but the rate of decline is normal thereafter. Subject $\mathrm{C}$ has a normal plateau and normal decline in initial years but the rate of decline accelerates thereafter. Most published literature uses $\mathrm{FEV}_{1}$ to study the natural history of disease $\mathrm{e}^{29-31}$; but if someone starts smoking very early they could just skip the plateau phase and proceed directly to rapid decline after early lung growth ${ }^{32}$. Gold. et. al. conducted a detailed study of tobacco smoke effects on adolescent boys and girls ${ }^{32}$. The study found that girls who smoke 5 or more cigarettes per day have 1.09\% (95\% CI: 0.71.47) slower growth of $\mathrm{FEV}_{1}$ per year versus non-smokers and $0.2 \%$ slower growth among boys who smokes versus non-smokers (95\% CI: -0.16 to 0.56$)$. In a detailed review of the pathophysiology and natural history of disease by Mannino et. al. ${ }^{33,34}$, the author's state that $\mathrm{FEV}_{1}$ is not the only parameter of interest in the natural history of COPD. Since COPD is a heterogeneous disease, it should be noted that the natural history of COPD is a mixture of naturally occurring phenotypes including small airway disease, systemic inflammation, chronic mucus secretion, auto immunity and bronchial hyperresponsiveness ${ }^{34}$. 


\section{Pharmacotherapy of COPD}

Apart from monitoring the disease and reducing risk factors, effective management of COPD includes management of stable COPD and also exacerbations which requires proper use of drugs ${ }^{11}$. The principal role of drugs in COPD treatment is to improve the symptoms, reduce frequency of exacerbations, reduce severity of disease, slow the progression of disease and improve the quality of life ${ }^{11}$. The primary categories of drugs given to COPD subjects are bronchodilators and corticosteroids ${ }^{35}{ }^{36}$. These can be given alone or in combination therapy and either inhaled or in oral form ${ }^{35}$.

I) Bronchodilators ${ }^{36}$

Any medication that dilates bronchi and bronchioles, by altering the tone of airway smooth muscle, is called a bronchodilator. Bronchodilators also improve $\mathrm{FEV}_{1}$ and other parameters like forced vital capacity and residual volume. There are three types of bronchodilators commonly given to COPD subjects. These include $\beta$ adrenergic receptor agonists, anti-cholinergic agents and methyxanthines ${ }^{36}$. A $\beta_{2}$ adrenergic receptor agonist relaxes airway smooth muscle by stimulating $\beta_{2}$ receptors present on respiratory airways resulting in increases in intracellular levels of cyclic adenosine monophosphate $(\mathrm{c}-\mathrm{AMP})^{37} . \beta_{2}$ agonists are either short acting (SABA) or long acting (LABA). SABA effects last for 4-6 hours and LABA have duration of effect lasting for up to 12 hours. The most common side effects of $\beta_{2}$ agonist bronchodilators include tremor, tachycardia, anxiety, nervousness and headache ${ }^{38}$. Anti-cholinergic drugs relax smooth muscle by blocking the action of acetylcholine on $\mathrm{M}_{3}$ and $\mathrm{M}_{2}$ receptors. The most common side effects of anti-cholinergic drugs include constipation, dryness of skin due to decreased 
sweating, dryness of mouth, headache, and blurring of vision. The last group of bronchodilators is the methyxanthines which dilate bronchioles by acting as non-selective phosphodiesterase inhibitors. The most common drug in this category is theophylline which has been used as a bronchodilator for over 80 years. Theophylline is not commonly used nowadays due to cardiac arrhythmias and the ready availability of other bronchodilators $^{39}$.

\section{II) Glucocorticosteroids}

Steroids can be given either orally (OCS) or inhaled (ICS) ${ }^{40}$. In contrast to asthma, subjects with COPD are less responsive to inhaled corticosteroids (ICS) if given alone and so ICS are given in combination with bronchodilators ${ }^{40,41}$. Inhaled corticosteroids given in combination with bronchodilators reduce acute COPD exacerbations and improve overall quality of life ${ }^{42,43}$. Anuzeto conducted a randomized clinical trial comparing the effect of fluticasone propionate (ICS) given in combination with salmeterol versus salmeterol alone and found that there was a significant reduction in moderate to severe acute exacerbations in the combination arm (1.1 vs. 1.50 per subject per year) along with fewer hospitalizations than in the salmeterol alone $\operatorname{arm}^{44}$. Several other studies support the use of inhaled corticosteroids to improve outcomes and reduce exacerbations among COPD subjects ${ }^{45,46}$. Common side effects of oral steroids include weight gain, mood changes, increase in blood sugar, increase in blood pressure, and osteoporosis (if used for long term). Side effects associated with inhaled steroids are few and include sore throat, hoarseness of voice ${ }^{36}$. 


\section{Epidemiology of COPD}

COPD is a leading cause of morbidity and mortality not only in the USA but also

globally ${ }^{4,47}$. Chronic Obstructive Pulmonary Disease (COPD) is a major cause of chronic morbidity and a public health problem of increasing concern in the United States ${ }^{12,48}$. According to World Health Organization (WHO), the estimated prevalence of moderate to severe COPD is 65 million and COPD is the fourth leading cause of mortality (3.4 million) worldwide after ischemic heart disease (7 million), stroke (6.2 million) and lower respiratory infections $(3.2 \text { million })^{49}$.

\section{Prevalence of COPD}

The prevalence of COPD varies depending on the definition and type of survey used to estimate its prevalence. The first national survey to estimate the prevalence of COPD was NHIS (National Health Interview Survey) ${ }^{50}$. In that survey, COPD prevalence was estimated by adding the cases of chronic bronchitis ( 50.5 per 1000 persons for all age) and emphysema (6.0 per 1000 persons for all age $)^{51}$. Accordingly, the NHIS survey calculated that there were approximately 12.7 million adults above 25 years of age living with COPD. Unfortunately, COPD is under diagnosed as the diagnosis is based on self-report to two questions ${ }^{12}$. Due to this limitation, Mannino et. al. used pulmonary function test measures from the NHANES-III survey to estimate the prevalence of COPD ${ }^{12}$. NHANES-III used a stratified, clustered design to select a representative sample of the civilian, non-institutionalized USA population from 1988 to 1994 and it included pulmonary function testing ${ }^{52}$. Prevalence was estimated by applying GOLD stage criteria to pulmonary function test measures from NHANES-III ${ }^{12}$. That 
study found an estimated prevalence of COPD of 23.4 million (13.9\%) among people aged $25-75$ years. The estimated prevalence of mild COPD (defined FEV ${ }_{1} / \mathrm{FVC}<70 \%$ and $\mathrm{FEV}_{1} \geq 80 \%$ predicted) was $6.9 \%$ and moderate $\mathrm{COPD}$ (defined as $\mathrm{FEV}_{1} / \mathrm{FVC}<70 \%$ and $\mathrm{FEV}_{1} 50-80 \%$ predicted) was $6.6 \%{ }^{12}$.

The state-based Behavioral Risk factor Surveillance System (BRFSS) ${ }^{53}$ was also used to estimate the prevalence of COPD nationally and statewide ${ }^{54}$. BRFSS used only one question to assess COPD prevalence i.e. "Have you ever been diagnosed with COPD, emphysema or chronic bronchitis?" The 2011 BRFSS was the first year that provided a complete estimate of the prevalence of COPD by each state ${ }^{54}$. According to BRFSS, 6.3 $\%$ of US adults (approximately 15 million) have COPD with the highest prevalence among subjects aged between $65-75$ years $(12.1 \%)^{47,54}$. Prevalence varies by state with Kentucky and Alabama having the highest prevalence of COPD (>9\%) ${ }^{54}$. There has not been a significant change in prevalence of COPD from 1998 to 2009 and it remains mostly stable around 5\% among all adults aged greater than 18 years for all gender ${ }^{55}$. Age specific prevalence's and unadjusted prevalence rates of COPD in US adults aged $\geq 25$ years is shown in figure 1 . Numbers used in creating Figure 1 are taken from Ford et. al. article of COPD surveillance in United States from 1999-2011 using BRFSS survey $^{47}$. From the figure, COPD rates gradually increase from age 25 to 75 years but decline thereafter due to more mortality among subjects more than 75 years of age. 
Figure 1 Age specific prevalence of COPD among US adults aged $\geq 25$ years (BRFSS)

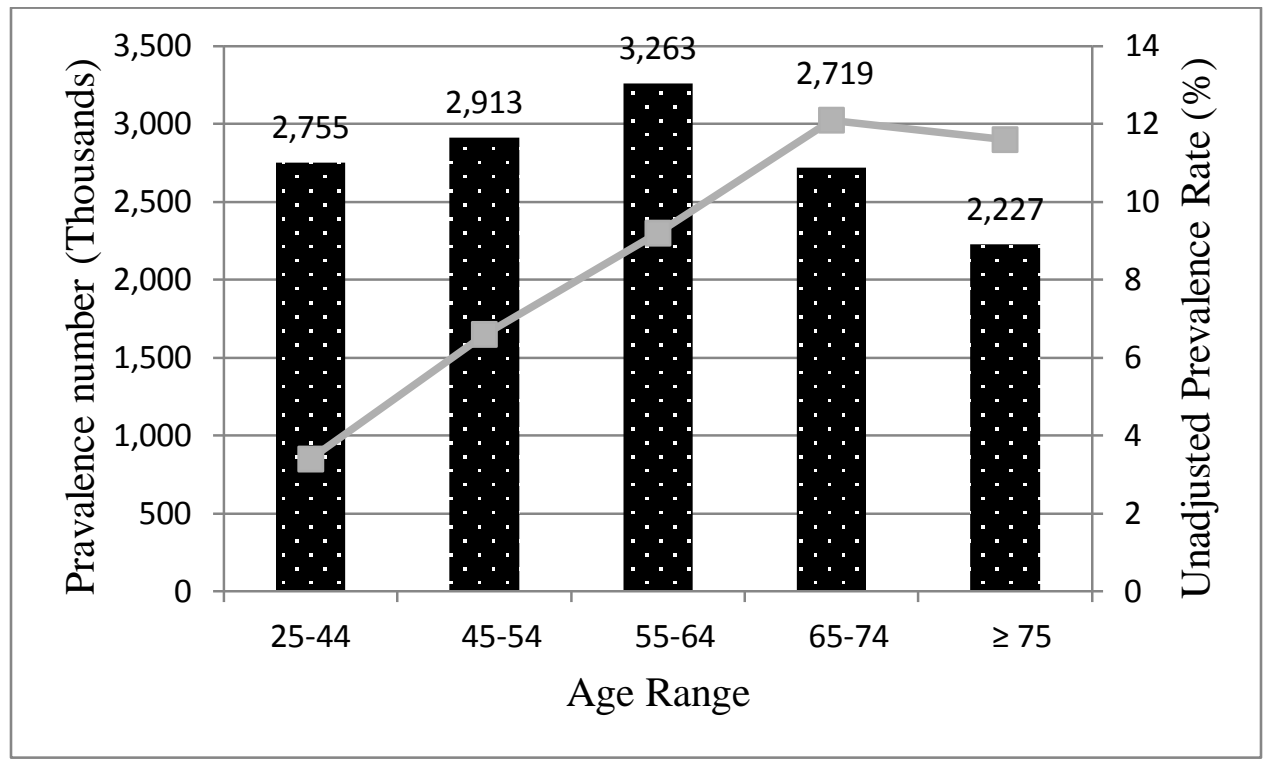

A thorough review of COPD prevalence and trends in mortality in different countries were discussed by Rycroft el. $\mathrm{al}^{56}$. According to that review, there is a significant variation in the prevalence of COPD worldwide; mainly due to type of definitions and classification used to diagnose COPD along with type of survey used to estimate the prevalence. The prevalence is high among men aged $\geq 75$ years with decrease in mortality among men in several countries like Australia, while increasing or stabilizing among women in countries like USA.

COPD is projected to be the third leading cause of death for both males and females by $2030^{57}$. In USA According to preliminary reports of deaths from vital statistics by Hoyert et. al. ${ }^{58}$, COPD is the third leading cause of death with approximately 150,000 total deaths contributed to COPD following that of heart disease and cancer. 
The prevalence of COPD is increasing and will continue to climb as our population grows. In the report on COPD surveillance published by Mannino et. al., in the year 2000 alone COPD accounted for 8 million physician office and hospital outpatient visits, 1.5 million emergency department visits, 726,000 hospitalizations, and 119,000 deaths $^{12}$.

Overall there has been a decline in COPD mortality in many countries, but in a few countries including the US, Australia and France, the mortality rate has increased in women and decreased in men ${ }^{56}$. In the US, there has been a huge increase in the COPD death rate in females that has occurred over the last 20 years: i.e. a rise from 20.1 per 100,000 in 1980 to 56.7 per 100,000 in 2000 for females versus 73.0 per 100,000 in 1980 to 82.6 per 100,000 in $2000^{12}$.

In summary, COPD is a disease of major public health concern and measures must be taken to decrease the rate and improve the quality of life of subjects living with COPD. This project reviews the effectiveness of implementing a COPD disease management program (DMP).

\section{Risk factors for COPD}

The most important risk factor for COPD is smoking as documented by numerous epidemiological studies, summarized in Table 2. Although smoking is the most important risk factor for COPD ${ }^{59-62}$, not all smokers will develop COPD which implies involvement of other factors including genetic predisposition ${ }^{63}$, socioeconomic status ${ }^{64}$, exposure to occupational dust and chemicals ${ }^{65}$, and outdoor air pollution ${ }^{66}$. An interaction between genetic and environmental risk factors increases the risk for COPD. 
The most common genetic factor associated with COPD is the deficiency of $\alpha_{1}$ antitrypsin ${ }^{67,68}$. Subjects with $\alpha_{1}$-antitrypsin deficiency have reduced levels of circulating proteinase inhibitor which protect the lungs against proteolytic attack which results in the occurrence of emphysema ${ }^{68}$.

Table 2 Epidemiological studies of Smoking and COPD

\begin{tabular}{|c|c|c|c|c|c|}
\hline Study & Type of Study & Location & Smoking status & Risk measure & Estimate \\
\hline \multirow{2}{*}{$\begin{array}{l}\text { Lokke et. al., } \\
2006^{60}\end{array}$} & \multirow{2}{*}{$\begin{array}{l}25 \text { years of cohort, } \\
\text { (Copenhagen city } \\
\text { heart study) }\end{array}$} & \multirow{2}{*}{$\begin{array}{l}\text { Copenhagen, } \\
\text { Denmark }\end{array}$} & Never & \multirow{2}{*}{$\begin{array}{l}\text { Incidence } \\
\text { rate }\end{array}$} & $39 / 401(9.7 \%)$ \\
\hline & & & Ever & & $\begin{array}{l}196 / 806 \\
(24.3 \%)\end{array}$ \\
\hline \multirow[t]{3}{*}{$\begin{array}{l}\text { Mastrangelo } \\
\text { et. al., 2003 }\end{array}$} & \multirow[t]{3}{*}{ Case control study } & \multirow[t]{3}{*}{ Padova, Italy } & $\begin{array}{l}\text { Never } \\
(15 \text { cases, } \\
99 \text { controls })\end{array}$ & \multirow[t]{3}{*}{ Odds Ratio } & 1 \\
\hline & & & $\begin{array}{l}\text { Former } \\
\text { (31 cases, } \\
96 \text { controls) }\end{array}$ & & $\begin{array}{l}2.13 \\
(1.08-4.2)\end{array}$ \\
\hline & & & $\begin{array}{l}\text { Current } \\
\text { (76 cases, } \\
86 \text { controls) }\end{array}$ & & $\begin{array}{l}5.83 \\
(3.12-10.9)\end{array}$ \\
\hline \multirow{3}{*}{$\begin{array}{l}\text { Jordan, et. } \\
\text { al., } 2011^{59}\end{array}$} & \multirow{3}{*}{$\begin{array}{l}\text { Cross sectional } \\
\text { study (Health } \\
\text { survey of England, } \\
\text { HSE) }\end{array}$} & \multirow[t]{3}{*}{ England } & Never & \multirow[t]{3}{*}{ Odds Ratio } & 1 \\
\hline & & & Ex-smokers & & $\begin{array}{l}1.50 \\
(1.30 \text { to } 1.72) \\
\end{array}$ \\
\hline & & & Current & & $\begin{array}{l}3.94 \\
(3.43 \text { to } 4.52)\end{array}$ \\
\hline \multirow{3}{*}{$\begin{array}{l}\text { Higgins, et. } \\
\text { al., } 1993^{62}\end{array}$} & \multirow{3}{*}{$\begin{array}{l}\text { Cross sectional } \\
\text { study } \\
\text { (Cardiovascular } \\
\text { Health study, CHS) }\end{array}$} & \multirow[t]{3}{*}{ USA } & Never & \multirow{3}{*}{$\begin{array}{l}\text { Prevalence } \\
(\%)\end{array}$} & 7.3 \\
\hline & & & Former & & 18.5 \\
\hline & & & Current & & 45.1 \\
\hline
\end{tabular}

Several genome wide association studies (GWAS) $)^{69-72}$ and candidate gene studies $^{71,73}$ had been completed in last few years to begin to identify genes associated with COPD and also to understand the pharmacogenetics ${ }^{74}$ of COPD. Pillai et. al. conducted a GWAS in a homogenous case-control cohort from Bergen, Norway (823 COPD cases and 810 smoking controls) and evaluated the top 100 single nucleotide polymorphisms (SNPs) in the family-based International COPD Genetics Network (ICGN) study. Further evaluation of polymorphisms was done among subjects from US National Emphysema Treatment Trial (NETT) cohort, Normative Aging Study (NAS) 
cohort and Boston Early-Onset COPD population cohort ${ }^{69}$. From that study researchers found two polymorphisms in the $\alpha$-nicotinic acetylcholine receptor $3 / 5$ locus on chromosome 15 that showed definite evidence of association with COPD.

\section{Economic burden of COPD}

COPD also imposes a major economic burden in the USA and globally ${ }^{75,76}$. According to the American Lung Association, in the year 2010, COPD cost approximately $\$ 50$ billion which included $\$ 30$ billion in direct health care costs and $\$ 20$ billion in indirect $\operatorname{costs}^{77}$. The direct medical cost for COPD has almost doubled since 1996 when they were $\$ 14.5$ billion $^{78}$. Direct costs refer to expenditures related to diagnosis, treatment and prevention of disease directly related to COPD, including office visits for COPD, investigations related to COPD, medical management costs and hospitalization costs related to COPD exacerbation ${ }^{79}$. Indirect costs are related to morbidity and mortality caused by $\mathrm{COPD}^{79}$. Indirect costs are associated with output losses (loss of work time and productivity) and family costs as a result of COPD

consequences $^{79,80}$. Many studies have estimated direct and indirect costs of CODP in the USA and globally ${ }^{75,80-82}$. Ward et. al. conducted a retrospective study using a publicpayer perspective to estimate direct medical costs of COPD in the USA and these authors found that approximately out of $\$ 6.6$ billion, $\$ 2.3$ billion was due to the cost of long-term oxygen therapy, $\$ 1.9$ billion was associated with in-hospitalizations usage while the remaining cost were attributable to outpatient visits and medications for $\mathrm{COPD}^{81}$. 
A more recent retrospective study using a managed care claims database to estimate the direct cost of COPD was done by Dalal et. $\mathrm{al}^{82}$ in 2010 . The study includes 37,089 COPD patients divided into five cohorts i.e. outpatient, urgent outpatient, emergency department, standard inpatient admission, and intensive care unit (ICU). Mean standard annual COPD-related health care costs (2008 US\$) increased across the cohorts ( $\mathrm{P}$ value 0.001 ), ranging from $\$ 2003$ for the outpatient cohort to $\$ 43,461$ for the ICU cohort. Average cost, combining patients from all cohorts, was \$3943 which included \$2731 in medical costs and \$1211 in pharmacy cost ${ }^{82}$. Akazawa et. al. also conducted a similar type of retrospective administrative claims data analysis ${ }^{83}$ and concluded that COPD patients in the U.S. had significantly more healthcare utilization and higher costs in the year prior to COPD diagnosis than matched control subjects. Teo et. al. ${ }^{75}$ conducted a study to estimate direct medical costs of COPD in two public health clusters in Singapore from 2005 to 2009 and study found that average cost of COPD was $\$ 9.9$ million per year with hospitalization contributing to approximately $73 \%$ of total cost.

According to study by Simoni et. al., among Medicare beneficiaries residing in long term facilities, twelve-month COPD-related and all-cause direct expenditures per beneficiary were US $\$ 7391$ and $\$ 48,183^{84}$. The Center for Medicare and Medicaid services reported that approximately 12 percent of Medicare beneficiaries aged 65 years and above have $\mathrm{COPD}^{85}$. Blanchette et. al. reported that the respiratory-related costs accounted for 22 percent of total all-cause health care costs for among Medicare beneficiaries with $\mathrm{COPD}^{86}$. In summary COPD is major contribution to the overall 
economic burden of healthcare costs in USA and globally with in-patient hospitalization contributing a major portion of all COPD related costs.

\section{Chronic Disease Management}

\section{Definition of chronic disease management}

Many definitions of chronic disease management have been proposed since this innovative approach was introduced in the $\mathrm{USA}^{87-91}$. Epstein and colleagues ${ }^{88}$ defined disease management as " the use of an explicit systematic population-based approach to identify person at risk, intervene with specific programs of care and measure clinical outcome". More recently Faxon et. al. ${ }^{91}$ in 2004 defined disease management as " a multidisciplinary effort to improve the quality and cost-effectiveness of care for selected patients suffering from chronic conditions". With several definitions in practice, the primary goal of disease management is to improve both objective and subjective quality of life of subjects with chronic disease.

In summary disease management is a multidisciplinary coordinated preventive intervention focusing on target groups with chronic diseases like diabetes, heart disease, and chronic obstructive pulmonary disease with an overall goal to improve both objective clinical outcomes and subjective quality of life. 


\section{Disease management Program (DMP)}

As discussed above, the primary goal of any disease management program is to improve overall quality of life for subjects living with chronic conditions and to reduce total health care costs. Several studies have evaluated the effect of disease management programs on clinical outcomes among subjects with heart failure, diabetes, and chronic obstructive pulmonary disease. McAlister et. al. conducted a systemic review of 11 randomized clinical trials of DMP in heart failure and found significant reductions in follow up hospitalizations (RR 0.87, with 95\% CI: 0.79 to 0.96 ) for DMP enrollees with even greater reductions in recurrent hospitalization if the DMP trial includes follow up by a multidisciplinary specialized team rather than limited follow up by telephone. These findings were supported by a recent retrospective study conducted in Spain, which found that heart failure subjects who had exposure to a DMP had a lower risk of death and readmission due to heart failure ${ }^{92}$. Apart from heart failure subjects, DMPs are also effective in diabetes patients. Sidorov et. al. evaluated a Health management organization (HMO) sponsored DMP for Diabetes and this study found a significant improvement in quality of life and reduction in cost for those enrolled in the program ${ }^{93}$.

Our present study will focus on the effectiveness of the COPD management program by comparing several clinical outcomes and claims related costs for those enrolled in the DMP versus for those receiving usual care. 


\section{COPD management program}

As discussed previously, COPD is a serious public health problem with major extrapulmonary manifestations of disease leading to chronic morbidity and resulting in the fourth leading cause of mortality in USA. COPD also imposes a major economic burden not only in the USA but globally with total expenditures estimated to be upwards of $\$ 50$ billion, including both direct and indirect $\operatorname{cost}^{77}$. Since COPD is a chronic disease with multiple co-morbidities, a multidisciplinary approach to disease management is recommended to in order to improve quality of life and reduce health care utilization related to COPD exacerbations ${ }^{94-96}$. Several studies have been published in the last 10 years regarding the role of disease management program in COPD but the results are inconsistent and inconclusive. Most of the studies evaluated clinical outcomes and selfreported quality measures (like St George Respiratory Questionnaire, COPD assessment test) with few studies evaluating cost effectiveness of the program.

Components of COPD disease management programs include self-management, patient centered education, case management, home-based pulmonary rehabilitation and an action plan for identification and treatment of exacerbation ${ }^{97-99}$. Some studies evaluated the effect of one component, like self-education, or combined more than one component in an integrated approach to study different clinical outcomes with the goal of improving quality of life on COPD subjects ${ }^{97}$. Another approach, called the Proactive Integrated care (PIC) approach, is a combination of disease specific education and selfmanagement principles along with simple remote monitoring platform and was used by

Koff et. at. ${ }^{99}$ and Linderman et. al. ${ }^{98}$. Fan et. al. used a Comprehensive Care Management Program (CCMP) including four individual COPD education sessions, one 
group session, an action plan for exacerbations, and scheduled proactive telephone calls for case management ${ }^{100}$. A detailed review of self-management education was done by Effing et. al. ${ }^{101}$. The review includes results from 14 different trials and reported a significant reduction in hospital admission among self-management group versus usual care and also significant reduction in SGRQ score and BORG dyspnea score for those who enrolled into self-management program.

A recent multi-center randomized clinical trial was completed by Fan et. al. ${ }^{100}$ that included COPD patients from 20 Veteran Affairs hospital with the objective to determine the efficacy of CCMP in reducing COPD hospitalization. The trial was stopped prematurely due to excess mortality in the intervention group (28 deaths) versus the comparison group (10 death) with hazard ratio of 3 (95\% CI: 1.46 to $6.17 ; \mathrm{P}=0.003)$. At the time of termination, the 1-year cumulative incidence of COPD-related hospitalization was $27 \%$ in intervention group versus $24 \%$ in the usual care group (hazard ratio, 1.13 [95\% CI, 0.70 to 1.80$] ; P=0.62)^{100}$. A similar study by Mehring et. al. evaluated retrospectively the effect of a German Disease management program on $\mathrm{COPD}^{96}$. This study found significant reductions in prescription of theophylline and oral corticosteroids along with an increased utilization of patient education, smoking cessation and a reduction in the occurrence of exacerbations ${ }^{96}$ and study conclude that the German DMP for COPD was effective in enhancing the quality of care but was not able to prevent increase in emergency admissions for stable COPD cohort.

Moullec et. al. used a combination of patient centered education and case management as an integrated care approach to evaluate its effectiveness and found significant reductions in COPD related hospitalization (OR: 0.44; 95\% CI: 0.23-0.85) 
compared to usual care ${ }^{97}$. In the proactive integrated care approach by Linderman et. al., there was a significant improvement in SGRQ score (from 50.8 to 39.2), BODE index (4.3 to 2.9), mMRC (from 2.0 to 1.7) and six minute walk distance (from 265.1 to 319.4) after the implementation of proactive integrated care approach among COPD patients.

\section{Respiratory measures in COPD}

As discussed above spirometry is the most important pulmonary function test not only to diagnose COPD but also to assess the prognosis of COPD patient. Apart from spirometry, other measures routinely performed among COPD patients includes six minute walk test (6 MWT), COPD assessment test (CAT), St George respiratory questionnaire (SGRQ) and BODE index.

\section{$\underline{\text { Six Minute Walk Test (6 MWT) }}$}

The 6MWT is an important measure of daily living among COPD subjects ${ }^{102}$, and simply measures the distance that a patient can quickly walk on a flat, hard surface in a period of 6 minutes. Functional and exercise capacity is determined by the integrated response of multiple systems, including the pulmonary, cardiovascular, hematopoietic, skeletal and metabolic $^{102}$. The $6 \mathrm{MWT}$ does not provide specific information on the function of each organ and system involved in the exercise mechanism; instead, it serves as a surrogate estimate of the collective mechanism ${ }^{102}$.

In clinical practice, the $6 \mathrm{MWT}$ is used for measuring the response to medical interventions for patients with moderate to severe heart or lung disease ${ }^{102}$. Solway et al. 
(2001) performed a qualitative review of measurement properties of the shuttle walk test and 6MWT and concluded that exercise performed was similar to a symptom-limited, maximal, incremental treadmill test ${ }^{103}$. The shuttle walk test is more difficult to administer, requires more equipment, and is less reflective of activities of daily living ${ }^{103}$. The 6MWT is easy to administer, better tolerated, and more reflective of activities of daily living. Therefore, currently, the $6 \mathrm{MWT}$ is the test of choice when administering a functional walk test for clinical or research purposes especially among COPD cohort ${ }^{102}$.

Hernandes et. al. investigated the reproducibility of the 6 MWT in COPD patients in a retrospective cohort study and also quantified the learning effect between two 6MWTs performed on subsequent days ${ }^{104}$. The study ${ }^{104}$ found that, on average, the second 6MWT increased by $27 \mathrm{~m}$ (or $7 \%$ ), and $82 \%$ of patients showed improvement in their second 6MWT distance. Additional factors associated with improvement on the second six minute walk distance (6MWD) by $>42 \mathrm{~m}$ are first 6MWD $>350 \mathrm{~m}$, Charlson index $<2$ and body mass index $<30 \mathrm{~kg} / \mathrm{m}^{2}$.

By conducting the 6MWT in the follow up visits of COPD subjects, it is important to understand whether change in walking distance observed over time represents a clinically important effect on subjects overall quality of life because a change in 6MWD from previous values may be significant statistically but not clinically ${ }^{105,106}$. Holland et. al. conducted a prospective study to establish the minimal important difference (MID) in 6MWD in COPD subjects and authors found that a MID of 25 meter (95\% CI: 20-61 meter) in COPD or a 14\% change in 6MWD compared with baseline represents clinically important effect; but the \% change is less sensitive $(0.70)$ than absolute change $(0.85)^{106}$. 


\section{MMRC Dyspnea Scale}

The modified Medical Research Council (mMRC) scale is a validated tool and most commonly used scale to assess dyspnea in subjects with chronic respiratory lung disease $^{107}$. See Appendix 4 for MMRC dyspnea scale. To assess health related quality of life using MMRC, a cross-sectional study of 328 COPD patients was conducted and mMRC was found to be a good and reliable indicator ${ }^{108}$. Currently, GOLD supports the use of either the mMRC or CAT index to assess the severity of breathless among COPD subjects $^{109}$.

\section{$\underline{\text { BODE Index }}$}

BODE index is a multidimensional staging tool first developed and validated by Celli. et. al. in 2004 to assess the pulmonary and systemic manifestation among subjects with $\mathrm{COPD}^{110}$. The BODE index consists of four components: BMI [B], Obstruction [O] as measured by $\mathrm{FEV}_{1}$, Dyspnea [D] severity as measured by Modified Medical Research Council (MMRC) Dyspnea scale, and exercise [E] capacity as measured by distance covered in $6 \mathrm{MWT}^{110}$. Before the development of the BODE index, the only variable that could predict mortality among COPD patients was $\mathrm{FEV}_{1}{ }^{111}$. As COPD is a systemic disease and $\mathrm{FEV}_{1}$ will explain only the respiratory component of COPD, it is important to include measures that also reflect systemic components and exercise capacity along with spirometric measures which predicts all-cause mortality, CODP specific mortality and hospitalization due to $\mathrm{COPD}^{112}$. 
Development and validation of BODE Index ${ }^{110}$

Celli. et. al. used several variables to predict mortality among 207 COPD patients. These variables includes age, gender, smoking, $\mathrm{FEV}_{1}, \mathrm{FVC}, 6 \mathrm{MWT}$, BMI, degree of dyspnea measures suing MMRC dyspnea scale, functional residual capacity, inspiratory capacity, hematocrit, and albumin level ${ }^{110}$. By evaluating the association of each of these explanatory variables to predict one year mortality using stepwise logistic regression method, researchers found only four variables (BMI, $\mathrm{FEV}_{1}$, dyspnea severity and 6 MWD) that had a strongest association to predict mortality. The BODE index was then created using those 4 variables. The BODE index can be calculated by summing a score assigned to each component as outlined in the table below. For all-cause mortality, the HR was 1.34 (1.26 to $1.42 ; \mathrm{p}<0.001)$ and for respiratory death it was1.62 (1.48 to 1.77$)$ for every one point increase in BODE index. The $\mathrm{C}$ statistic of BODE index to evaluate the ability of the index to predict death was 0.74 versus 0.65 for $\mathrm{FEV}_{1}$ alone $(0.74 \mathrm{v}$ 0.65). The BODE index will range from 0-10, with higher scores indicating a high risk of mortality (See Appendix 5 for complete scoring of BODE index).

Since the development of BODE index in 2004, many studies had been done among COPD subjects to predict mortality ${ }^{113}$, to predict hospitalization ${ }^{114}$, and to compare BODE with GOLD criteria to assess anxiety and depressive symptoms ${ }^{115}$. Study by Cote et. al. used BODE index to compare the outcome among COPD patients who received pulmonary rehabilitation $(\mathrm{PR})$ versus those without PR and the study found that at the end of 1 year the BODE index improved by $19 \%$ among patients in PR group and worsened by $4 \%$ among patients in no PR group ${ }^{116}$. Ong et. al. ${ }^{114}$ conducted a study 
to predict hospitalization for COPD and found that the BODE index is a significant better predictor for hospitalization than $\mathrm{FEV}_{1}$.

\section{$\underline{\text { St George Respiratory questionnaire }}$}

St George Respiratory questionnaire (SGRQ) is the metric to measure the health related quality of life of subjects with respiratory problems like COPD and Asthma ${ }^{117,118}$. SGRQ was first developed and validated by Paul Jones from St George University London $^{119}$. See Appendix 6 for the detailed SGRQ questionnaire. The original SGRQ consisted of 76 items categorized into three sections ${ }^{119}$

1. Symptoms related items: consists of item related to cough, wheeze, breathlessness and its severity

2. Activity related items: consists of questions related to activity that is affected by breathlessness

3. Impact related items: consists of items related to the impact (either social or psychological) due to breathlessness

Interpretation of scores:

A score can be calculated individually for each section (i.e. symptom score, activity score, and impact score) as well as a total score ${ }^{119,120}$. Factors taken into consideration for calculating score include age, gender, weight, disease duration, current and worst pulmonary function test measures ${ }^{119}$. The SGRQ score ranges from 0 to 100 ; with higher scores indicating more severe disease and causing more limitations in daily living of COPD subjects ${ }^{119,120}$. A study by Ferrer et. al. relating to the interpretation of 
the quality of life scores from SGRQ, found that the strongest association of SGRQ total scores is \% predicted $\mathrm{FEV}_{1}$ along with smoking, age, gender and education which independently associated with the SGRQ total score ${ }^{121}$. The current American version of the SGRQ consists of 50 items classified into the same three categories ${ }^{122}$.

As full version of SGRQ is lengthy and more generalized. Meguro et. al. developed a shorter and improved version of SGRQ designed specifically for COPD patients called the SGRQ-C $\mathrm{C}^{123}$. This study was conducted with the aim of identifying items that are weak, have low response rate, redundant and fit poorly with other items using the Rausch reduction technique. A total of 10 weaker items were identified and removed without altering the performance of the instrument ${ }^{123}$. One item that was removed due to low response rate was employment because most of subjects were retired. The SGRQ-C has been developed using COPD data only, so it is valid for subjects with $\mathrm{COPD}^{123}$. In conclusion SGRQ-C is short, reliable, valid, and contains most of the items from original SGRQ and the principal differences from the original SGRQ are smaller number of items (reduction from 50 to 40 items).

Several studies had been published to identify and interpret the threshold for clinical significant change in SGRQ in COPD patients ${ }^{124-126}$. Based on a study by Jones et. al. 2002, an improvement of mean score of 4.3 is considered an effective treatment and mean score of 8.1 is considered very effective treatment ${ }^{124}$. 


\section{COPD Assessment Test (CAT)}

COPD assessment test is a short, simple questionnaire to measure the quality of life and monitor the health status of person's living with COPD. ${ }^{127,128}$ It's a simple questionnaire that is useful to patients and also to clinicians to assess the severity of COPD. Because of the length of several other questionnaires [like SGRQ, COPD clinical questionnaire, chronic respiratory questionnaire (CRQ)] to measure health related quality of life in COPD subjects; there is a need to create a short and easy questionnaire for COPD subjects. This led to the development of COPD assessment test (CAT) by Dr. PW Jones in $2009^{127}$. See Appendix 7 for detailed CAT questionnaire.

Development of CAT and Interpretation of CAT score ${ }^{127}$ : Initially the CAT consisted of 21 questions but following a structured approach to item reduction, the final CAT consists of 8 questions assessing cough, phlegm, chest tightness, breathlessness, activities, confidence, sleep and energy. An item reduction process was used to create a tool which is bias free from demographic factors such as sex, country, language spoken and the instrument which has a good reliable measurement property. Countries studied for the development of CAT includes USA $(n=229)$, Spain $(n=369)$, The Netherlands $(n=109)$, Germany $(n=431)$, France $(n=294)$, Belgium $(n=71)$. By studying in 6 different countries for testing internal consistency, the CAT score provides a reliable measure of COPD severity independent of the language spoken. The CAT scores range from 0-40 with the higher scores indicating more severe impact of COPD on daily life. A reduction in the CAT score by 2 points is considered a minimal clinically important difference $(\mathrm{MCID})^{129}$. 
Since the development of the CAT score, many studies had been published to discuss the properties of CAT score ${ }^{130}$, responsiveness of CAT following acute exacerbation and pulmonary rehabilitation in COPD subjects ${ }^{128}$. The CAT score is a good reliable tool to measure the severity of COPD GOLD stage (Stage I: 16.2 \pm 8.8 , Stage II: $16.3 \pm 7.9$, Stage III: $19.3 \pm 8.2$, Stage IV: $22.3 \pm 8.7$ ) and has a strong correlation with SGRQ $(r=0.8, \mathrm{p}$ value $<0.0001)$ suggesting that the patient's response to the eight item CAT were valid ${ }^{130}$.

\section{Fractional Exhaled Nitric Oxide}

FENO testing is a simple noninvasive test that will measure the amount of nitric oxide in exhaled air ${ }^{131}$. It is a marker for eosinophilic inflammation in respiratory diseases like COPD and asthma ${ }^{132}$. ATS published guidelines on the measurement of FENO and how to interpret the level of FENO in COPD and Asthma ${ }^{131}$. FENO is measured in parts per billion ( $\mathrm{ppb}$ ) and based on its value can categorized into three levels low ( $<25 \mathrm{ppb})$, medium (25-50 ppb) and high ( $>50 \mathrm{ppb})$. The primary role of FENO in COPD patients is to measure the level of inflammation that will predict the response to inhaled steroids. Several studies strongly support the association of eosinophilic inflammation, as measured by high FENO, with the response to inhaled steroid treatment ${ }^{133-135}$. In a case control study by Ziekowski, a higher baseline FENO level in COPD subjects was directly related to significant improvements in $\mathrm{FEV}_{1}$ after treatment of inhaled steroids. 


\section{General health measures}

\section{Duke Profile}

The Duke profile is a self-report instrument widely used to measure and assess overall health as an outcome in medical interventions and health promotion programs like chronic disease management programs ${ }^{136}$. The Duke health profile is the shorter version of the original 67 item Duke UNC health profile ${ }^{136}$. The current version consists of 17 items with respective questions responses to a 3 point Likert scale and can be completed in 5-8 minutes ${ }^{136}$. See the Appendix 8 for Duke Health profile questionnaire. From the 17 items, 6 summary scores are calculated for health function and include physical health, mental health, social health, general health, perceived health, self-esteem; while 4 summary scores for health dysfunction includes anxiety, depression, pain and disability ${ }^{136}$. Duke health profile is available in many languages and several studies had been published worldwide using this profile to measure quality of life among subjects ${ }^{137}$ including COPD subjects ${ }^{138}$.

\section{PHQ-9}

PHQ-9 is an instrument to screen and diagnose depression ${ }^{139,140}$. It is also used clinically to monitor and measure the severity of depression in different clinical conditions like prenatal depression ${ }^{141}$, depression in HIV patients ${ }^{142}$ and also in COPD patients $^{143}$. It consists of 9 questions with a total score ranging from 0 to 27 as each item is scored from 0 (not at all) to 3 (nearly every day). (See Appendix 9 for detailed PHQ9 questionnaire). Scores from 5-9 is mild depression, 10-14 is moderate depression, 15-19 is moderately severe depression and $>20$ is severe depression ${ }^{140}$. Diagnostic validity of 
PHQ 9 has been shown in several studies conducted in different countries like Japan ${ }^{144}$, China $^{145}$, and in USA ${ }^{140}$. Minimal clinical important difference for PHQ9 measured on a scale from 0-27 is 5 which represent true change rather than a measurement error ${ }^{146}$.

\section{$\underline{\text { Sleepiness Scale }}$}

As COPD is strongly associated with sleep disorders like obstructive sleep apnea ${ }^{147,148}$ it is important to assess sleep hygiene among COPD patients. Most commonly used measure for sleep disorders are Epworth sleepiness scale ${ }^{149}$ and Berlin questionnaire $^{150}$. Epworth sleepiness scale was first invented by Johns et. al. in year 1991 as a new method of measuring daytime sleepiness ${ }^{149}$. It's a valid, reliable measure to quantify daytime sleepiness in different countries and it's a valuable tool for clinical practice and multicenter research $^{151,152}$. The Berlin questionnaire consists of three categories of questionnaire related to risk of having sleep apnea and depending on their response to questionnaire subject can classified as high risk (if 2 or more categories where the score is positive) or low risk (if 1 or no categories where the score is positive $)^{150}$. See Appendix 10 for a detailed Berlin Questionnaire and scoring and Appendix 11 for Epworth sleepiness scale.

Table 3 summarizes the range score and minimal clinical important difference for all the important parameters (both general and respiratory) measured in COPD subjects to assess the impact of COPD on individual subjects life and to assess general health of the subject. 
Table 3 Summary of Respiratory and General Measures in COPD

\begin{tabular}{|c|c|c|c|}
\hline Measure & Score Range & $\begin{array}{l}\text { Interpretation of } \\
\text { Score }\end{array}$ & $\begin{array}{l}\text { Minimal Clinical } \\
\text { Important } \\
\text { Difference (MCID) }\end{array}$ \\
\hline \multicolumn{4}{|c|}{ Respiratory measures } \\
\hline SGRQ & $0-100$ & $\begin{array}{l}\text { Higher scores } \\
\text { indicates more } \\
\text { limitation }\end{array}$ & 4.3 units $^{124}$ \\
\hline MMRC Dyspnea & $0-5$ & $\begin{array}{l}\text { Lower value } \\
\text { indicates less severe } \\
\text { dyspnea }\end{array}$ & \\
\hline $6 \mathrm{MWD}$ & $\begin{array}{l}\text { Continuous } \\
\text { measure }\end{array}$ & $\begin{array}{l}\text { Lower distance } \\
\text { walked indicates } \\
\text { more impact of } \\
\text { CODP in patients } \\
\text { life }\end{array}$ & 25 meter $^{106}$ \\
\hline BODE index & $0-10$ & $\begin{array}{l}\text { Higher score } \\
\text { indicates high risk } \\
\text { of mortality }\end{array}$ & \\
\hline $\begin{array}{l}\text { COPD Assessment } \\
\text { Test }\end{array}$ & $0-40$ & $\begin{array}{l}\text { Higher scores } \\
\text { denote a more } \\
\text { severe impact of } \\
\text { COPD on a patient's } \\
\text { life }\end{array}$ & 2 units $^{129}$ \\
\hline \multicolumn{4}{|c|}{ General measures } \\
\hline PHQ9 & $0-27$ & $\begin{array}{l}\text { Mild (5-9) } \\
\text { Moderate (10-14) } \\
\text { Moderately severe } \\
(15-19) \\
\text { Severe (>20) }\end{array}$ & 5 units $^{146}$ \\
\hline Duke profile & $0-100$ & $\begin{array}{l}\text { For health measures } \\
\text { high score means } \\
\text { good health }\end{array}$ & \\
\hline
\end{tabular}




$$
\text { 5( 6( \$ 5 \& + } 7675 \$ 7(*<\square
$$

Disease management, a multidisciplinary approach proposed to enhance the quality and cost-effectiveness of health care for chronic conditions ${ }^{91}$ has been defined as "an approach to patient care that emphasizes coordinated, comprehensive care along the continuum of disease and across health care delivery systems". The purpose of the present study is to evaluate the effectiveness of the COPD disease management program implemented at the University of Louisville in year 2011. We conducted a retrospective comparative effectiveness research study of pulmonary clinic patients with Chronic Obstructive Pulmonary Disease (COPD) that compares clinical outcomes of those enrolled in the disease management program to those under usual care. Primary outcomes included pulmonary function test (PFT) results, six minute walk distance, quality of life measures and cost related to COPD. The disease management program was intended to improve the quality of life of persons living with COPD by reducing the number of exacerbations and in-patient hospitalizations, improving overall respiratory health and reducing the burden of disease and mortality.

The disease management program, per se, is an innovative approach to improve the quality of life and overall health of persons living with COPD. This study will be the first application of comparative effectiveness research to COPD subjects using the 
propensity score (PS) method to evaluate the effectiveness of a COPD disease management program by comparing important clinical outcomes between DMP group and usual care group. Propensity score matching is a common method used in

comparative effectiveness research and in pharmacoepidemiology ${ }^{153}$. The PS estimates each patient's probability of enrollment in the intervention group rather than usual care. Propensity score is a probability ranging from 0 to 1 . Subjects with a low propensity score will have a lower probability of enrolling in the disease management program. Similarly, a higher score suggests a higher probability of enrolling in the disease management program. The propensity score can be used as a matching variable or as a covariate in regression analyses; we opted for the latter approach.

\section{Goals}

The overall goal of the disease management program is to delay the progression of COPD, enhance quality of life, improve clinical outcomes, and also to reduce health care utilizations and overall health care costs.

\section{Specific Aims}

Specifically, the following aims were proposed to assess and evaluate the effectiveness of the disease management program. Aim 1 will evaluate the clinical effectiveness of the program and Aim 2 will focus on evaluating cost effectiveness of the program. 


\section{Aim 1}

a) To test for differences in key clinical parameters, such as the pulmonary function test and six minute walk distance, between COPD subjects enrolled in disease management program and those who are in usual care.

b) To compare longitudinal changes in respiratory and general measures among subjects in disease management program.

Aim 2

To test for differences in cost between the DMP group and the usual care group

\section{Hypothesis}

Primary Hypothesis 1

Research Hypothesis $\left(\mathrm{H}_{1 \mathrm{a}}\right)$ : Subjects participating in the disease management program will experience better clinical outcomes compared to patients receiving usual care. Null Hypothesis $\left(\mathrm{H}_{0 \mathrm{a}}\right)$ : Implementation of disease management program will not improve clinical outcomes among COPD subjects comparing to COPD subjects under usual care.

Research Hypothesis $\left(\mathrm{H}_{1 \mathrm{~b}}\right)$ : Subjects participating in the disease management program will improve their clinical outcomes longitudinally from baseline. Null Hypothesis $\left(\mathrm{H}_{0 \mathrm{~b}}\right)$ : Implementation of disease management program will not improve clinical outcomes among COPD subjects longitudinally from baseline. 
Primary Hypothesis 2

Research Hypothesis $\left(\mathrm{H}_{2}\right)$ : Health care costs for subjects enrolled in the disease management program will be lower than for subjects receiving usual care.

Null Hypothesis $\left(\mathrm{H}_{0}\right)$ : Implementation of disease management program will not lower cost for COPD subjects than for subjects receiving usual care.

\section{Methods}

We conducted a retrospective observational cohort study of COPD subjects using clinical data from medical records and cost data from a claims dataset.

The COPD subjects were obtained from three data sources:

i. From Administrative claims dataset: Male and female University of Louisville health plan members who are beneficiaries of United health care during the time frame from January $1^{\text {st }} 2009$ through December 31 st 2013 (five years).

ii. From Pulmonary Function Test dataset: Male and female subjects who had physician diagnosed COPD and had pulmonary function testing done at the University of Louisville hospital and/or clinics.

iii. From Disease management dataset: Male and female subjects diagnosed with COPD and are under University of Louisville Disease Management Program (DMP). See Appendix 3 for a detailed description of University of Louisville DMP for COPD.

Inclusion criteria for the study included physician diagnosed COPD while exclusion criteria include pregnant women and non-ambulatory subjects. The study 
subjects were divided into two groups based on their enrollment into the disease management program. Group A included COPD subjects in the disease management program (DMP group). Group B included COPD subjects in the usual care (Usual Care group), including those subjects who have health care claims for COPD (from claims data) or whose physicians diagnosed COPD and are cared for at the University of Louisville clinics.

\section{Sources of Data}

Data was collected primarily from two sources:

\section{i. Clinical charts}

Data from the clinic charts were retrieved electronically through Allscripts ${ }^{\mathrm{TM}}$ electronic medical record system. These data included demographics, co-morbidities, pulmonary function test parameters, six minute walk distance, general measures and sleepiness scales.

ii. Claims data

Navigator MD Design 180 was used to retrieve claims data. Navigator MD is a data analytic company which focuses on processing administrative claims data through its product named Design 180. Design 180 is flexible and easy to use database software that can query claims data for specific medical conditions like COPD ${ }^{154}$. Subjects who had claims for COPD were retrieved from the data set first. Costs related to COPD and other major co-morbidities like asthma, heart disease, hypertension, diabetes mellitus, arthritis, rhinitis, depression were extracted from the dataset in the Microsoft Excel format. Costs for those who enrolled in the disease management program were collected 
as COPD related costs in the first, second and third years of the program. Costs of COPD subjects in usual care were collected from January $1^{\text {st }} 2009$ to December $31^{\text {st }} 2013$. Person-years for each subject were calculated from the effective and termination date of the health coverage plan. Costs were calculated as average cost per person per year. Costs related to COPD were further classified into in-patient hospitalization cost, outpatient hospitalization cost, office cost, laboratory cost and home cost. Home service costs included those associated with oxygen concentrator, nebulizer, and continuous positive airway pressure device.

\section{$\underline{\text { Statistical methods }}$}

Predictors (independent or explanatory variables)

The key variable in analysis was group membership: Group A (Disease management group) or Group B (Usual care group). Other covariates were age, gender, race, time of measurement of respiratory and general measures, co morbidities (diabetes, heart disease, hyperlipidemia, hypertension, depression, asthma, rhinitis, osteoporosis, obstructive sleep apnea). Time variable was categorized as 0 (baseline), 6 months, 12 months, and 18 months with the increment of 6 months from baseline. For DMP group, 0 months means at the time of enrollment into disease management program and for usual care group first pulmonary function test measure available from PFT dataset was consider as 0 month and follow-up longitudinal values were rounded up to nearest 6 months, 12 months, etc. The propensity score was used as a covariate in regression analysis. 
For each subject, the baseline probability of participation in the disease management program was calculated by the propensity score method using logistic regression analysis. Variables included in logistic regression analysis included baseline age, gender, race, co-morbidities like asthma, rhinitis, diabetes, heart disease, hyperlipidemia, sleep disorders, arthritis, hypertension and osteoporosis.

At baseline, chi-square test for categorical variable and t-test for continuous variable was used to check for any difference between the two groups. For comparison between two groups (DMP group versus Usual care group), Odds Ratio (OR) was used as a risk measure along with $95 \% \mathrm{CI}$ and associated $\mathrm{P}$ value. $\mathrm{P}$ value $<0.05$ was considered statistically significant.

\section{Outcome (dependent variables)}

Absolute and predicted $\mathrm{FEV}_{1}, \mathrm{FVC}$, quality of life measures (Duke, PHQ9 questionnaire), respiratory measures (6MWD, CAT score, BODE index, mMRC scale), cost related to COPD (from claims data).

To compare longitudinal changes in quality of life measures like SGRQ, CAT score, mMRC scale, BODE index, six minute walk distance and PFT measures in DMP group paired t-test were performed to check for any significant difference in respiratory and general measures from baseline. Longitudinal values of absolute $\mathrm{FEV}_{1}(\mathrm{ml})$ and absolute FVC (ml) were displayed by using CDC Spirola software. Multiple linear regression analysis was performed to assess the rate of deterioration of various clinical parameters like $\mathrm{FEV}_{1}$ and $\mathrm{FVC}$ between two groups. Regression models were also 
adjusted for propensity score. Regression coefficient and $\mathrm{P}$ value intervals will be reported for comparing clinical outcomes between two groups.

Regression model for clinical outcomes:

$$
\begin{aligned}
& \mathrm{Y}_{\mathrm{ij}}=\alpha+\beta_{0} \mathrm{X}_{1 \mathrm{i}}+\mathrm{b}_{0 \mathrm{i}}+\left(\mathrm{b}_{1 \mathrm{i}}+\beta_{1}\right) \mathrm{X}_{2 \mathrm{ij}}+\beta_{2} \mathrm{X}_{1 \mathrm{i}} \mathrm{X}_{2 \mathrm{ij}}+€_{\mathrm{ij}} ; \\
& b_{0 i} \sim N\left(0, \sigma_{b 0 i}^{2}\right) ; b_{i 1} \sim N\left(0, \sigma_{b 1 i}^{2}\right) ; € \mathrm{ij} \sim N\left(0, \sigma^{2}\right)
\end{aligned}
$$

Where "Y" is the dependent or response variable (for e.g. absolute or predicted $\mathrm{FEV}_{1}$, absolute or predicted FVC); " $\mathrm{X}_{1}$ " is an independent indicator variable for DMP group (1) or usual care group (0); $i$ ' is the subject; ' $\mathrm{j}$ ' is time; $\mathrm{X}_{2}$ is the time in months $(0,6,12,24) ; \alpha+\beta_{0}$ and $\beta_{1}+\beta_{2}$ are intercepts and slopes for DMP group respectively; $\mathrm{b}_{0 \mathrm{i}}$ is the random deviation of the $\mathrm{i}^{\text {th }}$ subject from the overall or population' intercept $\left(\beta_{0}\right)$; $b_{1 \mathrm{i}}$ is the random deviation of the $i^{\text {th }}$ subject from the population slope $\left(\beta_{1}\right), \beta_{1}$ is the estimate slope for variable $X_{1}$; $Y_{i j}$ is the outcome variable value (for e.g. $\mathrm{FEV}_{1}$ ) of subject 'i' at time 'j'.

Cost analysis was done by comparing the cost related to COPD among subjects in DMP group versus those under usual care. These costs included total COPD cost, and also sub-categories of cost like office visit cost, in-patient hospitalization (IPH) cost, outpatient hospitalization $(\mathrm{OPH})$ cost, pharmacy cost, cost related to home care and laboratory cost. Regression analysis will be performed for cost related to COPD. All the analysis will be done using SAS 9.3 Statistical software. 
Linear regression model for cost

$Y i=\alpha+\beta_{1} X_{1 i}+\beta_{2} X_{2 i}+\beta_{3} X_{3 i}+\epsilon_{i}$

Where $Y_{\mathrm{i}}$ is the total cost related to COPD from 2009-2013; $\mathrm{X}_{1}=1$ if less than one year in program, else $0 ; X_{2}=1$ if one to two years in program, else $0 ; X_{3}=1$ if more than three year in program, else $0 ; \beta_{1}, \beta_{2}, \beta_{3}$ are regression coefficients respectively for $X_{1}, X_{2}$ and $\mathrm{X}_{3}$

Sample size calculation

Sample size was calculated based on difference in 6MWT between two disease management group and usual care group. If the mean difference in 6MWT distance between the two group is 7.5 with standard deviation of 17.5 in the both groups, the sample size needed to detect a difference with alpha level of 0.05 , and power of $80 \%$ will be 48 (for intervention group) and 144 (for usual care group) based on t-test and allocation ratio of 3:1 usual care versus DMP group. In this study, we have a total of 52 subjects in the intervention group and 662 subjects in usual care group. 
$5(68 / 76 \square$

\section{Descriptive statistics and baseline characteristics of the study subjects}

A total of 52 subjects were enrolled into disease management program between February $1^{\text {st }} 2011$ and December $31^{\text {st }} 2013: 37$ in 2011, 11 in 2012 and 4 in 2013. The usual care group consists of 662 subjects diagnosed with COPD from the University of Louisville Pulmonary function test database or subjects who had claims related to COPD from the Navigator MD claims database. Table 4 describes the baseline demographic characteristics of both the groups. There is a significant difference in average age of subjects between the two groups (54.2 in DMP versus 58.3 in usual care; P value 0.0094). $41 \%$ of subjects in usual care group are current smokers and only $28.8 \%$ in DMP group but the difference is not statistically significant $(\mathrm{P}=0.07)$. Both groups have approximately same number of white subjects (P value 0.77$)$.

Table 4 Baseline characteristics of study subjects

\begin{tabular}{|l|l|l|l|l|}
\hline & All subjects & DMP Group & $\begin{array}{l}\text { Usual Care } \\
\text { Group }\end{array}$ & $\begin{array}{l}\text { DMP vs. } \\
\text { UC group }\end{array}$ \\
\hline $\mathrm{N}$ & 714 & 52 & 662 & $\underline{\underline{P} \text { value }}$ \\
\hline Baseline Age & $58.1 \pm 11.1$ & $54.2 \pm 7.4$ & $58.3 \pm 11.2$ & 0.0094 \\
\hline Male gender & 334 & $27,51.9$ & $307,46.3$ & 0.44 \\
\hline Race & & & & \\
\hline White & 367 & $40,76.9$ & $327,75.1$ & 0.77 \\
\hline AA & 117 & $11,21.1$ & $106,24.3$ & \\
\hline Smokers & & & & $162,40.7$ \\
\hline Current & 177 & $15,28.8$ & 0.07 \\
\hline Former & 247 & $31,59.6$ & $216,54.2$ & 0.23 \\
\hline Never & 26 & $6, \quad 11.5$ & $20,5.0$ & \\
\hline
\end{tabular}


Additional data at baseline on sleep and FENO were collected from subjects enrolled in the disease management program. Mean \pm SD for baseline FENO level is $23.8 \pm 15.3$ and Epworth sleepiness scale is $7.5 \pm 4.5$. Total of $31(59.6 \%)$ subjects had high baseline Berlin score in DMP group. Based on COPD GOLD stage at the time of enrollment, 29 subjects have stage 1 COPD, 16 subjects have stage 2, 6 subjects have stage 3 and only 1 subject has Stage 4 .

\section{Comorbidities}

Table 5 describes the prevalence of comorbidities in both groups. The DMP group has a high prevalence of asthma, rhinitis, hyperlipidemia, osteoporosis and obstructive sleep apnea. Table 5 also presents unadjusted relative risks for comparing different morbidities between two groups. The diagnosis of asthma is a labelled diagnosis based on their pre bronchodilators pulmonary function test and high prevalence among DMP group is likely due to increased screening for asthma at the time of enrollment in the disease management program. There is no significant difference in the prevalence of depression and heart disease between two groups. These comorbidities were used in the multiple logistic regression models to calculate propensity score. 
Table 5 Prevalence of Co-morbidities among the study subjects

\begin{tabular}{|l|l|l|l|l|l|l|l|l|}
\hline & \multicolumn{2}{|l|}{$\begin{array}{l}\text { All subjects } \\
(\mathrm{N}=714)\end{array}$} & \multicolumn{2}{l|}{$\begin{array}{l}\text { DMP Group } \\
(\mathrm{N}=52)\end{array}$} & \multicolumn{2}{l|}{$\begin{array}{l}\text { Usual Care } \\
\text { Group (N=662) }\end{array}$} & $\begin{array}{l}\text { Relative } \\
\text { Risk }\end{array}$ & P value \\
\hline & $\mathrm{n}$ & $\%$ & $\mathrm{n}$ & $\%$ & $\mathrm{n}$ & $\%$ & & \\
\hline Asthma & 149 & 22.1 & 28 & 53.8 & 121 & 17.9 & 2.77 & $<0.0001$ \\
\hline Rhinitis & 220 & 34.1 & 35 & 67.3 & 195 & 31.3 & 2.14 & $<0.0001$ \\
\hline Arthritis & 238 & 35.3 & 26 & 50.0 & 212 & 64.1 & 1.46 & 0.02 \\
\hline Depression & 141 & 20.1 & 16 & 30.7 & 125 & 20.0 & 1.53 & 0.06 \\
\hline Heart Disease & 314 & 46.5 & 25 & 48.0 & 289 & 46.3 & 1.03 & 0.8 \\
\hline Hypertension & 396, & 58.7 & 37 & 71.1 & 359 & 57.7 & 1.23 & 0.058 \\
\hline Hyperlipidemia & 270, & 40.1 & 31 & 59.6 & 239 & 38.4 & 1.55 & 0.002 \\
\hline Diabetes & 160 & 23.7 & 18 & 34.6 & 142 & 22.8 & 1.51 & 0.055 \\
\hline Osteoporosis & 138 & 20.5 & 19 & 36.5 & 119 & 19.2 & 1.90 & 0.002 \\
\hline $\begin{array}{l}\text { Obstructive Sleep } \\
\text { Apnea }\end{array}$ & 116 & 26.2 & 26 & 50.0 & 90 & 23.0 & 2.17 & $<0.0001$ \\
\hline
\end{tabular}

\section{Propensity score calculation}

Table 6 Logistics regression model for propensity score calculation

\begin{tabular}{|l|l|l|}
\hline & Odds Ratio & P value \\
\hline Age & 0.91 & $<0.001$ \\
\hline Male Gender & 1.99 & 0.07 \\
\hline Asthma & 4.76 & $<0.0001$ \\
\hline Rhinitis & 3.46 & 0.0006 \\
\hline Arthritis & 2.58 & 0.01 \\
\hline Heart Disease & 1.18 & 0.66 \\
\hline Hypertension & 0.96 & 0.92 \\
\hline Hyperlipidemia & 2.03 & 0.06 \\
\hline Diabetes & 0.97 & 0.94 \\
\hline Depression & 1.09 & 0.82 \\
\hline Osteoporosis & 0.91 & 0.82 \\
\hline
\end{tabular}

As discussed above, propensity is the probability of being enrolled in the disease management program after controlling for important variables. Multiple logistic regression method was used to calculate the probability of each subject being enrolled in the disease management program rather than usual care. Subjects who suffered from 
asthma, rhinitis and arthritis were significantly more likely to enroll in the disease management program (Table 6).

Figure 2 Distribution of Propensity score in DMP group and Usual care group

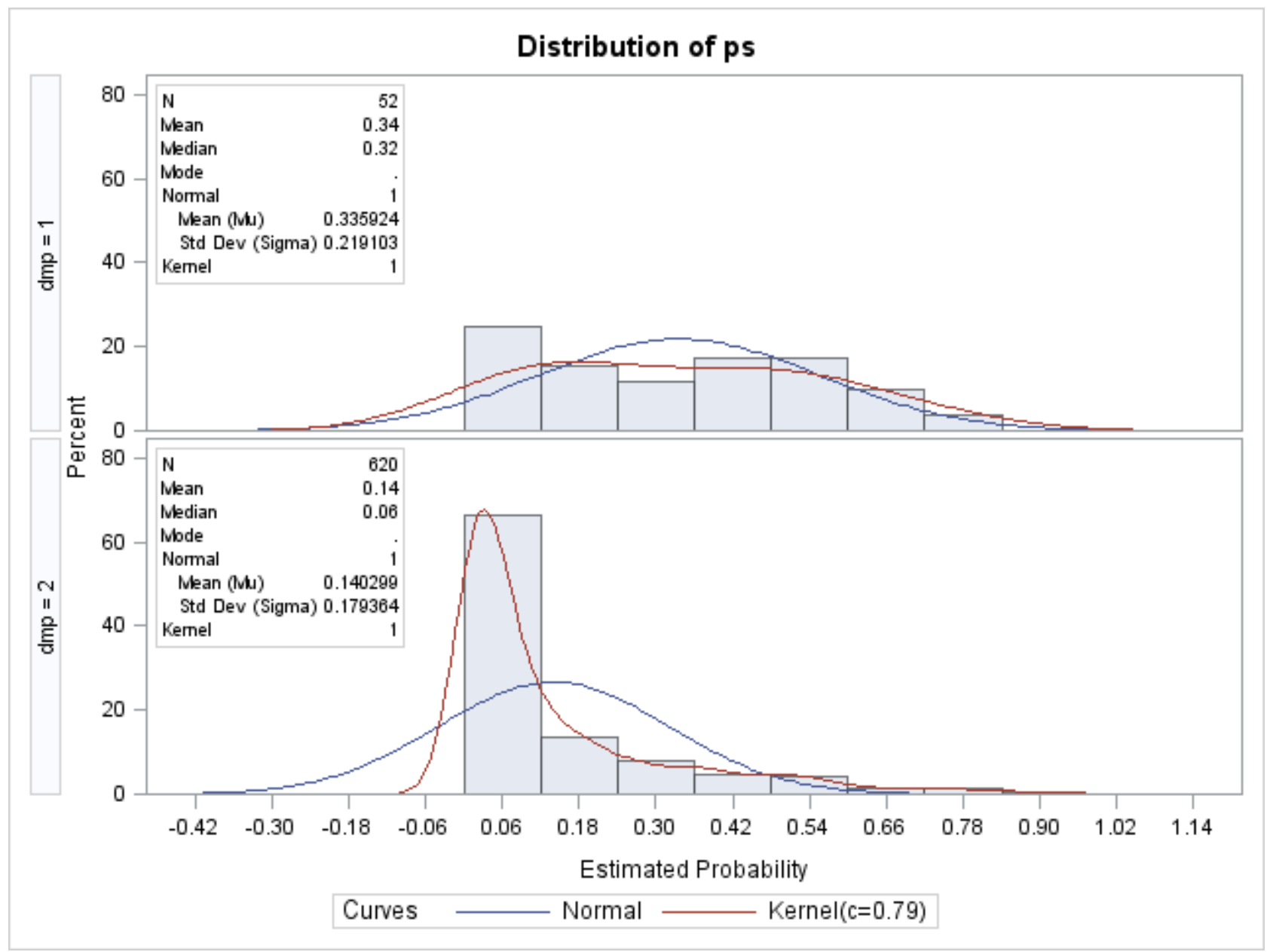

Distribution of probability for both groups is shown in figure 2. Average

propensity score in disease management group were 0.34 versus 0.14 in usual care group.

From the figure 2 there is an overlap in the distribution of propensity score between disease management group and usual care group. The propensity score has been 
incorporated as a covariate in multiple regression analysis when comparing primary outcomes like $\mathrm{FEV}_{1}, \mathrm{FVC}$, and cost related to COPD.

\section{Clinical effectiveness of the program}

The clinical effectiveness of the program was assessed by both general measures and respiratory measures. General measures like PHQ9 (for assessing depression) and Duke Profile (for assessing general health) were used among COPD subjects in the DMP group. Respiratory measures like pulmonary function test, SGRQ, CAT score, BODE index, 6MWT and MMRC dyspnea scale were used to assess the severity of disease and impact of COPD on individual's daily activities. Six minute walk distance and

pulmonary function test (absolute and \% predicted values of $\mathrm{FEV}_{1}$ and $\mathrm{FVC}$ ) were primary outcomes used to compare two groups and also to compare longitudinal changes within each group from their baseline values.

\section{Longitudinal changes of General Measures in DMP group}

Table 7 represents the longitudinal changes of PHQ9 and Duke Profile among subjects in DMP group.

Table 7 Longitudinal changes of general measures in DMP group

\begin{tabular}{|l|l|l|l|}
\hline & 0 month & 12 month & 24 month \\
\hline PHQ9 (n, & 19 & 30 & 13 \\
Mean \pm SD) & $6.3 \pm 5.4$ & $4.0 \pm 4.4$ & $3.1 \pm 2.1 *$ \\
\hline & & & \\
\hline DUKE (n, & 52, & 30 & 19 \\
Mean \pm SD) & $64.1 \pm 17.4$ & $71.6 \pm 16.7 *$ & $70.8 \pm 18.7 *$ \\
\hline & * represents statistically significant from baseline \\
\hline
\end{tabular}




\section{PHQ9}

PHQ9 is a measure for depression; lower values indicate fewer depressive symptoms. At baseline, the average PHQ9 was 6.3 which improved at the end of 12 months $($ mean $=4)$ and at 24 months $($ mean $=3.1)$. Figure 3 depicts longitudinal changes in PHQ9 (mean \pm SE) every six months from baseline to 30 months. There is a gradual decline in PHQ9 from baseline to 30 months except for a surge from 12 to 18 months. PHQ9 was implemented later in the program resulting in missing baseline PHQ9 values for 33 subjects. Notwithstanding the small number of subjects, change in PHQ9 from baseline is statistically significant at 24 months and we can conclude that disease management program significantly improves depressive symptoms among COPD subjects enrolled in the disease management program.

Figure 3 Longitudinal changes in PHQ9 in DMP group

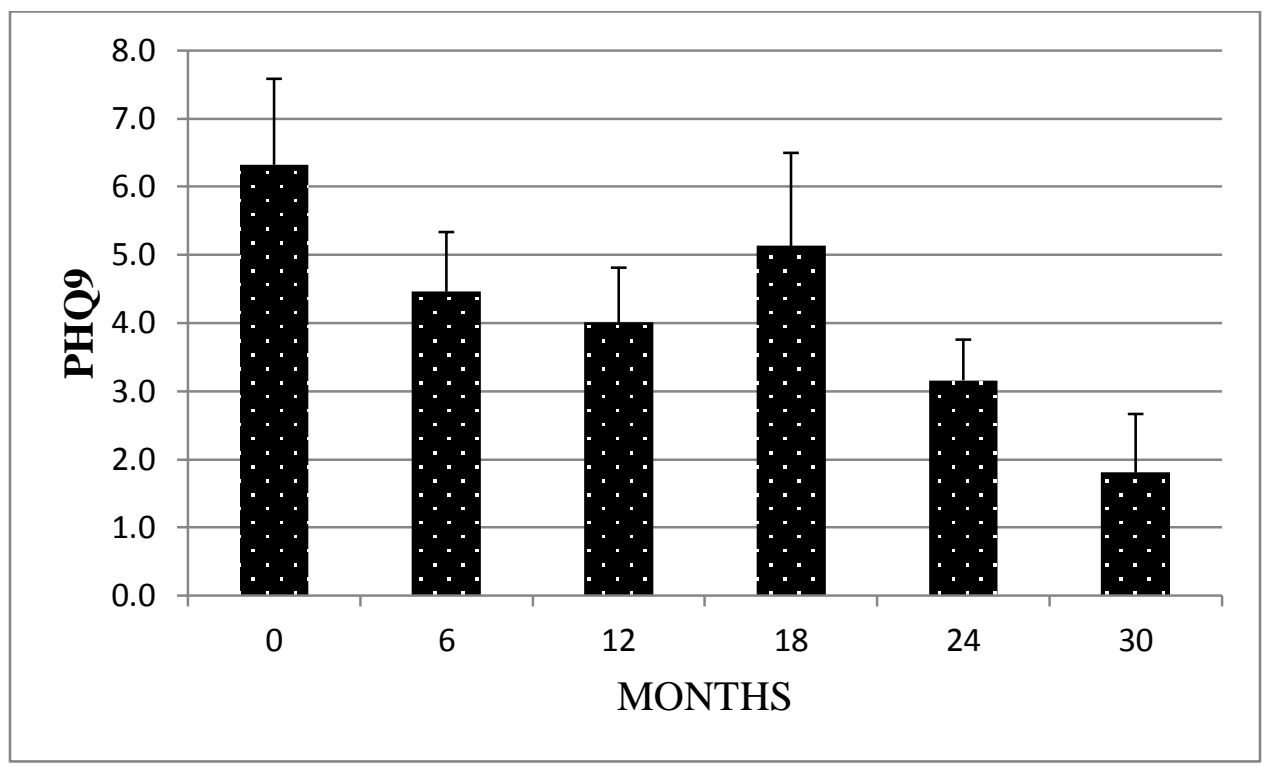




\section{Duke Profile}

Duke profile is a self-reported measure of general health status and higher scores are better. At baseline, the average duke score was 64.1 which were improved at the end of 12 months and 24 months. Figure 4 depicts longitudinal changes in duke score (mean \pm SE) every six months from baseline to 30 months. There is a gradual improvement in duke score from baseline to 12 months. Notwithstanding score declined slightly at 18 and at 30 months it is still significantly high than baseline. In conclusion, the disease management program improves general quality of life of COPD subjects over baseline.

Figure 4 Longitudinal changes in Duke score in DMP group

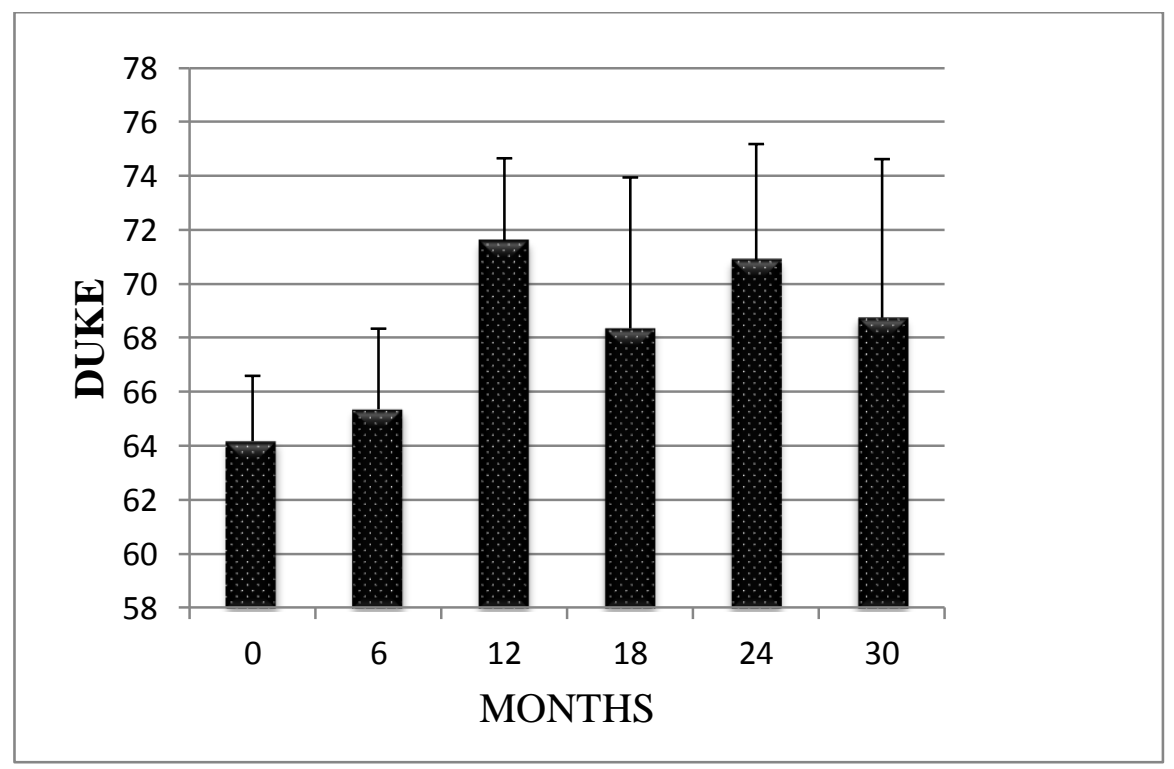




\section{Longitudinal changes of Respiratory Measures in DMP group}

The respiratory measures followed longitudinally among subjects in DMP group include St George Respiratory Questionnaire (SGRQ), COPD Assessment Test (CAT), mMRC dyspnea scale, BODE index along with pulmonary functions test and Six Minute Walk Distance (6MWD). Table 8 summarizes longitudinal changes of SGRQ, CAT score and mMRC dyspnea scale among subjects in DMP group at baseline, 12 months and 24 months.

Table 8 Longitudinal changes of Respiratory measures in DMP group

\begin{tabular}{|l|l|l|l|}
\hline & 0 month & 12 month & 24 month \\
\hline $\begin{array}{l}\text { SGRQ (n, } \\
\text { Mean } \pm \text { SD) }\end{array}$ & 52, & 29, & 11, \\
\hline & $37.1 \pm 17.1$ & $28.4 \pm 16.1 *$ & $30.2 \pm 16.1$ \\
\hline CAT score (n, & 14, & & \\
Mean \pm SD) & $18.4 \pm 6.7$ & 22, & 18, \\
\hline & & $12.2 \pm 5.9 *$ & $14.2 \pm 7.7$ \\
\hline mMRC (n, & 50, & & \\
Mean \pm SD) & $0.56 \pm 0.7$ & 32, & 21, \\
\hline & $*$ represents statistically significant from baseline \\
\hline
\end{tabular}


St George Respiratory Questionnaire (SGRQ)

SGRQ is an instrument used among obstructive lung disease subjects to measure impact on overall health, daily life, and perceived well-being. Score is ranging from 0 to 100, higher the score indicates more severe limitation. At baseline average SGRQ score was 37.1 which were improved at the end of 12 months $(\mathrm{P}=0.02)$ and 24 months from $(\mathrm{P}$ $=0.21$ ). Figure 5 depicts longitudinal changes in SGRQ score from baseline. There is slight deterioration in score at 24 months but it is still low from baseline. The difference in SGRQ after 12 months is not only statistically significant but also clinically significant as the minimal clinical important difference for SGRQ is 4 for effective treatment thus we can conclude that there is a significant improvement in overall health, daily life and perceived well-being of COPD subjects after enrollment in the disease management program.

Figure 5 Longitudinal changes in SGRQ score in DMP group

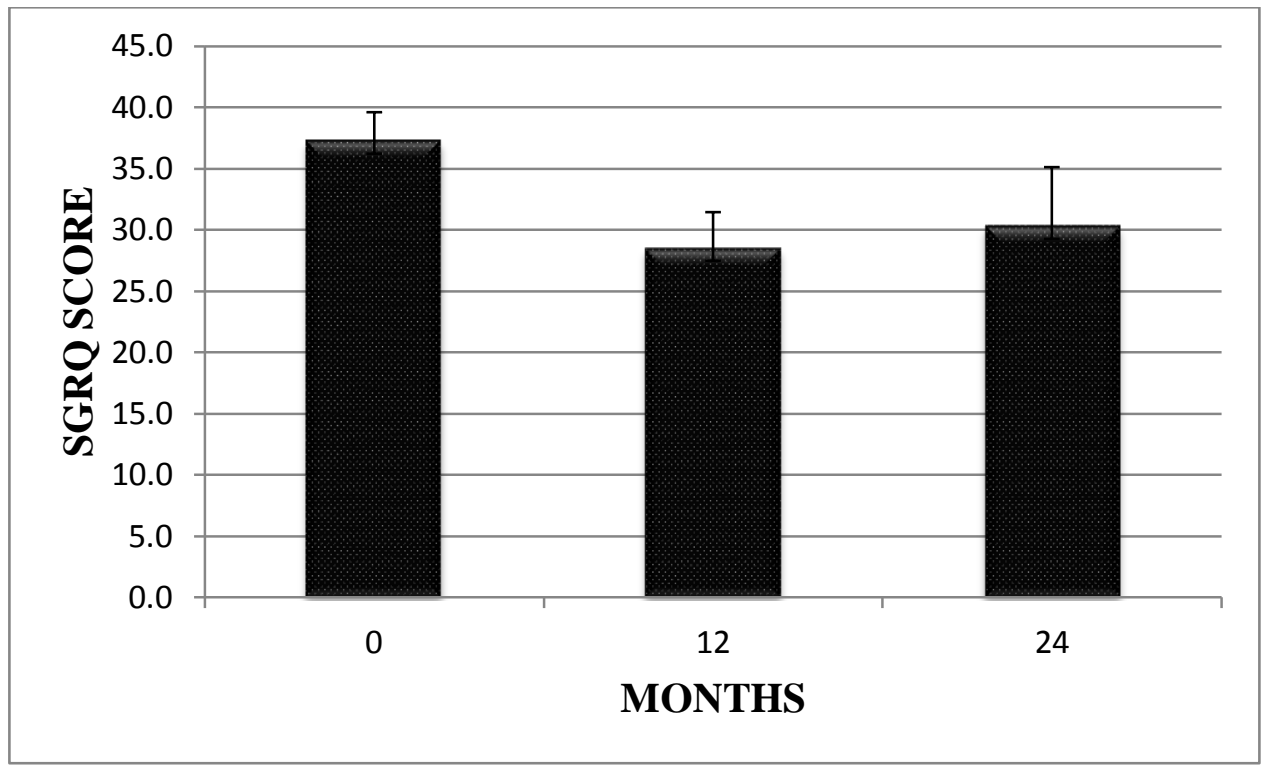




\section{COPD Assessment Test (CAT)}

CAT is a shorter version of SGRQ questionnaire and is designed to measure the impact of COPD on subject's life and score can be compared to assess the changes over time. Score is ranging from $0-40$ with higher scores indicate more severe impact of COPD on an individual's life. Figure 6 depicts longitudinal changes in CAT score from baseline. There is significant decline in mean CAT score from baseline to 12 months (P $=0.01$. From one year to two year score slightly deteriorates to 14.4 , but remains below baseline. Based on minimal clinical important difference (MCID) value of 2 for CAT, this measure is also clinically significant at 12 and 24 months.

Figure 6 Longitudinal changes in CAT score in DMP group

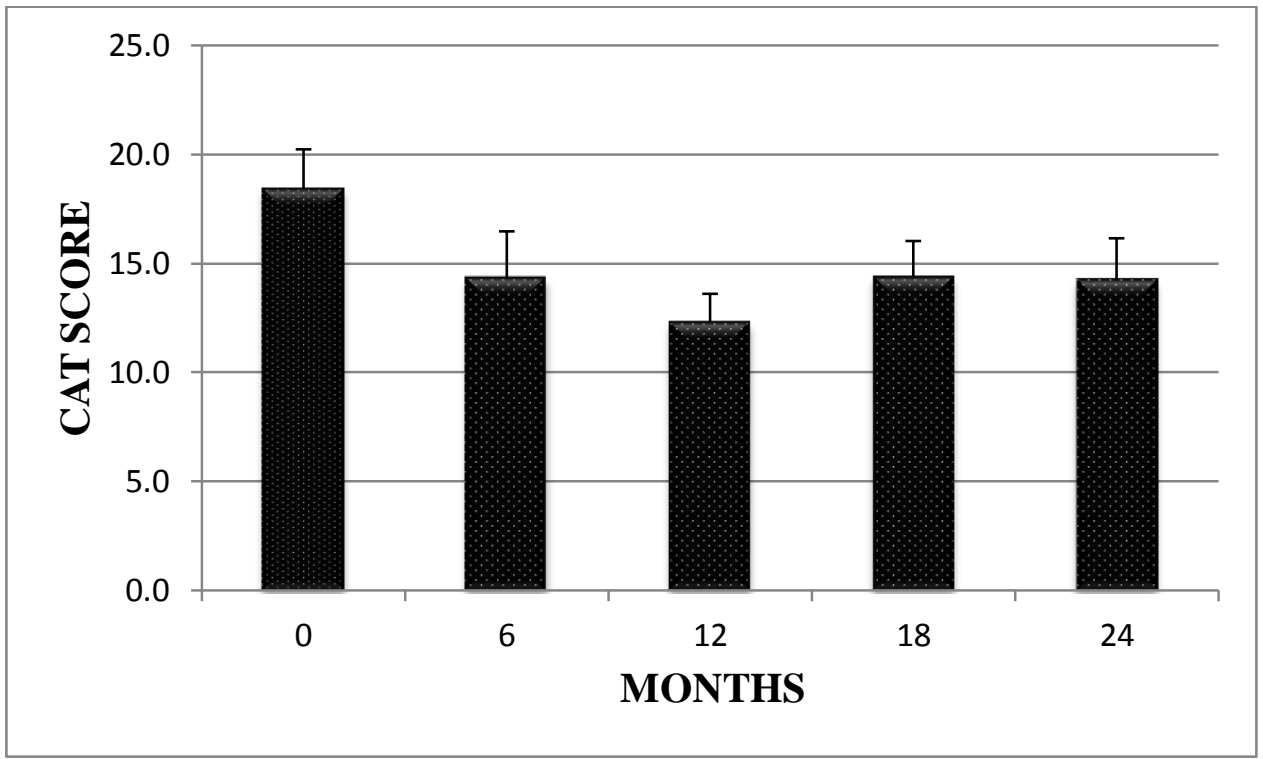


$\mathrm{mMRC}$ is a subjective assessment of breathlessness in respiratory diseases like COPD and its value are ranging from 0-5. Table 9 describes longitudinal comparison of changes in scale from baseline to 1 year and 2 years. mMRC scale decreased by 0.06 at 1 year $(\mathrm{P}=0.57)$ and increased by 0.20 units at 2 year $(\mathrm{P}=0.29)$ but the changes are not statistically significant from baseline.

Figure 7 Longitudinal changes in mMRC scale in DMP Group

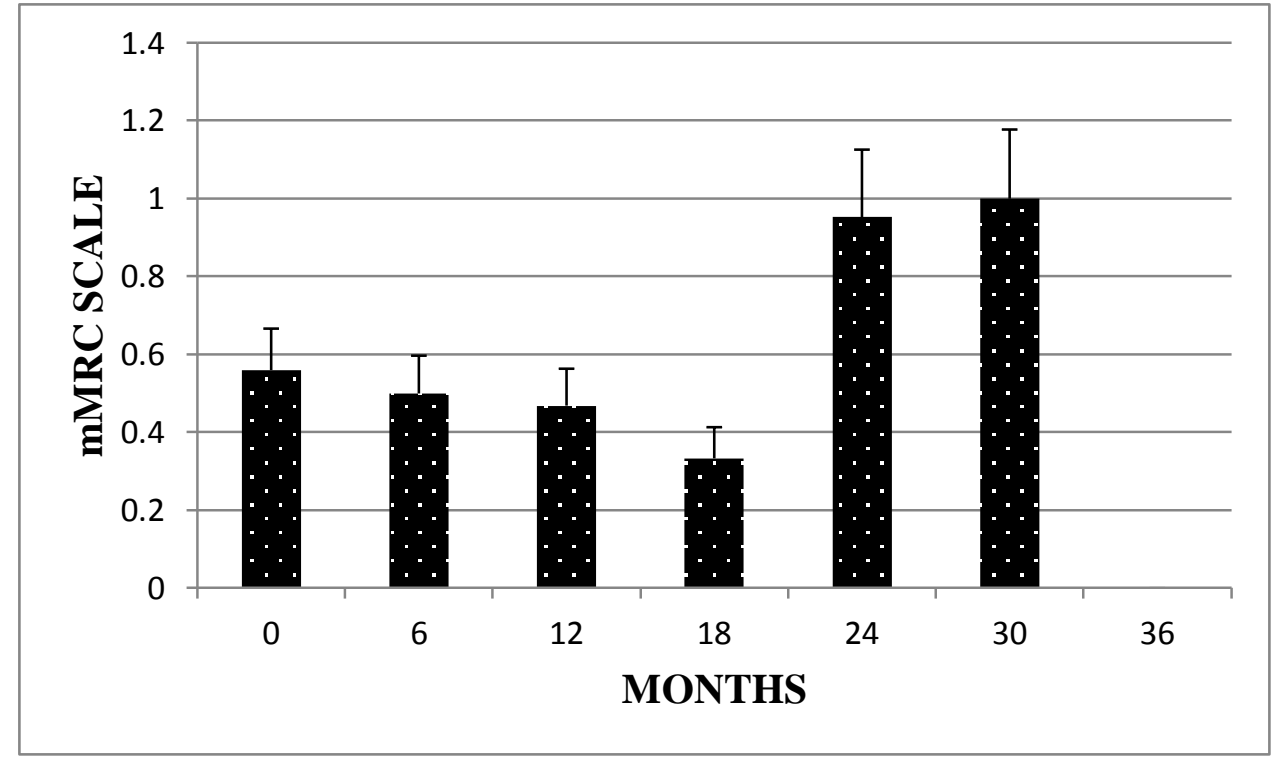

Table 9 Longitudinal comparison of mMRC Dyspnea Scale

\begin{tabular}{|l|l|l|}
\hline \multicolumn{3}{|c|}{ MMRC Dyspnea scale } \\
\hline & 12 months vs. & 24 months vs. \\
& 0 month & 0 month \\
\hline $\mathrm{N}$ & 32 & 21 \\
\hline Mean difference & -0.06 & 0.20 \\
$(95 \% \mathrm{CI})$ & $(-0.30,0.17)$ & $(-0.19,0.59)$ \\
\hline $\mathrm{P}$ value & 0.57 & 0.29 \\
\hline
\end{tabular}


Longitudinal changes of Pulmonary Function Test in DMP Group and Usual Care Group

Pulmonary function test is most common spirometry measured among COPD subjects. Table 10 describes longitudinal changes in $\mathrm{FEV}_{1}$ (absolute and \% predicted) and FVC (absolute and \% predicted) for DMP group and Usual care group. Percent predicted $\mathrm{FEV}_{1}$ is defined $\mathrm{FEV}_{1} \%$ of the patient divided by the average $\mathrm{FEV}_{1} \%$ in the population for any person of similar age, sex and body composition (height) ${ }^{19}$. Out of 52 subjects, 39 subjects had measured values at 1 year and 23 subjects at 2 year in DMP group; while 94 out of 426 subjects had measured values at 1 year and 48 at 2 year in usual care group.

Table 10 Longitudinal changes in Pulmonary Function test measures in DMP and Usual care group

\begin{tabular}{|c|c|c|c|}
\hline & 0 month & 12 month & 24 month \\
\hline \multicolumn{4}{|c|}{ DMP Group } \\
\hline & $\mathrm{N}=52$ & $\mathrm{~N}=39$ & $\mathrm{~N}=23$ \\
\hline $\mathrm{FEV}_{1}$ (liter) & $2.16 \pm 0.7$ & $2.27 \pm 0.7$ & $2.04 \pm 0.8$ \\
\hline$\%$ Predicted $\mathrm{FEV}_{1}$ & $0.67 \pm 0.2$ & $0.72 \pm 0.2$ & $0.69 \pm 0.2$ \\
\hline FVC (liter) & $3.49 \pm 1.1$ & $3.58 \pm 0.9$ & $3.30 \pm 1.1$ \\
\hline$\%$ Predicted FVC & $0.83 \pm 0.2$ & $0.9 \pm 0.2$ & $0.87 \pm 0.2$ \\
\hline \multicolumn{4}{|c|}{ Usual Care Group } \\
\hline & $\mathrm{N}=426$ & $\mathrm{~N}=94$ & $\mathrm{~N}=48$ \\
\hline $\mathrm{FEV}_{1}($ liter $)$ & $1.44 \pm 0.8$ & $1.37 \pm 0.6$ & $1.21 \pm 0.56$ \\
\hline \% Predicted $\mathrm{FEV}_{1}$ & $0.50 \pm 0.2$ & $0.49 \pm 0.2$ & $0.45 \pm 0.18$ \\
\hline FVC (liter) & $2.78 \pm 1.1$ & $2.67 \pm 1.1$ & $2.47 \pm 1.2$ \\
\hline$\%$ Predicted FVC & $0.74 \pm 0.2$ & $0.74 \pm 0.2$ & $0.69 \pm 0.2$ \\
\hline
\end{tabular}


Forced Expiratory Volume in one second $\left(\mathrm{FEV}_{1}\right)$

Table 11 presents longitudinal comparison of changes in absolute $\mathrm{FEV}_{1}$ at the end of 1 year, 2 year and 3 years for both the groups. From the table subjects in DMP group has significant improvement in their absolute $\mathrm{FEV}_{1}(140 \mathrm{ml})$ from baseline to 12 months ( $\mathrm{P}$ value 0.0046 ). There is also improvement in $\mathrm{FEV}_{1}$ at 24 months by $30 \mathrm{ml}$ and at 36 months by $60 \mathrm{ml}$ but the difference is not statistically significant due to less number subjects at the end of 2 years and 3 years. $\mathrm{FEV}_{1}$ in usual care group is monotonically declining at 12 months $(-5 \mathrm{ml}), 24$ months $(-130 \mathrm{ml})$ and at 36 months $(-130 \mathrm{ml})$. So in addition to improvement in general measures, subjects in DMP group had significant improvement in $\mathrm{FEV}_{1}$ which is also one of the predictor for mortality among COPD subjects.

Table 11 Longitudinal comparison of changes in absolute $\mathrm{FEV}_{1}(\mathrm{ml})$

\begin{tabular}{|l|l|l|l|}
\hline Absolute FEV $_{1}(\mathrm{ml})$ & $\begin{array}{l}12 \text { month vs. } \\
0 \text { month }\end{array}$ & $\begin{array}{l}24 \text { month vs. } \\
0 \text { month }\end{array}$ & $\begin{array}{l}36 \text { month vs. } \\
0 \text { month }\end{array}$ \\
\hline \multicolumn{5}{|c|}{ DMP Group } \\
\hline $\mathrm{N}$ & 39 & 23 & 3 \\
\hline $\begin{array}{l}\text { Mean difference } \\
(95 \% \mathrm{CI})\end{array}$ & $\begin{array}{l}140 \\
(40-250)\end{array}$ & $\begin{array}{l}30 \\
(-90,170)\end{array}$ & $\begin{array}{l}60 \\
(-170,290)\end{array}$ \\
\hline $\mathrm{P}$ value & 0.0046 & 0.55 & 0.36 \\
\hline \multicolumn{5}{|}{ Usual Care Group } \\
\hline $\mathrm{N}$ & 92 & 46 & 30 \\
\hline $\begin{array}{l}\text { Mean difference } \\
(95 \% \mathrm{CI})\end{array}$ & -5 & -130 & -130 \\
$(-60,50)$ & $(-230,-30)$ & $(-260,-10)$ \\
\hline $\mathrm{P}$ value & 0.85 & 0.01 & 0.03 \\
\hline
\end{tabular}


Linear regression estimates for $\mathrm{FEV}_{1}$ as a 'dependent variable' while DMP group versus usual care, time of measurement of $\mathrm{FEV}_{1}$ and propensity score as an 'independent variable' is shown in Table 12. Main effect model will include DMP variable, time and interaction between them (Model 1). Model 2 is an adjusted model with addition of propensity score in the regression analysis. From the results of Model $1, \mathrm{FEV}_{1}$ for usual care group is $1455 \mathrm{ml}$ (estimate for intercept) and for DMP group is $2207.1 \mathrm{~m} 1$ (by adding estimates for intercept and DMP group). Slope for usual care group is $-3.77 \mathrm{ml}$ which means $\mathrm{FEV}_{1}$ is declining by time in usual care group but in DMP group slope is $1.126 \mathrm{ml}$ means there is an improvement in $\mathrm{FEV}_{1}$ with time and its marginally significant ( $\mathrm{P}=0.0536)$. From model 2 propensity score was found to be significantly associated with $\mathrm{FEV}_{1}$. AIC and BIC for model 2 is less than model 1 and thus model 2 is a more fitted model. Even after adding propensity score, slope is still positive for DMP group (1.001 ml) but not statistically significant $(\mathrm{P}=0.0916)$.

Table 12 Estimates from Linear regression Models for examining changes in absolute $\mathrm{FEV}_{1}(\mathrm{ml})$

\begin{tabular}{|c|c|c|c|c|c|c|}
\hline & \multicolumn{3}{|l|}{ Model 1} & \multicolumn{3}{|l|}{ Model 2} \\
\hline \multicolumn{7}{|c|}{ Fixed Effects } \\
\hline & Estimates & SE & $\mathrm{P}$ value & Estimates & SE & $\mathrm{P}$ value \\
\hline Intercept & 1455 & 35.97 & $<0.0001$ & 1349.6 & 42.74 & $<0.0001$ \\
\hline DMP group & 752.1 & $\mid 108.8$ & $<.0001$ & 527 & 121.8 & $<.0001$ \\
\hline Time & -3.77 & 1.057 & 0.0005 & -3.28 & 1.082 & 0.0028 \\
\hline Time*DMP & 4.896 & 2.52 & 0.0536 & 4.281 & 2.523 & 0.0916 \\
\hline Propensity score & & & & 996.4 & 240.4 & $<0.0001$ \\
\hline \multicolumn{7}{|c|}{ Error variance } \\
\hline Intercept & 516.2 & 36.06 & $<0.0001$ & 493 & 36.07 & $<0.0001$ \\
\hline Time & 0.039 & 0.024 & 0.0542 & 0.043 & 0.025 & 0.0444 \\
\hline Residuals & 39.46 & 4.109 & $<0.0001$ & 37.93 & 4.058 & $<0.0001$ \\
\hline \multicolumn{7}{|c|}{ Model Fitness } \\
\hline AIC & 1199.7 & & & 1074.3 & & \\
\hline BIC & 1216.4 & & & 1090.6 & & \\
\hline
\end{tabular}




\section{Forced Vital Capacity (FVC)}

Table 13 represents longitudinal comparisons of changes in absolute $\mathrm{FVC}(\mathrm{ml})$ at 1 year, 2 year and 3 year in both groups. FVC is monotonically improving in DMP group at the end of 1 year, 2 years and 3 years but the changes were not significant from baseline. But in Usual care group FVC improved only at the end of 1 year, but is declining thereafter from baseline. Subjects in usual care group had mean decline of 130 $\mathrm{ml}$ (at 24 months) and $210 \mathrm{ml}$ (at 26 months) in FVC from baseline, but FVC among subjects in DMP group monotonically improves from baseline.

Table 13 Longitudinal comparison of changes in absolute FVC (ml)

\begin{tabular}{|l|l|l|l|}
\hline Absolute FVC (ml) & $\begin{array}{l}12 \text { month vs. } \\
0 \text { month }\end{array}$ & $\begin{array}{l}24 \text { month vs. } \\
0 \text { month }\end{array}$ & $\begin{array}{l}36 \text { month vs. } \\
0 \text { month }\end{array}$ \\
\hline \multicolumn{5}{|l|}{ DMP Group } \\
\hline $\mathrm{N}$ & 39 & 23 & 3 \\
\hline $\begin{array}{l}\text { Mean difference } \\
(95 \% \mathrm{CI})\end{array}$ & $\begin{array}{l}100 \\
(-10,210)\end{array}$ & $\begin{array}{l}40 \\
(-100,190)\end{array}$ & $\begin{array}{l}130 \\
(-530,780)\end{array}$ \\
\hline $\mathrm{P}$ value & 0.06 & 0.53 & 0.49 \\
\hline \multicolumn{5}{|}{ Usual Care Group } \\
\hline $\mathrm{N}$ & 92 & 46 & 30 \\
\hline $\begin{array}{l}\text { Mean difference } \\
(95 \% \mathrm{CI})\end{array}$ & 40 & -130 & -210 \\
$(-50,140)$ & $(-270,10)$ & $(-440,10)$ \\
\hline P value & 0.39 & 0.07 & 0.06 \\
\hline
\end{tabular}


Linear regression estimates for FVC as a dependent variable for both the models is shown in Table 14. From the table FVC for usual care group is $2795.8 \mathrm{ml}$ (model 1) and for DMP group is $3519.7 \mathrm{ml}$. Here also slope for FVC is negative $(-3.43 \mathrm{ml})$ for subjects in usual care group and positive for subjects in DMP group. For every one month increase in time, subjects in usual care had a decline of FVC by $3.43 \mathrm{ml}$, while subjects in disease management program actually had an improvement of $1.32 \mathrm{ml}$. Propensity score is found to be significantly associated with FVC with P value of 0.0046 (Model 2). Propensity score adjusted model fits well as evident by decrease in AIC and BIC values comparing to Model 1.

Table 14 Estimates from linear regression models for examining change in absolute FVC (ml)

\begin{tabular}{|c|c|c|c|c|c|c|}
\hline & \multicolumn{3}{|l|}{ Model 1} & \multicolumn{3}{|l|}{ Model 2} \\
\hline \multicolumn{7}{|c|}{ Fixed Effects } \\
\hline & Estimates & SE & $\mathrm{P}$ value & Estimates & $\mathrm{SE}$ & $\mathrm{P}$ value \\
\hline Intercept & 2795.8 & 53.36 & $<0.0001$ & 2690.5 & 63.85 & $<0.0001$ \\
\hline DMP group & 723.9 & 161.4 & $<0.0001$ & 485.3 & 182 & 0.0084 \\
\hline Time & -3.43 & 1.624 & 0.0360 & -2.95 & 1.691 & 0.0825 \\
\hline Time*DMP & 4.754 & 3.834 & 0.2167 & 4.306 & 3.864 & 0.2668 \\
\hline Propensity score & & & & 1034.5 & 36.02 & 0.0046 \\
\hline \multicolumn{7}{|c|}{ Error variance } \\
\hline Intercept & 1134.8 & 79.1 & $<0.0001$ & 1100.3 & 80.05 & $<0.0001$ \\
\hline Slope & 0.1 & 0.045 & 0.0133 & 0.117 & 0.048 & 0.0076 \\
\hline Residual & 87.54 & 8.313 & $<0.0001$ & 81.61 & 8.065 & $<0.0001$ \\
\hline \multicolumn{7}{|c|}{ Model Fitness } \\
\hline $\mathrm{AIC}$ & 1874.0 & & & 1707.3 & & \\
\hline $\mathrm{BIC}$ & 1890.7 & & & 1723.5 & & \\
\hline
\end{tabular}


Figure 8 Longitudinal $\mathrm{FEV}_{1}$ and FVC changes in DMP Group and Usual Care Group (by SPIROLA software)
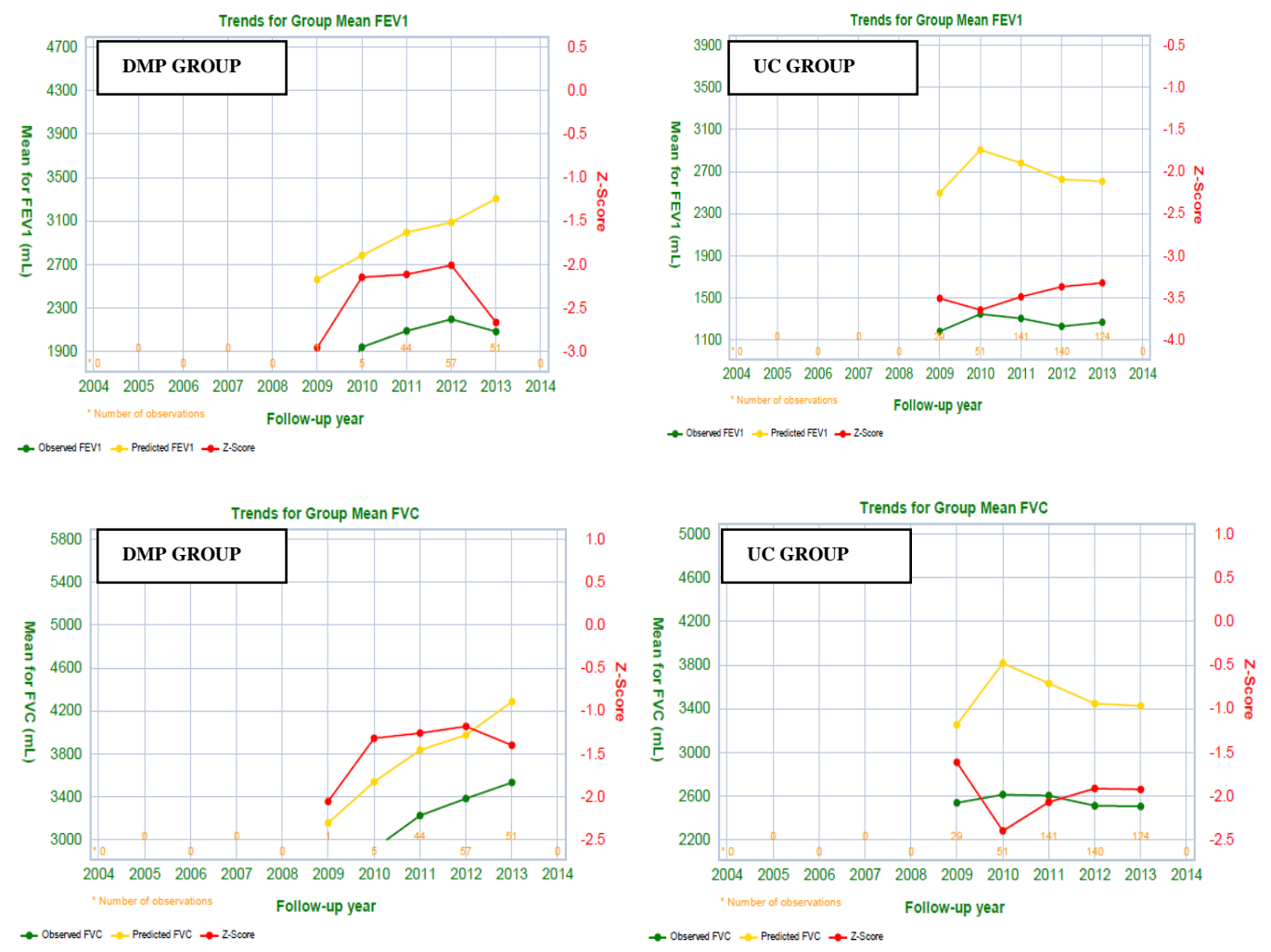

Figure 8 is displaying longitudinal $\mathrm{FEV}_{1}$ and $\mathrm{FVC}$ in both the groups from 2009 to 2013 created through CDC SPIROLA software. Visually from the figure, there is a significant improvement in $\mathrm{FEV}_{1}$ among COPD subjects in disease management program from 2011 to 2012 and slight decline in $\mathrm{FEV}_{1}$ in third year but it is still high from baseline values of 2011. But the values of $\mathrm{FEV}_{1}$ are monotonically declining from 2011 to 2012 in usual care group. 


\section{$\underline{\text { Six minute Walk Distance (6MWD) }}$}

Table 15 and Table 16 presents longitudinal changes and comparison to baseline in six minute walk distance in meter at 0 month, 12 months and 24 months for both the group. In DMP group 52 subjects have baseline 6MWD, 32 subjects have values at 12 months and 21 subjects have values at 24 months. There is a monotonic decline in six minute walk distance in DMP group from baseline to 2 years but after doing a paired $\mathrm{t}$ test analysis at 12 months and 24 months comparing values to baseline, difference is not statistically significant. In usual care group distance declined slightly at 12 months but improved at 24 months, but doing a paired t-test analysis subjects in usual care group declined by 24.8 meter at 1 year and by 13.5 meter at 2 year but again the difference is not statistically significant.

Table 15 Longitudinal changes in 6 MWD (meter) in DMP and Usual care group

\begin{tabular}{|l|l|l|l|}
\hline & 0 month & \multicolumn{1}{|c|}{ 12 month } & DMP Group \\
\hline & \multicolumn{3}{|c|}{ month } \\
\hline & $\mathrm{N}=52$ & $\mathrm{~N}=32$ & $\mathrm{~N}=21$ \\
\hline 6 MWD (meter) & $435.2 \pm 99.1$ & $432.3 \pm 117.2$ & $408.2 \pm 134.5$ \\
\hline \% predicted 6MWD & $83.1 \pm 4.5$ & $85.7 \pm 15.7$ & $82.5 \pm 20.2$ \\
\hline & \multicolumn{3}{|c|}{ Usual Care Group } \\
\hline & $\mathrm{N}=143$ & $\mathrm{~N}=26$ & $\mathrm{~N}=11$ \\
\hline & $318.1 \pm 101.4$ & $317 \pm 90.9$ & $347.2 \pm 90.3$ \\
\hline \% MWD (meter) & $65.1 \pm 38.4$ & $67.4 \pm 15.8$ & $68.5 \pm 19.1$ \\
\hline
\end{tabular}


Table 16 Longitudinal comparison of changes in 6 MWD

\begin{tabular}{|l|l|l|}
\hline \multicolumn{3}{|c|}{ Longitudinal comparison of changes in 6 MWD } \\
\hline & $\begin{array}{l}12 \text { month vs. } \\
0 \text { month }\end{array}$ & $\begin{array}{l}\text { 24 month vs. } \\
0 \text { month }\end{array}$ \\
\hline \multicolumn{3}{|c|}{ DMP Group } \\
\hline $\mathrm{N}$ & 32 & 21 \\
\hline $\begin{array}{l}\text { Mean difference } \\
(95 \% \mathrm{CI})\end{array}$ & $3(-10.2,16.2)$ & $-15.2(-39.8,9.5)$ \\
\hline $\mathrm{P}$ value & 0.64 & 0.22 \\
\hline & Usual Care Group \\
\hline $\mathrm{N}$ & 26 & 11 \\
\hline $\begin{array}{l}\text { Mean difference } \\
(95 \% \mathrm{CI})\end{array}$ & $-24.8(-56.3,6.5)$ & $-13.5(-40.9,13.9)$ \\
\hline $\mathrm{P}$ value & 0.11 & 0.29 \\
\hline
\end{tabular}

\section{BODE Index}

BODE index is a multidimensional grading system to evaluate COPD subjects. BODE index made of BMI, FEV1, mMRC dyspnea scale and six minute walk distance. Average BMI of subjects in disease management program at baseline was $36.1 \pm 9.1$, at 12 months it was $37.2 \pm 10.1$ and at 24 months it was $37.9 \pm 9.2$. Change in BMI was not statistically significant from baseline. Figure 9 display longitudinal BODE index values for subjects in disease management program from baseline to 36 months. Longitudinal comparison of changes in BODE index (mean difference and associated $\mathrm{P}$ value) is presented in Table 17. At baseline average BODE index was 1.5 which was improved significantly at the end of 12 months with mean difference of -0.40 and $\mathrm{P}$ value of 0.03 (Paired t-test). There is also decline in BODE index at 24 months (mean difference 0.14 ) but it's not statistically significant from baseline as there are fewer subjects at 24 months and thereafter. 
Figure 9 Longitudinal changes in BODE index in DMP Group

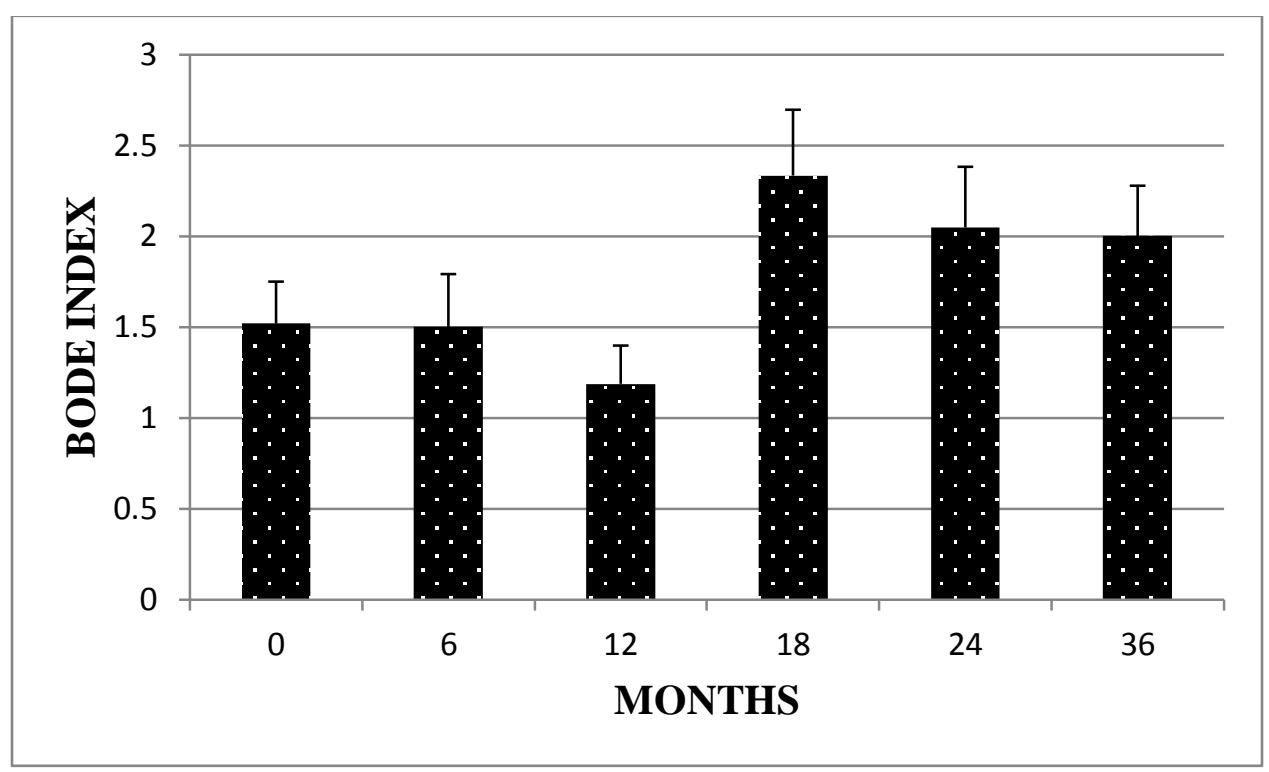

Table 17 Longitudinal comparison of changes in BODE index in DMP Group

\begin{tabular}{|l|l|l|}
\hline \multicolumn{3}{|c|}{$\begin{array}{c}\text { Longitudinal comparison of changes in BODE index in DMP } \\
\text { group }\end{array}$} \\
\hline & 12 month vs. & 24 month vs. \\
& 0 month & 0 month \\
\hline $\mathrm{N}$ & 32 & 21 \\
\hline Mean difference & -0.40 & -0.14 \\
$(95 \% \mathrm{CI})$ & $(-0.78,-0.03)$ & $(-0.55,0.27)$ \\
\hline $\mathrm{P}$ value & 0.03 & 0.48 \\
\hline
\end{tabular}




\section{Cost effectiveness of the program}

Cost analysis will be done for cost related to COPD and also cost related to major co-morbidities like arthritis, rhinitis, hyperlipidemia, depression, diabetes, hypertension, heart disease among COPD subjects in disease management program and usual care. Table 18 represents COPD related cost for subjects in DMP group from the time they first enrolled in the disease management program and this cost categorized into three groups (i.e. cost in first year of program, cost in second year of program and cost in third year of program). From the table average cost per person per year in first year is $\$ 3693$, which decreased to $\$ 3608.8$ in second year and to $\$ 2934$ in third year. Pharmacy cost contributes majority of total COPD cost followed by office cost and out-patient hospitalization. There are no claims for in-patient hospitalization in the third year.

All cost related to COPD for those who are in the program is presented in Table 18

Table 18 COPD related cost in DMP Group

\begin{tabular}{|l|c|c|c|}
\hline Time in Program & $\begin{array}{c}\text { First Year } \\
(\mathrm{N}=52)\end{array}$ & $\begin{array}{c}\text { Second Year } \\
(\mathrm{N}=39)\end{array}$ & $\begin{array}{c}\text { Third Year } \\
(\mathrm{N}=23)\end{array}$ \\
\hline Total cost & $\$ 3693.0$ & $\$ 3608.8$ & $\$ 2934.0$ \\
\hline Office cost & $\$ 770.3$ & $\$ 338.5$ & $\$ 249.1$ \\
\hline In-patient cost & $\$ 4.1$ & $\$ 191.0$ & $\$ 0$ \\
\hline Out-patient cost & $\$ 223.6$ & $\$ 357.0$ & $\$ 252.5$ \\
\hline Home cost & $\$ 28.3$ & $\$ 14.1$ & $\$ 0$ \\
\hline Laboratory cost & $\$ 7.0$ & $\$ 8.4$ & $\$ 4.2$ \\
\hline Pharmacy cost & $\$ 2327.0$ & $\$ 2591.7$ & $\$ 2360.2$ \\
\hline \multicolumn{3}{|r|}{ *Values are presented in average cost per person year } \\
\hline
\end{tabular}


Table 19 represents COPD cost for DMP group and usual care group from 20092013. This cost is also average cost per person per year based on the effective and termination dates into health coverage. There are total of 226 subjects in usual care group who claims for COPD. Average cost per person per year for in-patient hospitalization is significantly high for subjects in usual care (\$5578.7) versus subjects in DMP group (\$250.9). Pharmacy cost is high for subjects in DMP group. Histogram of cost is shown in Figure 10. Figure 11 graphically presents average cost per person per year for different sub-categories of COPD cost.

\section{Comparison of COPD related cost between two groups}

Table 19 Comparison of COPD related cost between two groups from 2009-2013

\begin{tabular}{|l|c|c|}
\hline & DMP Group & UC Group \\
\hline Total COPD cost & $\$ 2297.9$ & $\$ 1675.3$ \\
\hline \multicolumn{1}{|c|}{ 1 year in the program } & 1329.8 & \\
\hline 1-2 years in the program & 1487.9 & \\
\hline 2-3 years in the program & 2949.9 & $\$ 158.9$ \\
\hline Office cost & $\$ 376.2$ & $\$ 5578.7$ \\
\hline $\begin{array}{l}\text { In-patient hospitalization } \\
\text { (IPH) cost }\end{array}$ & $\$ 250.9$ & $\$ 341.1$ \\
\hline $\begin{array}{l}\text { Out-patient hospitalization } \\
\text { (OPH) cost }\end{array}$ & $\$ 290.3$ & $\$ 53.1$ \\
\hline Home cost & $\$ 202.7$ & $\$ 496.0$ \\
\hline Laboratory cost & $\$ 1694.8$ & * Values are presented in average cost per person year \\
\hline Pharmacy cost & & \\
\hline
\end{tabular}


Figure 10 Histogram of COPD related cost
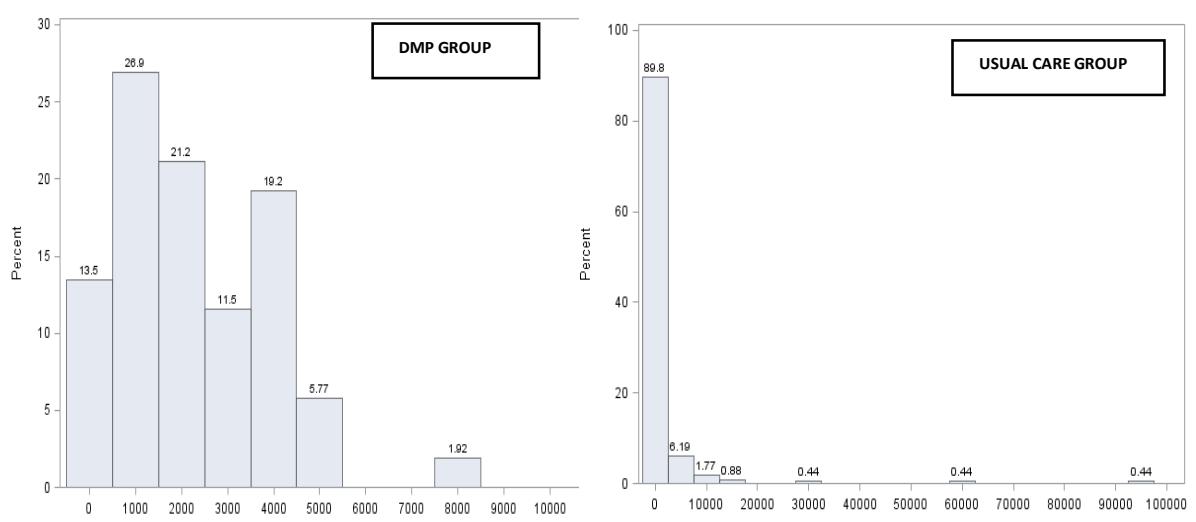

Figure 11-Categories of COPD cost in DMP and Usual Care Group

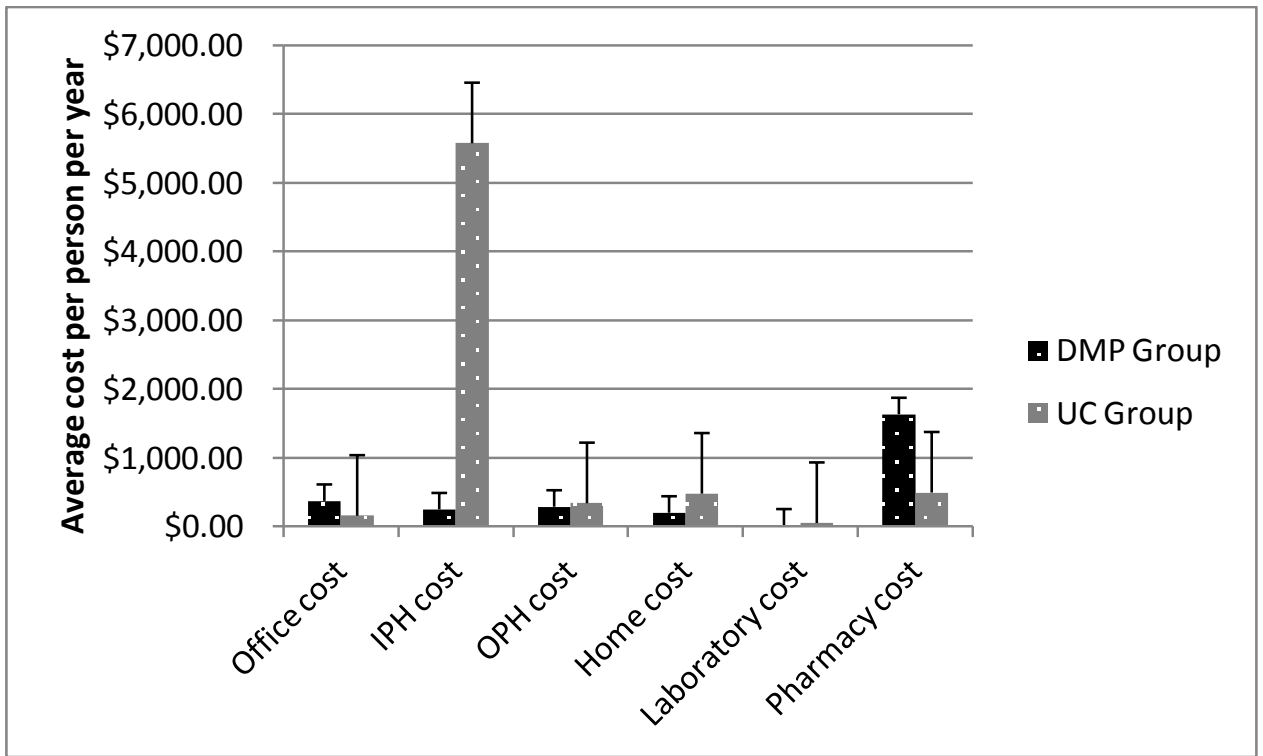

Regression analysis results for COPD related cost from 2009-2013 were shown in

Table 20. Exposure time is the total time contributed into program ( 0 represent usual care, 1 means less than one year in the program, 2 means between one to two years in the program and 3 mean between two-three years in the program). From table 20, subjects who are in program less than one year have lower COPD related cost comparing to those who are in usual care. In the adjustment model propensity score is not significantly associated with COPD cost. 
Table 20 Regression model for COPD related cost

\begin{tabular}{|l|c|c|c|c|}
\hline All COPD cost & \multicolumn{2}{|c|}{ Model 1 } & \multicolumn{2}{c|}{ Model 2 } \\
\hline & Estimates & P value & Estimates & P value \\
\hline Intercept & 1675.3 & 0.0005 & 2183.1 & 0.0010 \\
\hline Enrollment duration* & & & & \\
\hline 1 vs. 0 & -345.5 & 0.87 & -134.2 & 0.95 \\
\hline 2 vs. 0 & -187.4 & 0.93 & -105.4 & 0.96 \\
\hline 3 vs. 0 & 1274.6 & 0.36 & 1574.1 & 0.27 \\
\hline Propensity score & & & -2301.1 & 0.26 \\
\hline & *Enrollment duration is coded as 0, 1, 2, 3; cost is presented in average cost per person per \\
year; Model 2 is adjusted for propensity score
\end{tabular}

\section{Health Care Utilizations}

Table 21 summarized health care utilizations related to COPD for both the groups. Subjects in disease management program have higher claims associated with office visits, out-patient hospitalization and laboratory testing. Subjects in both group had approximately same percentage for in-patient hospitalization claims, but those in DMP group had significantly less number of average claims per subject (2.2 versus 12.2).

Table 21 Health Care Utilizations and Average number of claims

\begin{tabular}{|l|l|l|}
\hline & DMP Group & $\begin{array}{l}\text { Usual Care } \\
\text { Group }\end{array}$ \\
\hline$\geq 1$ IPH, $\mathrm{n}(\%)$ & $\mathrm{N}=52$ & $\mathrm{~N}=226$ \\
\hline $\begin{array}{l}\text { Mean (SD) number of IPH } \\
\text { Claims }\end{array}$ & $8,15.3$ & $34,15.1$ \\
\hline$\geq 1$ OPH, $\mathrm{n}(\%)$ & 2.2 & 12.2 \\
\hline $\begin{array}{l}\text { Mean (SD) number of OPH } \\
\text { Claims }\end{array}$ & $35,67.3$ & $112,49.5$ \\
\hline$\geq 1$ Office visit, $\mathrm{n}(\%)$ & $47,90.3$ & 3.4 \\
\hline $\begin{array}{l}\text { Mean (SD) number of office } \\
\text { visit Claims }\end{array}$ & 15.69 & $160,70.7$ \\
\hline$\geq 1$ home service, $\mathrm{n}(\%)$ & $8,15.3$ & 2.7 \\
\hline $\begin{array}{l}\text { Mean (SD) number of home } \\
\text { service Claims }\end{array}$ & 3.8 & 8.9 \\
\hline$\geq 1$ laboratory, $\mathrm{n}(\%)$ & $20,38.4$ & $50,22.1$ \\
\hline $\begin{array}{l}\text { Mean (SD) number of } \\
\text { laboratory Claims }\end{array}$ & 1.9 & 2.3 \\
\hline
\end{tabular}


Cost associated with major co-morbidities

As discussed in the background, COPD also imposes major economic burden through cost associated with major co-morbidities. Figure 12 depicts co-morbidities among COPD subjects before and after enrollment in the disease management program. This cost was calculated as average cost per person per year. There is a significant decline in cost related to all major diseases like arthritis, hypertension, hyperlipidemia, diabetes, and osteoporosis after enrollment of COPD subjects into disease management program comparing to cost before enrollment into program.

Figure 12 Co-morbidities cost before and after enrollment into disease management group

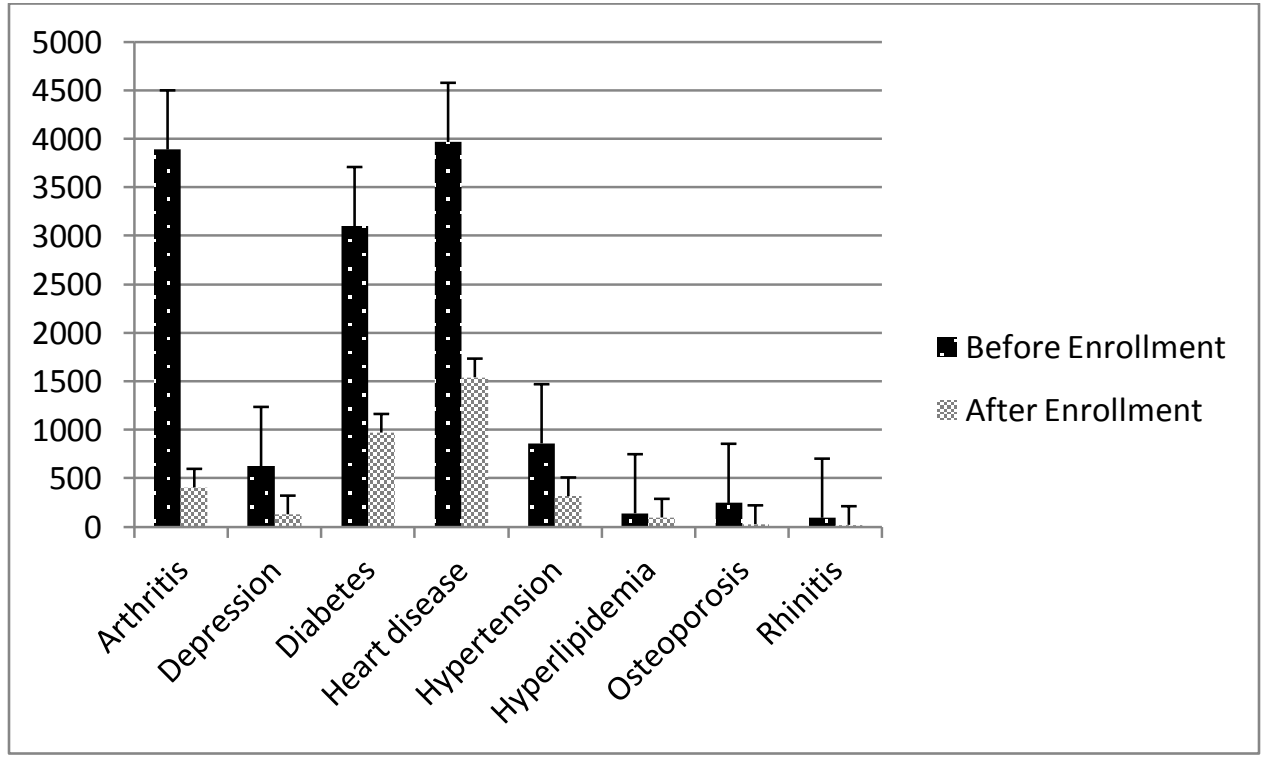

Table 22 summarizes total healthcare cost (combining COPD related cost and associated morbidities), COPD related cost and cost related to major co-morbidities among all COPD subjects in DMP and Usual care group from 2009-2013. From table 22 
subjects in disease management group had lower cost for arthritis, rhinitis, hypertension, hyperlipidemia, depression and osteoporosis.

Table 22 Co-morbidities related cost in Usual Care Group and Disease management Group from 2009-2013

\begin{tabular}{|l|c|c|}
\hline & DMP Group & Usual Care Group \\
\hline $\begin{array}{l}\text { Total health care } \\
\text { cost }\end{array}$ & $\$ 18246.1$ & $\$ 13164.1$ \\
\hline COPD related cost & $\$ 2297.9$ & $\$ 1675.3$ \\
\hline Asthma & $\$ 1146.3$ & $\$ 752.2$ \\
\hline Arthritis & $\$ 1221.8$ & $\$ 1790.6$ \\
\hline Rhinitis & $\$ 120.7$ & $\$ 469.89$ \\
\hline Heart disease & $\$ 9128.8$ & $\$ 3263.6$ \\
\hline Hypertension & $\$ 858.0$ & $\$ 1007.7$ \\
\hline Hyperlipidemia & $\$ 278.8$ & $\$ 435.6$ \\
\hline Diabetes & $\$ 2399.7$ & $\$ 2249.9$ \\
\hline Depression & $\$ 540.5$ & $\$ 1007.6$ \\
\hline Osteoporosis & $\$ 253.6$ & $\$ 511.7$ \\
\hline
\end{tabular}


' ,688 66, 210

\section{Introduction}

We have evaluated the effectiveness of the University of Louisville Disease management program for Chronic Obstructive Pulmonary disease by comparing clinical outcomes and cost with usual care. Our main findings include improvement in respiratory measures like $\mathrm{FEV}_{1}, \mathrm{FVC}$ along with subjective measures like SGRQ. Implementing this chronic disease management program will reduce the impact of COPD on daily activities and improve overall health. Even though subjects in disease management program had higher COPD related cost, cost associated with major comorbidities were significantly reduced for subjects in DMP group after enrollment in the program.

\section{Clinical effectiveness of the program}

There are several general and respiratory measures used to assess the clinical effectiveness of the program and also to compare with the subjects in the usual care group. PHQ9 depression scores were significantly reduced from 6.3 to 3.1 after 24

months in the program. Several studies ${ }^{155-157}$ had been done in the past to study role of depression among COPD cohort and found the COPD subjects with co-morbid depressive symptoms had significantly shorter survival (Hazard ratio: 1.93; $95 \%$ 
confidence interval, 1.04-3.58), longer hospital stay (1.1 more days; $\mathrm{P}=.02)$, persistent smoking 2.30 (95\% confidence interval, 1.17-4.52), increased symptom burden, and poorer physical and social functioning ${ }^{155}$ and also exacerbations were more frequent among COPD subjects with depression ${ }^{157}$. Likewise general health related quality of life and functional health status as measured by Duke Health profile also improved from mean baseline value of 64.1 to 70.8 after 24 months in the disease management program. Thus implementing this program will significantly reduce depressive symptoms and comorbid outcomes associated with depression like exacerbations and longer hospital stay among COPD cohort.

Among respiratory measures, ones that are significantly improves are SGRQ, CAT score and BODE index. SGRQ which is a disease specific valid instrument to measure the impact of COPD on health and daily life activities was improved from 37.1 at baseline to 28.4 at 12 months $(\mathrm{P}=0.02)$ and 30.2 at 24 months $(\mathrm{P}=0.21)$. Reduction of score by at least 4 point is considered to be clinically effective. These findings are similar to study conducted by Labrecque et. al. about the role of self-management education program in improving quality of life ${ }^{158}$. In that study subjects who were in intervention trial (self-management education arm) had significant improvement in SGRQ score at three months (mean reduction of 5 points, $\mathrm{P}=0.006$ ) and 12 months (mean reduction of $6.7, \mathrm{P}<0.001$ ) in contrast to increase in score by 3.7 units in control group $^{158}$. But in that study only self-management education component was used in the intervention group. CAT score was also improved significantly from 18.4 to 12.2 at the end of one year into program and also at the end of 2 year (Figure 6). 
Apart from subjective measures, objective measures of pulmonary function were also improved significantly from baseline to 1 year and 2 year (Table 10-14). Mean FEV 1 at baseline was 2.16 liter which improved to 2.27 at the end of 1 year into program $(\mathrm{P}=0.0046) . \mathrm{FEV}_{1}$ is a good predictor for mortality and thus implementing this program is expected to reduce the mortality among COPD subjects. Subjects in disease management program had a positive longitudinal slope for $\mathrm{FEV}_{1}$ compared to subjects in usual care. BODE index which is a multidimensional grading system to evaluate COPD subject is a good predictor of mortality among COPD subjects. In our study BODE index declined by 0.40 units ( $95 \%$ CI: -0.78 to -0.03 , P value 0.03 ) from baseline to 12 months among subjects in disease management group (Table 17). These results are in agreement with the results from study by Linderman et. al. ${ }^{98}$ where authors studied the effect of proactive integrated care for COPD subjects and found that mean BODE index decreased by 1.1 units at the end of 12 weeks into the integrated care program. Several previous studies predicted mortality among COPD subjects by longitudinally following the BODE index ${ }^{112}$. In a longitudinal cohort study of COPD subjects by Martinez et. al., researchers conclude that increase in mean BODE index by more than 1 point from baseline to 6,12 , and 24 months of follow-up was predictive of subsequent mortality. In our study even with the small number of subjects in disease management program, BODE index was significantly reduced at 12 months so implementing this program in a larger COPD cohort for a longer period of time will be expected to reduce subsequent mortality among COPD subjects. In conclusion, University of Louisville COPD Disease Management Program appears to be highly effective in improving lung health and reducing airflow limitations. 


\section{Cost effectiveness of the program}

Average cost related to COPD after enrollment into program in first year was $\$ 3693$, in second year was $\$ 3608.8$ and in third year it was $\$ 2934$. Average cost per person per year in DMP group was \$2297.9 and in usual care group was \$1675.3. Although cost related to COPD was higher among disease management subjects, there was significant improvement in health related quality of life of COPD subjects. The inpatient hospitalization cost was lower and most costs among subjects in disease management group were attributable to pharmaceutical expenses related to COPD (Figure 11). This suggests that subjects in the disease management program were more adherent to their medicines and will enhance their healthy life expectancy as compared to those receiving usual care. Disease management program participants also had more claims associated with office visits. These findings are in agreement with the results by Chuang et. al. who studied the effect of patient-centric chronic obstructive pulmonary disease program among 141 COPD patients and found primary care physician visit were significantly higher among subjects in the intervention group ${ }^{159}$. Patient-centric approach consists of initial face to face assessment by nurse, supplementation of education material and action plan and call from nurse staff to the subjects once every week. The reason for more office visits is because subjects in disease management program have more planned office visits as a protocol for disease management program, but this is expected to improve overall quality of life and reduce the impact of COPD on daily activities and reduce in-patient hospitalization. In a recent randomized control trial study of disease management program at different VA centers by Dewan et. al, authors found that average 
cost per person for subjects in intervention group is $\$ 593$ less than those in usual care $\operatorname{group}^{160}$

Despite the higher cost related to COPD among subjects in the disease management program, costs associated with major co-morbidities were subsequently reduced after enrollment into disease management program (Figure 12). Cost associated with heart disease and diabetes was significantly lower after enrollment into the disease management program. Average cost per person per year for heart decreased from $\$ 3969$ before the enrollment to $\$ 1543$ after the enrollment and for diabetes it decreased from $\$ 3101$ to $\$ 972$. Subjects in the disease management program had significant lower cost for hypertension, hyperlipidemia, depression and osteoporosis comparing to subjects in usual care. According to American Lung Association, indirect cost contributes approximately $\$ 20$ billion among COPD subjects ${ }^{77}$, so implementing the disease management program is expected to significantly reduce the economic burden associated with COPD.

\section{Strengths}

This study contributes to the growing literature on the effectiveness of disease management programs in chronic diseases like COPD. We demonstrated improvement in absolute $\mathrm{FEV}_{1}$; previous studies showed that decreasing level of $\mathrm{FEV}_{1}$ is one significant predictor of mortality among COPD cohort ${ }^{161}$. Implementing this chronic disease management program is expected to reduce the impact of COPD on daily activities and reduce the mortality from COPD. 


\section{Limitations}

There are several limitations of this study. Certain limitations are associated with any retrospective record review, such as bias associated with different follow-up time for each group and lack of complete information on certain measures among subjects in the usual care group. Secondly, the sample size in disease management group was small; nevertheless, we were able to detect a significant difference in $\mathrm{FEV}_{1}$ at 12 months. Third, enrollment of subjects into the disease management program was not randomized and so there was no comparison group who had detailed and completes information on subjects in the same calendar time comparing to subjects in disease management program. Fourth, there are always limitations associated with using administrative claims data. The main pitfall of the claims data is that it can only identify services received for which a bill was submitted. So if the charges were delayed or not submitted at all, there is always a chance of missing data from administrative claims database. Also claims data do not provide sufficiently detailed clinical history to allow researchers to classify subjects based on severity of COPD. Fifth, use of propensity score as a covariate in the regression analysis is not the best method we use as there are other methods like matching based on propensity score is an appropriate approach to control for baseline differences. Finally, we were not able to identify which component of this disease management program works as all the subjects in the program received the full spectrum of interventions. More evidence will be needed by conducting large randomized controlled trial with a long term follow up of atleast 5 years. 


\section{Future recommendations}

Future implementation of this program at a larger scale can be recommended among COPD cohort and it can be randomized. Randomization of subjects with few components of program in one group versus other components in second group will help researchers to understand exactly which component of disease management program works. It may also prove worthwhile to explore a more comprehensive program for the simultaneous management of multiple chronic diseases (e.g. diabetes mellitus, congestive heart failure or hypertension). 


\section{Conclusion}

The University of Louisville COPD disease management program appears to be highly effective in improving lung health and reducing airflow limitations among COPD subjects as evidence by significant improvement in objective measures like $\mathrm{FEV}_{1}$. Program is also effective in reducing the impact of COPD on daily activities as evident by significant improvement in subjective measures for health related quality of life like St George Respiratory Questionnaire, COPD assessment test, PHQ9 and Duke Profile. Notwithstanding subjects in DMP had higher COPD related cost, they had significantly low in-patient hospitalization cost and also significant reduction in cost associated with major co-morbidities after enrollment in the University of Louisville COPD disease management program. 


\section{5()$(5(1 \&(6$}

पा Celli BR, MacNee W, Force AET. Standards for the diagnosis and treatment of patients with COPD: a summary of the ATS/ERS position paper. The European respiratory journal. Jun 2004;23(6):932-946.

पए Calverley PM, Walker P. Chronic obstructive pulmonary disease. Lancet. Sep 27 2003;362(9389):1053-1061.

Qu Lin SH, Kuo PH, Kuo SH, Yang PC. Severity staging of chronic obstructive pulmonary disease: differences in pre- and post-bronchodilator spirometry. Yonsei medical journal. Oct 31 2009;50(5):672-676.

૧ए Diaz-Guzman E, Mannino DM. Epidemiology and Prevalence of Chronic Obstructive Pulmonary Disease. Clinics in chest medicine. Mar 2014;35(1):7-16.

Qu Tomashefski JF. Definition, differentiation, and classification of COPD. Postgraduate medicine. Jul 1977;62(1):88-97.

पए Petty TL. Definitions in chronic obstructive pulmonary disease. Clinics in chest medicine. Sep 1990;11(3):363-373.

पष Fletcher CM. [Definition, classification and etiology of chronic bronchitis]. Le Poumon et le coeur. 1965;21(10):1239-1248. 
पu Heard BE, Khatchatourov V, Otto H, Putov NV, Sobin L. The morphology of emphysema, chronic bronchitis, and bronchiectasis: definition, nomenclature, and classification. Journal of clinical pathology. Sep 1979;32(9):882-892.

Qu Standards for the diagnosis and care of patients with chronic obstructive pulmonary disease. American Thoracic Society. American journal of respiratory and critical care medicine. Nov 1995;152(5 Pt 2):S77-121.

प०( Siafakas NM, Vermeire P, Pride NB, et al. Optimal assessment and management of chronic obstructive pulmonary disease (COPD). The European Respiratory Society Task Force. The European respiratory journal. Aug 1995;8(8):13981420.

प०ए Pauwels RA, Buist AS, Calverley PM, Jenkins CR, Hurd SS, Committee GS. Global strategy for the diagnosis, management, and prevention of chronic obstructive pulmonary disease. NHLBI/WHO Global Initiative for Chronic Obstructive Lung Disease (GOLD) Workshop summary. American journal of respiratory and critical care medicine. Apr 2001;163(5):1256-1276.

प०प Mannino DM, Homa DM, Akinbami LJ, Ford ES, Redd SC. Chronic obstructive pulmonary disease surveillance--United States, 1971-2000. Morbidity and mortality weekly report. Surveillance summaries. Aug 2 2002;51(6):1-16.

प0. Ranu H, Wilde M, Madden B. Pulmonary function tests. The Ulster medical journal. May 2011;80(2):84-90.

प०५ Lung function testing: selection of reference values and interpretative strategies. American Thoracic Society. The American review of respiratory disease. Nov 1991;144(5):1202-1218. 
पQर Miller MR, Crapo R, Hankinson J, et al. General considerations for lung function testing. The European respiratory journal. Jul 2005;26(1):153-161.

प०स Morris JF. Spirometry in the evaluation of pulmonary function. The Western journal of medicine. Aug 1976;125(2):110-118.

प८५ Barreiro TJ, Perillo I. An approach to interpreting spirometry. American family physician. Mar 1 2004;69(5):1107-1114.

प०त Centers for Disease Control and Prevention (CDC). National Center for Health Statistics (NCHS). National Health and Nutrition Examination Survey Data. Hyattsville, MD: U.S. Department of Health and Human Services, Centers for Disease Control and Prevention http://www.cdc.gov/nchs/nhanes/about_nhanes.htm Last Accessed on Feb 14th 2014.

प४ए Hankinson JL, Odencrantz JR, Fedan KB. Spirometric reference values from a sample of the general U.S. population. American journal of respiratory and critical care medicine. Jan 1999;159(1):179-187.

प०र Plan and operation of the Third National Health and Nutrition Examination Survey, 1988-94. Series 1: programs and collection procedures. Vital and health statistics. Ser. 1, Programs and collection procedures. Jul 1994(32):1-407.

प०र Qaseem A, Wilt TJ, Weinberger SE, et al. Diagnosis and management of stable chronic obstructive pulmonary disease: a clinical practice guideline update from the American College of Physicians, American College of Chest Physicians, American Thoracic Society, and European Respiratory Society. Annals of internal medicine. Aug 2 2011;155(3):179-191. 
प0૫ Halbert RJ, Natoli JL, Gano A, Badamgarav E, Buist AS, Mannino DM. Global burden of COPD: systematic review and meta-analysis. The European respiratory journal. Sep 2006;28(3):523-532.

प०ए Spirometry Longitudinal Data Analysis (SPIROLA) software. Available from http://www.cdc.gov/niosh/topics/spirometry/spirola-software.html Last Accessed on $3 / 1 / 2014$.

प०त Hnizdo E, Yan T, Hakobyan A, et al. Spirometry Longitudinal Data Analysis Software (SPIROLA) for Analysis of Spirometry Data in Workplace Prevention or COPD Treatment. The open medical informatics journal. 2010;4:94-102.

प०५ Delafosse C, Similowski T, Derenne JP. Causes and pathophysiology of chronic obstructive pulmonary disease exacerbations. Monaldi archives for chest disease = Archivio Monaldi per le malattie del torace / Fondazione clinica del lavoro, IRCCS [and] Istituto di clinica tisiologica e malattie apparato respiratorio, Universita di Napoli, Secondo ateneo. Jun 1998;53(3):305-311.

प०स Brashier BB, Kodgule R. Risk factors and pathophysiology of chronic obstructive pulmonary disease (COPD). The Journal of the Association of Physicians of India. Feb 2012;60 Suppl:17-21.

प०ए Turino GM. Proteases in COPD: a critical pathway to injury. Chest. Dec 2007;132(6):1724-1725.

प०स Dentener MA, Creutzberg EC, Schols AM, et al. Systemic anti-inflammatory mediators in COPD: increase in soluble interleukin 1 receptor II during treatment of exacerbations. Thorax. Sep 2001;56(9):721-726. 
१०० Speizer FE, Tager IB. Epidemiology of chronic mucus hypersecretion and obstructive airways disease. Epidemiologic reviews. 1979;1:124-142.

पिए Weiss ST, Ware JH. Overview of issues in the longitudinal analysis of respiratory data. American journal of respiratory and critical care medicine. Dec 1996;154(6 Pt 2):S208-211.

प०४ Fletcher C, Peto R. The natural history of chronic airflow obstruction. British medical journal. Jun 25 1977;1(6077):1645-1648.

प०४ Gold DR, Wang X, Wypij D, Speizer FE, Ware JH, Dockery DW. Effects of cigarette smoking on lung function in adolescent boys and girls. The New England journal of medicine. Sep 26 1996;335(13):931-937.

प्य Mannino DM. The natural history of chronic obstructive pulmonary disease. Pneumonologia i alergologia polska. 2011;79(2):139-143.

पिए Mannino DM, Watt G, Hole D, et al. The natural history of chronic obstructive pulmonary disease. The European respiratory journal. Mar 2006;27(3):627-643.

पिए Mills EJ, Druyts E, Ghement I, Puhan MA. Pharmacotherapies for chronic obstructive pulmonary disease: a multiple treatment comparison meta-analysis. Clinical epidemiology. 2011;3:107-129.

प०० Caramori G, Adcock I. Pharmacology of airway inflammation in asthma and COPD. Pulmonary pharmacology \& therapeutics. 2003;16(5):247-277.

पिए Gao DW. [The changes in beta-adrenergic receptors and cyclic AMP levels of lymphocytes in patients with COPD]. Zhonghua jie he he hu xi za zhi= Zhonghua jiehe he huxi zazhi $=$ Chinese journal of tuberculosis and respiratory diseases. Feb 1989;12(1):27-29, 62. 
प0. Lulich KM, Goldie RG, Ryan G, Paterson JW. Adverse reactions to beta 2agonist bronchodilators. Medical toxicology. Jul-Aug 1986;1(4):286-299.

प०त Barnes PJ. Theophylline. American journal of respiratory and critical care medicine. Oct 15 2013;188(8):901-906.

पQ५ Park HY, Man SF, Sin DD. Inhaled corticosteroids for chronic obstructive pulmonary disease. Bmj. 2012;345:e6843.

१४ए Suissa S, McGhan R, Niewoehner D, Make B. Inhaled corticosteroids in chronic obstructive pulmonary disease. Proceedings of the American Thoracic Society.

Oct $12007 ; 4(7): 535-542$.

प०० van Schayck CP, Reid J. Effective management of COPD in primary care - the role of long-acting beta agonist/inhaled corticosteroid combination therapy. Primary care respiratory journal : journal of the General Practice Airways Group. Jun 2006;15(3):143-151.

प०त Mapel DW, Hurley JS, Dalal AA, Blanchette CM. The role of combination inhaled corticosteroid/long-acting beta-agonist therapy in COPD management. Primary care respiratory journal : journal of the General Practice Airways Group. Jun 2010;19(2):93-103.

प०ए Anzueto A, Ferguson GT, Feldman G, et al. Effect of fluticasone propionate/salmeterol (250/50) on COPD exacerbations and impact on patient outcomes. Copd. Oct 2009;6(5):320-329.

प०स Calverley PM, Boonsawat W, Cseke Z, Zhong N, Peterson S, Olsson H. Maintenance therapy with budesonide and formoterol in chronic obstructive pulmonary disease. The European respiratory journal. Dec 2003;22(6):912-919. 
प०४ Ferguson GT, Anzueto A, Fei R, Emmett A, Knobil K, Kalberg C. Effect of fluticasone propionate/salmeterol (250/50 microg) or salmeterol (50 microg) on COPD exacerbations. Respiratory medicine. Aug 2008;102(8):1099-1108.

प्य Ford ES, Croft JB, Mannino DM, Wheaton AG, Zhang X, Giles WH. COPD surveillance--United States, 1999-2011. Chest. Jul 2013;144(1):284-305.

१९७ Mannino DM. COPD: epidemiology, prevalence, morbidity and mortality, and disease heterogeneity. Chest. May 2002;121(5 Suppl):121S-126S.

१४० http://www.who.int/mediacentre/factsheets/fs310/en/ Last accessed on March 17 th 2013.

प०स National Health Interview Survey: research for the 1995-2004 redesign. Vital and health statistics. Series 2, Data evaluation and methods research. Jul 1999(126):1-119.

१०( Adams PF, Hendershot GE, Marano MA, Centers for Disease C, Prevention/National Center for Health S. Current estimates from the National Health Interview Survey, 1996. Vital and health statistics. Series 10, Data from the National Health Survey. Oct 1999(200):1-203.

१०स McDowell MA. The NHANES III Supplemental Nutrition Survey of older Americans. The American journal of clinical nutrition. Jan 1994;59(1 Suppl):224S-226S.

૧૯४ Remington PL, Smith MY, Williamson DF, Anda RF, Gentry EM, Hogelin GC. Design, characteristics, and usefulness of state-based behavioral risk factor surveillance: 1981-87. Public health reports. Jul-Aug 1988;103(4):366-375. 
प०४ Centers for Disease C, Prevention. Chronic obstructive pulmonary disease among adults--United States, 2011. MMWR. Morbidity and mortality weekly report. Nov 23 2012;61(46):938-943.

१९ा Akinbami LJ, Liu X. Chronic obstructive pulmonary disease among adults aged 18 and over in the United States, 1998-2009. NCHS data brief. Jun 2011(63):1-8.

प०त Rycroft CE, Heyes A, Lanza L, Becker K. Epidemiology of chronic obstructive pulmonary disease: a literature review. International journal of chronic obstructive pulmonary disease. 2012;7:457-494.

प०ए Mathers CD, Loncar D. Projections of global mortality and burden of disease from 2002 to 2030. PLoS medicine. Nov 2006;3(11):e442.

प८० Donna L. Hoyert PD, Jiaquan Xu, M.D. Deaths: Preliminary Data for 2011 National Vital Statistics Reports. 2012;61(6):4.

प0u Jordan RE, Cheng KK, Miller MR, Adab P. Passive smoking and chronic obstructive pulmonary disease: cross-sectional analysis of data from the Health Survey for England. BMJ open. Jan 1 2011;1(2):e000153.

प०ए Lokke A, Lange P, Scharling H, Fabricius P, Vestbo J. Developing COPD: a 25 year follow up study of the general population. Thorax. Nov 2006;61(11):935939.

प०ए Mastrangelo G, Tartari M, Fedeli U, Fadda E, Saia B. Ascertaining the risk of chronic obstructive pulmonary disease in relation to occupation using a casecontrol design. Occupational medicine. May 2003;53(3):165-172. 
प०५ Higgins MW, Enright PL, Kronmal RA, Schenker MB, Anton-Culver H, Lyles M. Smoking and lung function in elderly men and women. The Cardiovascular Health Study. Jama. Jun 2 1993;269(21):2741-2748.

पिए El-Zein RA, Young RP, Hopkins RJ, Etzel CJ. Genetic predisposition to chronic obstructive pulmonary disease and/or lung cancer: important considerations when evaluating risk. Cancer prevention research. Apr 2012;5(4):522-527.

૧૯प Kainu A, Rouhos A, Sovijarvi A, Lindqvist A, Sarna S, Lundback B. COPD in Helsinki, Finland: socioeconomic status based on occupation has an important impact on prevalence. Scandinavian journal of public health. Aug 2013;41(6):570-578.

प०स Mehta AJ, Miedinger D, Keidel D, et al. Occupational exposure to dusts, gases, and fumes and incidence of chronic obstructive pulmonary disease in the Swiss Cohort Study on Air Pollution and Lung and Heart Diseases in Adults. American journal of respiratory and critical care medicine. Jun 15 2012;185(12):12921300.

प०ए Schikowski T, Adam M, Marcon A, et al. Association of ambient air pollution with the prevalence and incidence of COPD. The European respiratory journal. Jan 312014.

प०५ Stoller JK, Aboussouan LS. Alpha1-antitrypsin deficiency. Lancet. Jun 25-Jul 1 2005;365(9478):2225-2236.

૧૯ख Stockley RA. Alpha1-antitrypsin Review. Clinics in chest medicine. Mar 2014;35(1):39-50. 
प०ए Pillai SG, Ge D, Zhu G, et al. A genome-wide association study in chronic obstructive pulmonary disease (COPD): identification of two major susceptibility loci. PLoS genetics. Mar 2009;5(3):e1000421.

प०ए Cho MH, McDonald ML, Zhou X, et al. Risk loci for chronic obstructive pulmonary disease: a genome-wide association study and meta-analysis. The lancet. Respiratory medicine. Mar 2014;2(3):214-225.

प०ए Yang J, Zhou H, Liang B, et al. Association of five genetic variants with chronic obstructive pulmonary disease susceptibility and spirometric phenotypes in a Chinese Han population. Respirology. Nov 292013.

प०ए Hansel NN, Ruczinski I, Rafaels N, et al. Genome-wide study identifies two loci associated with lung function decline in mild to moderate COPD. Human genetics. Jan 2013;132(1):79-90.

प०त Choo JY, Lee KY, Shin C, et al. Quantitative Analysis of Lungs and Airways With CT in Subjects With the Chronic Obstructive Pulmonary Disease (COPD) Candidate FAM13A Gene: Case Control Study for CT Quantification in COPD Risk Gene. Journal of computer assisted tomography. Mar 192014.

प०स Hersh CP. Pharmacogenetics of chronic obstructive pulmonary disease: challenges and opportunities. Pharmacogenomics. Feb 2010;11(2):237-247.

प्य Teo WS, Tan WS, Chong WF, et al. Economic burden of chronic obstructive pulmonary disease. Respirology. Jan 2012;17(1):120-126.

प४( D'Souza AO, Shah M, Dhamane AD, Dalal AA. Clinical and Economic Burden of COPD in a Medicaid Population. Copd. Oct 102013. 
प०० http://www.lung.org/lung-disease/copd/resources/facts-figures/COPD-FactSheet.html Last Accessed on March 3rd 2014.

प०ए Wilson L, Devine EB, So K. Direct medical costs of chronic obstructive pulmonary disease: chronic bronchitis and emphysema. Respiratory medicine. Mar 2000;94(3):204-213.

पQu Chapman KR, Mannino DM, Soriano JB, et al. Epidemiology and costs of chronic obstructive pulmonary disease. The European respiratory journal. Jan 2006;27(1):188-207.

परि Sullivan SD, Ramsey SD, Lee TA. The economic burden of COPD. Chest. Feb 2000;117(2 Suppl):5S-9S.

प०ए Ward MM, Javitz HS, Smith WM, Bakst A. Direct medical cost of chronic obstructive pulmonary disease in the U.S.A. Respiratory medicine. Nov 2000;94(11):1123-1129.

पिए Dalal AA, Christensen L, Liu F, Riedel AA. Direct costs of chronic obstructive pulmonary disease among managed care patients. International journal of chronic obstructive pulmonary disease. 2010;5:341-349.

प०त Akazawa M, Halpern R, Riedel AA, Stanford RH, Dalal A, Blanchette CM. Economic burden prior to COPD diagnosis: a matched case-control study in the United States. Respiratory medicine. Dec 2008;102(12):1744-1752.

परि Simoni-Wastila L, Blanchette CM, Qian J, et al. Burden of chronic obstructive pulmonary disease in Medicare beneficiaries residing in long-term care facilities. The American journal of geriatric pharmacotherapy. Oct 2009;7(5):262-270. 
प०० Chronic conditions among Medicare beneficiaries http://www.cms.gov/ResearchStatistics-Data-and-Systems/Statistics-Trends-and-Reports/ChronicConditions/Downloads/2012Chartbook.pdf.

प्य Blanchette CM, Gutierrez B, Ory C, Chang E, Akazawa M. Economic burden in direct costs of concomitant chronic obstructive pulmonary disease and asthma in a Medicare Advantage population. Journal of managed care pharmacy: JMCP. Mar 2008;14(2):176-185.

प०० Dellby U. Drastically improving health care with focus on managing the patient with a disease: the macro and micro perspective. International journal of health care quality assurance. 1996;9(2):4-8.

१०४ Epstein RS, Sherwood LM. From outcomes research to disease management: a guide for the perplexed. Annals of internal medicine. May 1 1996;124(9):832837.

१९७ Ellrodt G, Cook DJ, Lee J, Cho M, Hunt D, Weingarten S. Evidence-based disease management. Jama. Nov 26 1997;278(20):1687-1692.

प०त Weingarten SR, Henning JM, Badamgarav E, et al. Interventions used in disease management programmes for patients with chronic illness-which ones work? Meta-analysis of published reports. Bmj. Oct 26 2002;325(7370):925.

पिए Faxon DP, Schwamm LH, Pasternak RC, et al. Improving quality of care through disease management: principles and recommendations from the American Heart Association's Expert Panel on Disease Management. Circulation. Jun 1 2004;109(21):2651-2654. 
प०त Comin-Colet J, Verdu-Rotellar JM, Vela E, et al. Efficacy of an Integrated Hospital-primary Care Program for Heart Failure: A Population-based Analysis of 56742 Patients. Revista espanola de cardiologia. Feb 72014.

૧૯। Sidorov J, Shull R, Tomcavage J, Girolami S, Lawton N, Harris R. Does diabetes disease management save money and improve outcomes? A report of simultaneous short-term savings and quality improvement associated with a health maintenance organization-sponsored disease management program among patients fulfilling health employer data and information set criteria. Diabetes care. Apr 2002;25(4):684-689.

प०ए Kruis AL, Smidt N, Assendelft WJ, et al. Integrated disease management interventions for patients with chronic obstructive pulmonary disease. The Cochrane database of systematic reviews. 2013;10:CD009437.

प०० Make BJ. Chronic obstructive pulmonary disease: developing comprehensive management. Respiratory care. Dec 2003;48(12):1225-1234; discussion 12341227.

प०ए Mehring M, Donnachie E, Fexer J, Hofmann F, Schneider A. Disease Management Programs for Patients with chronic obstructive pulmonary disease in Germany - A longitudinal evaluation of routinely collected patient records. Respiratory care. Nov 122013.

प४ए Moullec G, Lavoie KL, Rabhi K, Julien M, Favreau H, Labrecque M. Effect of an integrated care programme on re-hospitalization of patients with chronic obstructive pulmonary disease. Respirology. May 2012;17(4):707-714. 
प०स Linderman DJ, Koff PB, Freitag TJ, Min SJ, Vandivier RW. Effect of integrated care on advanced chronic obstructive pulmonary disease in high-mortality rural areas. Archives of internal medicine. Dec 12 2011;171(22):2059-2061.

૧૯\ Koff PB, Jones RH, Cashman JM, Voelkel NF, Vandivier RW. Proactive integrated care improves quality of life in patients with COPD. The European respiratory journal. May 2009;33(5):1031-1038.

पिएप Fan VS, Gaziano JM, Lew R, et al. A comprehensive care management program to prevent chronic obstructive pulmonary disease hospitalizations: a randomized, controlled trial. Annals of internal medicine. May 15 2012;156(10):673-683.

प्रा Effing T, Monninkhof EM, van der Valk PD, et al. Self-management education for patients with chronic obstructive pulmonary disease. The Cochrane database of systematic reviews. 2007(4):CD002990.

प्राप Laboratories ATSCoPSfCPF. ATS statement: guidelines for the six-minute walk test. American journal of respiratory and critical care medicine. Jul 1 2002;166(1):111-117.

पिए। Solway S, Brooks D, Lacasse Y, Thomas S. A qualitative systematic overview of the measurement properties of functional walk tests used in the cardiorespiratory domain. Chest. Jan 2001;119(1):256-270.

प०स Hernandes NA, Wouters EF, Meijer K, Annegarn J, Pitta F, Spruit MA. Reproducibility of 6-minute walking test in patients with COPD. The European respiratory journal. Aug 2011;38(2):261-267.

प्रा Redelmeier DA, Bayoumi AM, Goldstein RS, Guyatt GH. Interpreting small differences in functional status: the Six Minute Walk test in chronic lung disease 
patients. American journal of respiratory and critical care medicine. Apr 1997;155(4):1278-1282.

पिएप Holland AE, Hill CJ, Rasekaba T, Lee A, Naughton MT, McDonald CF. Updating the minimal important difference for six-minute walk distance in patients with chronic obstructive pulmonary disease. Archives of physical medicine and rehabilitation. Feb 2010;91(2):221-225.

૧૯०७ Hajiro T, Nishimura K, Tsukino M, Ikeda A, Koyama H, Izumi T. Analysis of clinical methods used to evaluate dyspnea in patients with chronic obstructive pulmonary disease. American journal of respiratory and critical care medicine. Oct 1998;158(4):1185-1189.

पिएा Hsu KY, Lin JR, Lin MS, Chen W, Chen YJ, Yan YH. The modified Medical Research Council dyspnoea scale is a good indicator of health-related quality of life in patients with chronic obstructive pulmonary disease. Singapore medical journal. Jun 2013;54(6):321-327.

प०सा Vestbo J, Hurd SS, Agusti AG, et al. Global strategy for the diagnosis, management, and prevention of chronic obstructive pulmonary disease: GOLD executive summary. American journal of respiratory and critical care medicine. Feb 15 2013;187(4):347-365.

पिए। Celli BR, Cote CG, Marin JM, et al. The body-mass index, airflow obstruction, dyspnea, and exercise capacity index in chronic obstructive pulmonary disease. The New England journal of medicine. Mar 4 2004;350(10):1005-1012. 
प्र० Thomason MJ, Strachan DP. Which spirometric indices best predict subsequent death from chronic obstructive pulmonary disease? Thorax. Sep 2000;55(9):785788.

पिए। Celli BR, Cote CG, Lareau SC, Meek PM. Predictors of Survival in COPD: more than just the FEV1. Respiratory medicine. Jun 2008;102 Suppl 1:S27-35.

प००स Marin JM, Alfageme I, Almagro P, et al. Multicomponent indices to predict survival in COPD: the COCOMICS study. The European respiratory journal. Aug 2013;42(2):323-332.

प००४ Ong KC, Earnest A, Lu SJ. A multidimensional grading system (BODE index) as predictor of hospitalization for COPD. Chest. Dec 2005;128(6):3810-3816.

प्या Funk GC, Kirchheiner K, Burghuber OC, Hartl S. BODE index versus GOLD classification for explaining anxious and depressive symptoms in patients with COPD - a cross-sectional study. Respiratory research. 2009;10:1.

पिया Cote CG, Celli BR. Pulmonary rehabilitation and the BODE index in COPD. The European respiratory journal. Oct 2005;26(4):630-636.

प्र०ण Jones PW. Health status measurement in chronic obstructive pulmonary disease. Thorax. Nov 2001;56(11):880-887.

प००स Maria SPJ, Ramos Gonzalez J, Ignacio CAJ, Maria MNA, Pedro GGF. The health-related quality of life of patients with chronic obstructive pulmonary disease and asthma evaluated by the SGRQ. Revista portuguesa de pneumologia. Jul-Aug 2010;16(4):543-558.

पिया Jones PW, Quirk FH, Baveystock CM, Littlejohns P. A self-complete measure of health status for chronic airflow limitation. The St. George's Respiratory 
Questionnaire. The American review of respiratory disease. Jun 1992;145(6):1321-1327.

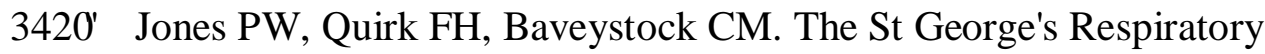
Questionnaire. Respiratory medicine. Sep 1991;85 Suppl B:25-31; discussion 3327.

प्या Ferrer M, Villasante C, Alonso J, et al. Interpretation of quality of life scores from the St George's Respiratory Questionnaire. The European respiratory journal. Mar 2002;19(3):405-413.

प्र० Barr JT, Schumacher GE, Freeman S, LeMoine M, Bakst AW, Jones PW. American translation, modification, and validation of the St. George's Respiratory Questionnaire. Clinical therapeutics. Sep 2000;22(9):1121-1145.

पिए। Meguro M, Barley EA, Spencer S, Jones PW. Development and Validation of an Improved, COPD-Specific Version of the St. George Respiratory Questionnaire. Chest. Aug 2007;132(2):456-463.

पिए। Jones PW. Interpreting thresholds for a clinically significant change in health status in asthma and COPD. The European respiratory journal. Mar 2002;19(3):398-404.

पिएप Osman IM, Godden DJ, Friend JA, Legge JS, Douglas JG. Quality of life and hospital re-admission in patients with chronic obstructive pulmonary disease. Thorax. Jan 1997;52(1):67-71.

१००४ Schunemann HJ, Griffith L, Jaeschke R, Goldstein R, Stubbing D, Guyatt GH. Evaluation of the minimal important difference for the feeling thermometer and 
the St. George's Respiratory Questionnaire in patients with chronic airflow obstruction. Journal of clinical epidemiology. Dec 2003;56(12):1170-1176.

पिया Jones PW, Harding G, Berry P, Wiklund I, Chen WH, Kline Leidy N.

Development and first validation of the COPD Assessment Test. The European respiratory journal. Sep 2009;34(3):648-654.

पिए। Jones PW, Harding G, Wiklund I, et al. Tests of the responsiveness of the COPD assessment test following acute exacerbation and pulmonary rehabilitation. Chest. Jul 2012;142(1):134-140.

प्रा Kon SS, Canavan JL, Jones SE, et al. Minimum clinically important difference for the COPD Assessment Test: a prospective analysis. The lancet. Respiratory medicine. Mar 2014;2(3):195-203.

पिपा Jones PW, Brusselle G, Dal Negro RW, et al. Properties of the COPD assessment test in a cross-sectional European study. The European respiratory journal. Jul 2011;38(1):29-35.

पिया Dweik RA, Boggs PB, Erzurum SC, et al. An official ATS clinical practice guideline: interpretation of exhaled nitric oxide levels (FENO) for clinical applications. American journal of respiratory and critical care medicine. Sep 1 2011;184(5):602-615.

पिए। Schneider A, Schwarzbach J, Faderl B, Welker L, Karsch-Volk M, Jorres RA. FENO measurement and sputum analysis for diagnosing asthma in clinical practice. Respiratory medicine. Feb 2013;107(2):209-216. 
प्रा Brightling CE, Monteiro W, Ward R, et al. Sputum eosinophilia and short-term response to prednisolone in chronic obstructive pulmonary disease: a randomised controlled trial. Lancet. Oct 28 2000;356(9240):1480-1485.

पिए। Zietkowski Z, Kucharewicz I, Bodzenta-Lukaszyk A. The influence of inhaled corticosteroids on exhaled nitric oxide in stable chronic obstructive pulmonary disease. Respiratory medicine. Jul 2005;99(7):816-824.

पिया Kunisaki KM, Rice KL, Janoff EN, Rector TS, Niewoehner DE. Exhaled nitric oxide, systemic inflammation, and the spirometric response to inhaled fluticasone propionate in severe chronic obstructive pulmonary disease: a prospective study. Therapeutic advances in respiratory disease. Apr 2008;2(2):55-64.

पिए। Parkerson GR, Jr., Broadhead WE, Tse CK. The Duke Health Profile. A 17-item measure of health and dysfunction. Medical care. Nov 1990;28(11):1056-1072.

प००० El Emrani L, Bendriss A, Senhaji M. [Health and quality of life: situation of the population of Tetouan (Morocco)]. Sante publique. Sep-Oct 2013;25(5):639-646.

प००स Ramirez-Velez R. [Quality of life and social support for patients suffering from chronic obstructive pulmonary disease]. Revista de salud publica. Oct-Dec 2007;9(4):568-575.

पिएत Cannon DS, Tiffany ST, Coon H, Scholand MB, McMahon WM, Leppert MF. The PHQ-9 as a brief assessment of lifetime major depression. Psychological assessment. Jun 2007;19(2):247-251.

प००य Kroenke K, Spitzer RL, Williams JB. The PHQ-9: validity of a brief depression severity measure. Journal of general internal medicine. Sep 2001;16(9):606-613. 
पिए। Sidebottom AC, Harrison PA, Godecker A, Kim H. Validation of the Patient Health Questionnaire (PHQ)-9 for prenatal depression screening. Archives of women's mental health. Oct 2012;15(5):367-374.

पिएस Pence BW, Gaynes BN, Atashili J, et al. Validity of an interviewer-administered patient health questionnaire-9 to screen for depression in HIV-infected patients in Cameroon. Journal of affective disorders. Dec 20 2012;143(1-3):208-213.

प००य Lamers F, Jonkers CC, Bosma H, Penninx BW, Knottnerus JA, van Eijk JT. Summed score of the Patient Health Questionnaire-9 was a reliable and valid method for depression screening in chronically ill elderly patients. Journal of clinical epidemiology. Jul 2008;61(7):679-687.

पिए। Inagaki M, Ohtsuki T, Yonemoto N, et al. Validity of the Patient Health Questionnaire (PHQ)-9 and PHQ-2 in general internal medicine primary care at a Japanese rural hospital: a cross-sectional study. General hospital psychiatry. NovDec 2013;35(6):592-597.

पिए। Zhang YL, Liang W, Chen ZM, et al. Validity and reliability of Patient Health Questionnaire-9 and Patient Health Questionnaire-2 to screen for depression among college students in China. Asia-Pacific psychiatry : official journal of the Pacific Rim College of Psychiatrists. Dec 2013;5(4):268-275.

पिए। Lowe B, Unutzer J, Callahan CM, Perkins AJ, Kroenke K. Monitoring depression treatment outcomes with the patient health questionnaire-9. Medical care. Dec 2004;42(12):1194-1201.

प००य Turcani P, Skrickova J, Pavlik T, Janousova E, Orban M. The prevalence of obstructive sleep apnea in patients hospitalized for COPD exacerbation. 
Biomedical papers of the Medical Faculty of the University Palacky, Olomouc, Czechoslovakia. Feb 252014.

प्र०प Crinion SJ, McNicholas WT. Sleep-related disorders in chronic obstructive pulmonary disease. Expert review of respiratory medicine. Feb 2014;8(1):79-88.

पस० Johns MW. A new method for measuring daytime sleepiness: the Epworth sleepiness scale. Sleep. Dec 1991;14(6):540-545.

૧uा Netzer NC, Stoohs RA, Netzer CM, Clark K, Strohl KP. Using the Berlin Questionnaire to identify patients at risk for the sleep apnea syndrome. Annals of internal medicine. Oct 5 1999;131(7):485-491.

प्र० Sandoval-Rincon M, Alcala-Lozano R, Herrera-Jimenez I, Jimenez-Genchi A. [Validation of the Epworth sleepiness scale in Mexican population]. Gaceta medica de Mexico. Jul-Aug 2013;149(4):409-416.

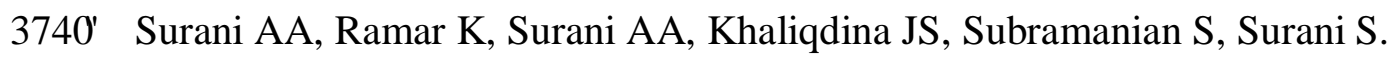
Validation of the Urdu version of the Epworth Sleepiness Scale. JPMA. The Journal of the Pakistan Medical Association. Sep 2012;62(9):986-988.

प्र० Glynn RJ, Schneeweiss S, Sturmer T. Indications for propensity scores and review of their use in pharmacoepidemiology. Basic \& clinical pharmacology \& toxicology. Mar 2006;98(3):253-259.

प्स० MD N. http://www.navigatormd.com/about/our-company.

पिए। Ng TP, Niti M, Tan WC, Cao Z, Ong KC, Eng P. Depressive symptoms and chronic obstructive pulmonary disease: effect on mortality, hospital readmission, symptom burden, functional status, and quality of life. Archives of internal medicine. Jan 8 2007;167(1):60-67. 
पिए Balcells E, Gea J, Ferrer J, et al. Factors affecting the relationship between psychological status and quality of life in COPD patients. Health and quality of life outcomes. 2010;8:108.

प्रा Ito K, Kawayama T, Shoji Y, et al. Depression, but not sleep disorder, is an independent factor affecting exacerbations and hospitalization in patients with chronic obstructive pulmonary disease. Respirology. Aug 2012;17(6):940-949.

पिए। Labrecque M, Rabhi K, Laurin C, et al. Can a self-management education program for patients with chronic obstructive pulmonary disease improve quality of life? Canadian respiratory journal : journal of the Canadian Thoracic Society. Sep-Oct 2011;18(5):e77-81.

प्रा Chuang C, Levine SH, Rich J. Enhancing cost-effective care with a patient-centric chronic obstructive pulmonary disease program. Population health management. Jun 2011;14(3):133-136.

प००स Dewan NA, Rice KL, Caldwell M, Hilleman DE. Economic evaluation of a disease management program for chronic obstructive pulmonary disease. Copd. Jun 2011;8(3):153-159.

प्रा Lindberg A, Larsson LG, Muellerova H, Ronmark E, Lundback B. Up-to-date on mortality in COPD - report from the OLIN COPD study. BMC pulmonary medicine. 2012;12:1. 


\section{\$33( $1^{\prime}$,;}

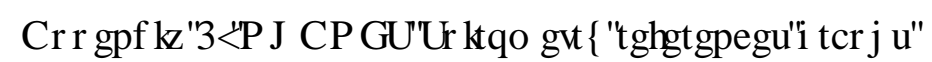
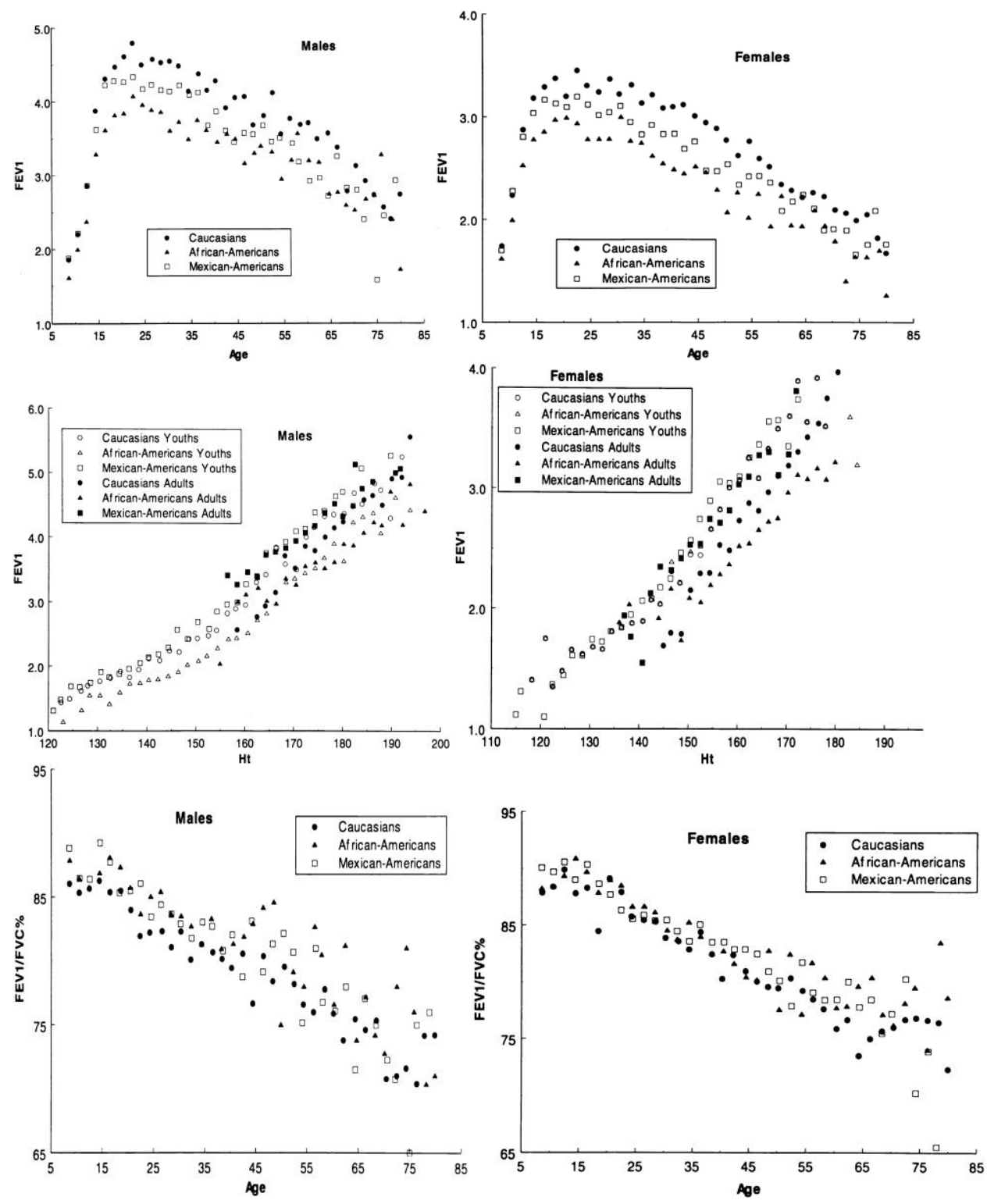


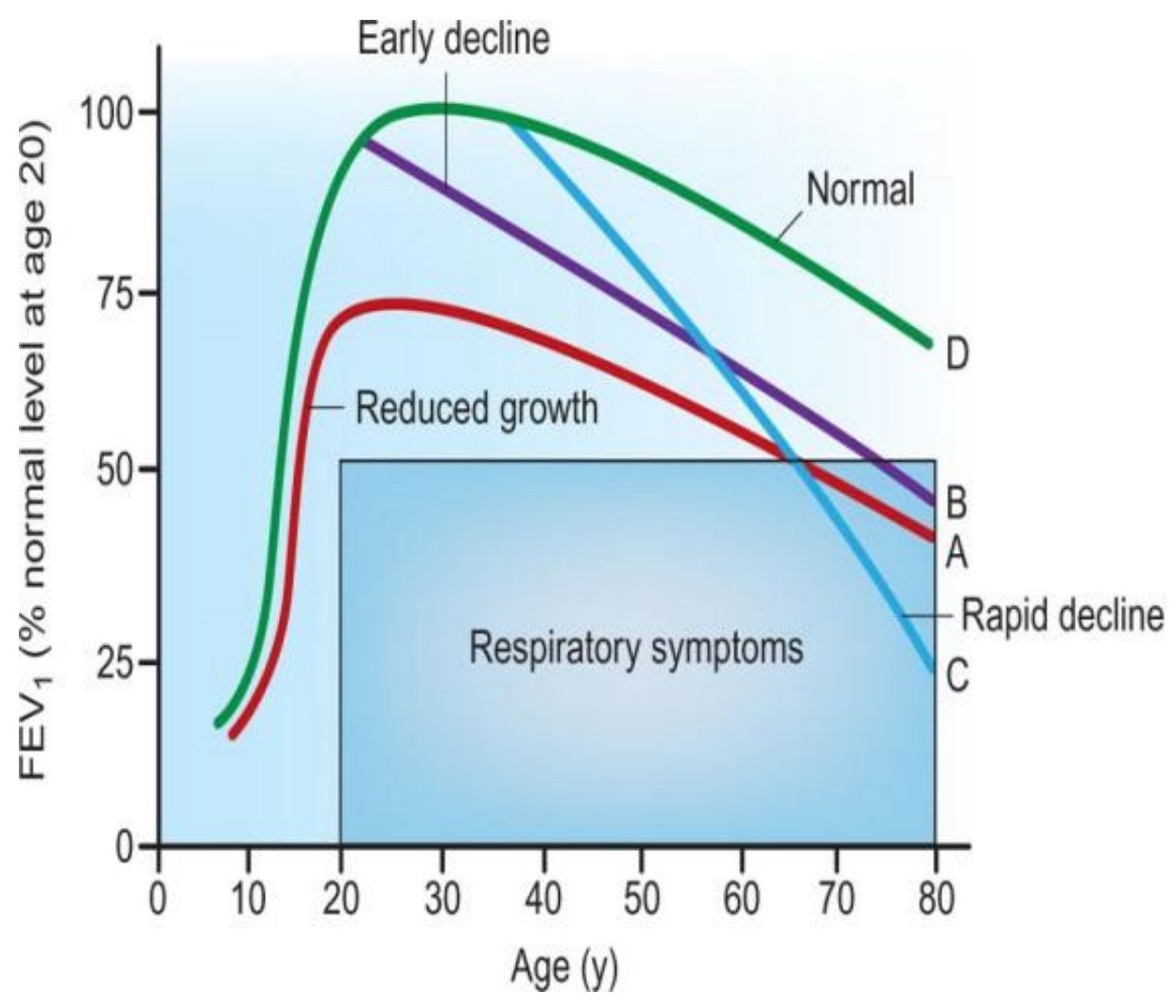




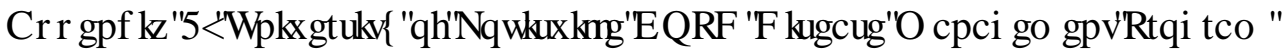

\section{Program Highlights:}

- Case Manager / Respiratory Therapist will serve as care manager to enrollees and liaison to physician and nurse practitioners.

- Case Manager is embedded and working closely with physicians and mid-level health care providers.

- Primary care physicians will be advised of program and provided clinical updates of enrollees.

- High amount of personal touch and face-to-face time with program participants.

Program Components:

I. COPD Screening:

- Potential enrollees will be targeted and recruited into the program as outlined above.

II. Participant requirements:

- The program will be explained and the potential enrollee will be required to sign a participation agreement documenting their intention to participate fully in the program.

III.a Each enrollee will have an initial Comprehensive Evaluation and Assessment, which will include:

Performed at Healthcare Outpatient Center by ULP

- Comprehensive Office visit

- 6 Minute Walk Test

- Pulmonary Function Testing, complete, with and without bronchodilator

- Fractional exhaled nitric oxide 
- Overnight oximetry

- ECG

- Alpha-1 anti-trypsin level (we use a HIPAA certified laboratory that provides this service at no charge)

- Questionnaires (PHQ9, St. George Respiratory Questionnaire, Epworth Sleepiness Score, Duke Profile)

\section{Performed at HealthCare Outpatient Center by ULH}

- Chest X-Ray (if not done within the past 12 months)

- Sputum Analysis (if enrollee fits into category of chronic bronchitis with sputum production)

III.b Follow-up Visits

- Follow-up visits and testing is based on disease risk stratification. In general, those with mild COPD, as determined by GOLD stages 1-2, are followed less often and less intensely. Those with more severe COPD, as determined by GOLD stages 3-4, are followed more closely. See below.

\section{COPD GOLD STAGES 1 or 2}

- 6 month follow-up clinic visits

- Spirometry

- Review Action Plan

- Questionnaire (PHQ9, Duke Profile, Respiratory Health)

\section{COPD GOLD STAGE 3 or 4}

- 3 month follow-up clinic visits 
- Spirometry

- Review Action Plan

- 6 minute walk test (every 6 months)

- Questionnaire (PHQ9, Duke Profile, Respiratory Health)

\section{Support Group Education Classes}

- All participants will be required to participate in a group education session which covers a variety of topics including COPD causes and prevention, nutrition, exercise, healthy life style, bone health, proper medication use, tobacco cessation and self-management of their disease. These classes are held monthly and are run by our certified respiratory therapists with support from our pulmonologists and nurse specialists.

- Additionally, individualized education and training is provided by the clinic respiratory therapists and these concepts are reinforced with most every participant / health care encounter. 


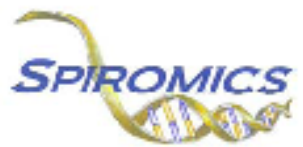

\section{MODIFIED MEDICAL RESEARCH COUNCIL DYSPNEA SCALE}

\begin{tabular}{|l|l|l|l|l|l|l|l|l|}
\hline ID NUMBER: & & & & & & & & \\
\hline
\end{tabular}

FORM CODE: MRC VERSION: $1.0 \quad 10 / 26 / 10$

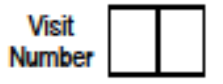
SEQ\#

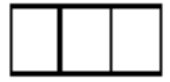

0a) Form Date
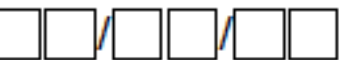

ob) Initials.

Instructions: This form should be completed during the participant's visit. Choose the one best response.

Please choose the one best response to describe your shortness of breath.

Grade

0 "I only get breathless with strenuous exercise"

1 "I get short of breath when hurrying on the level or walking up a slight hill"

2 "I walk slower than people of the same age on the level because of breathlessness or have to stop for breath when walking at my own pace on the level

3 "I stop for breath after walking about 100 yards or after a few minutes on the level"

4 "I am too breathless to leave the house" or "I am breathless when dressing"

1. Grade 


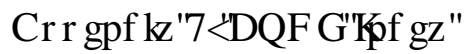

\begin{tabular}{|l|l|l|l|l|}
\hline Variable & \multicolumn{4}{l|}{ Points on BODE index } \\
\hline & 0 & 1 & 2 & 3 \\
\hline BMI & $>21$ & $\leq 21$ & & \\
\hline FEV $_{1}$ & $\geq 65$ & $50-64$ & $36-49$ & $\leq 35$ \\
\hline MMRC dyspnea scale & $0-1$ & 2 & 3 & 4 \\
\hline $\begin{array}{l}\text { Distance walked in 6 } \\
\text { minutes }\end{array}$ & $\geq 350$ & $250-349$ & $150-249$ & $\leq 149$ \\
\hline
\end{tabular}

Source: Celli. et. al. 2004 NEJM pg1005-1012 


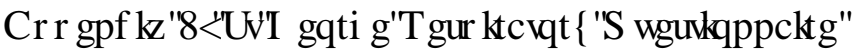

\section{The St. George's Respiratory Questionnaire}

This questionnaire is designed to help us learn more about how your breathing is troubling you and how it affects your life. We are using it to find out which aspects of your illness cause you the most problems, rather than what the doctors and nurses think your problems are.

Please read the questions carefully and ask the study nurse if you do not understand anything. Answer the questions as honestly as possible. There are no right or wrong answers; only the answer that best applies to you. Do not spend too much time deciding about your answers.

\section{Part 1}

Describe how often your lung/respiratory problems have affected you over the last $\mathbf{4}$ weeks. Please place a mark in one box for each question.

\begin{tabular}{|l|l|l|l|l|l|}
\hline & $\begin{array}{c}\text { almost } \\
\text { every } \\
\text { day }\end{array}$ & $\begin{array}{c}\text { several } \\
\text { days a } \\
\text { week }\end{array}$ & $\begin{array}{c}\text { a few } \\
\text { days a } \\
\text { month }\end{array}$ & $\begin{array}{c}\text { only with } \\
\text { lung/ } \\
\text { respirator } \\
\text { y } \\
\text { infections }\end{array}$ & $\begin{array}{c}\text { not } \\
\text { at } \\
\text { all }\end{array}$ \\
\hline $\begin{array}{l}\text { 1. Over the last 4 weeks, I have } \\
\text { coughed: }\end{array}$ & & & & & \\
\hline $\begin{array}{l}\text { 2. Over the last 4 weeks, I have } \\
\text { brought up phlegm (sputum): }\end{array}$ & & & & & \\
\hline $\begin{array}{l}\text { 3. Over the last 4 weeks, I have } \\
\text { had shortness of breath: }\end{array}$ & & & & & \\
\hline $\begin{array}{l}\text { 4. Over the last 4 weeks, I have } \\
\text { had episodes of wheezing: }\end{array}$ & & & & & \\
\hline
\end{tabular}

5. During the last $\mathbf{4}$ weeks, how many severe or very unpleasant episodes of lung/respiratory problems have you had? Mark one answer only.

more than 3 episodes

3 episodes

2 episodes

1 episode

no episodes

St. George's Respiratory Questionnairc. Reproduced and used with permission from PW Jones. U.S. version adapted and modified with permission by Judith Barr, Sc.D., Northeastern Univ., Boston. MA. 
6. How long did the worst episode of lung/respiratory problem last? Mark one answer only.

Go to question 7 if you didn't have a severe episode.

a week or more

3 or more days

1 or 2 days

less than a day

7. Over the last 4 weeks, in an average week, how many good days (with few lung/respiratory problems) have you had? Mark one answer only.

$\left[\begin{array}{l}\text { None } \\ 1 \text { or } 2 \\ 3 \text { or } 4 \\ \text { nearly every day } \\ \text { every day }\end{array}\right.$

8. If you wheeze, is it worse in the morning? If you don't wheeze, go to Part 2.

No
Yes

\section{Part 2}

\section{Section 1:}

How would you describe your lung/respiratory condition? Mark one answer only.

The most important problem I have

Causes me a lot of problems

Causes me a few problems

Causes me no problem

St. George's Respiratory Questionnaire. Reproduced and used with permission from PW Jones. U.S. version adapted and modified with permission by Judith Barr, Sc.D., Northeastern Univ., Boston, MA. 
If you have ever held a job, please mark one of these answers:

My lung/respiratory problem made me stop my job.

My lung/respiratory problem interferes with my job or made me change my job.

My lung/respiratory problem does not affect my job.

Section 2: These are questions about what activities usually make you feel short of breath. Mark either True or False as it applies to you now.

\begin{tabular}{|l|c|c|}
\hline & True & False \\
\hline Sitting or lying still & & \\
\hline Washing yourself or dressing & & \\
\hline Walking in the house & & \\
\hline Walking outside on level ground & & \\
\hline Walking up a flight of stairs & & \\
\hline Walking up hills & & \\
\hline Playing sports or active games (baseball, tennis, etc.) & & \\
\hline
\end{tabular}

Section 3: These are more questions about your cough and shortness of breath. Mark either True or False as it applies to you now.

\begin{tabular}{|l|l|l|}
\hline & True & False \\
\hline Coughing hurts. & & \\
\hline Coughing makes me tired. & & \\
\hline I am short of breath when I talk. & & \\
\hline I am short of breath when I bend over. & & \\
\hline My coughing or breathing disturbs my sleep. & & \\
\hline I become exhausted easily. & & \\
\hline
\end{tabular}

St. George's Respiratory Questionnaire. Reproduced and used with permission from PW Jones. U.S. version adapted and modified with permission by Judith Barr, Sc.D., Northeastern Univ., Boston, MA. 
Section 4: These are questions about other effects that your lung/respiratory problem may have on you. Mark either True or False as it applies to you now.

\begin{tabular}{|l|l|l|}
\hline & True & False \\
\hline My coughing or breathing is embarrassing in public. & & \\
\hline $\begin{array}{l}\text { My lung/respiratory problem is a nuisance to my family, friends } \\
\text { or neighbors. }\end{array}$ & & \\
\hline I panic or get afraid when I cannot catch my breath. & & \\
\hline I feel that I am not in control of my lung/respiratory problem. & & \\
\hline I do not expect my lung/respiratory problem to get any better. & & \\
\hline $\begin{array}{l}\text { I have become frail or an invalid because of my lung/respiratory } \\
\text { problem. }\end{array}$ & & \\
\hline Exercise is not safe for me. & & \\
\hline Everything seems too much of an effort. & & \\
\hline
\end{tabular}

Section 5: These are questions about your lung/respiratory medication, including oxygen, inhalers and pills. If you are not receiving medication, go to Section 6. Mark either True or False as it applies to you now.

\begin{tabular}{|l|l|l|}
\hline & True & False \\
\hline My lung/respiratory medication does not help me very much. & & \\
\hline $\begin{array}{l}\text { I get embarrassed using my lung/respiratory medication in } \\
\text { public. }\end{array}$ & & \\
\hline $\begin{array}{l}\text { I have unpleasant side effects from my lung/respiratory } \\
\text { medication. }\end{array}$ & & \\
\hline My lung/respiratory medication interferes with my life a lot. & & \\
\hline
\end{tabular}

St. George's Respiratory Questionnaire. Reproduced and used with permission from PW Jones. U.S. version adapted and modified with permission by Judith Barr, Sc.D., Northeastern Univ., Boston, MA. 
Section 6: These are questions about how your activities might be affected by your breathing problem. For each item, answer True if one or more parts applies to you because of your breathing problem. Otherwise answer False.

\begin{tabular}{|c|c|c|}
\hline \multirow{2}{*}{\multicolumn{3}{|c|}{ I take a long time to get washed or dressed. }} \\
\hline & & \\
\hline I cannot take a bath or shower, or I take a long time to do it. & & \\
\hline I walk slower than other people my age, or I stop to rest. & & \\
\hline $\begin{array}{l}\text { Jobs such as household chores take a long time, or I have to stop } \\
\text { to rest. }\end{array}$ & & \\
\hline If I walk up one flight of stairs, I have to go slowly or stop. & & \\
\hline If I hurry or walk fast, I have to stop or slow down. & & \\
\hline $\begin{array}{l}\text { My breathing problem makes it difficult to do things such as } \\
\text { walking up hills, carrying things up stairs, light gardening such as } \\
\text { weeding, dancing, playing golf or light sports such as horseshoes. }\end{array}$ & & \\
\hline $\begin{array}{l}\text { My breathing problem makes it difficult to do things such as } \\
\text { carrying heavy loads, digging in the garden or shoveling snow, } \\
\text { jogging or walking briskly, playing tennis or swimming. }\end{array}$ & & \\
\hline $\begin{array}{l}\text { My breathing problem makes it difficult to do things such as very } \\
\text { heavy manual labor, riding a bike, running, swimming fast or } \\
\text { playing competitive sports. }\end{array}$ & & \\
\hline
\end{tabular}

Section 7: We would like to know how your breathing usually affects your daily life. Mark True or False as it applies to you because of your lung/respiratory problem.

\begin{tabular}{|l|l|l|}
\hline & True & False \\
\hline I cannot play sports or active games. & & \\
\hline I cannot go out for entertainment or recreation. & & \\
\hline I cannot go out of the house to do the grocery shopping. & & \\
\hline I cannot do household chores. & & \\
\hline I cannot move far from my bed or chair. & & \\
\hline
\end{tabular}

St. George's Respiratory Questionnaire. Reproduced and used with permission from PW Jones. U.S. version adapted and modified with permission by Judith Barr, Sc.D., Northeastern Univ.. Boston, MA 
Here is a list of other activities that your lung/respiratory problem may prevent you from doing. (You do not have to fill these in, they are just to remind you of ways in which your shortness of breath may affect you):

- Going for walks or walking the dog

- Doing activities or chores at home or in the garden

- Having sexual intercourse

- Going to church, or place of entertainment

- Going out in bad weather or into smoky rooms

- Visiting family or friends or playing with children

Please write in any other important activities that your lung/respiratory problem may stop you from doing:

Now, would you mark the one statement which you think best describes how your breathing problem affects you:

It does not stop me from doing anything I would like to do.

It stops me from doing one or two things I would like to do.

It stops me from doing most of the things I would like to do.

It stops me from doing everything I would like to do.

Thank you for filling out this questionnaire. Please check to be sure that you have answered all questions.

St. George's Respiratory Questionnaire. Reproduced and used with permission from PW Jones. U.S. version adapted and modified with permission by Judith Barr, Sc.D., Northeastern Univ., Boston, MA. 


Your name: 1 Today's date:

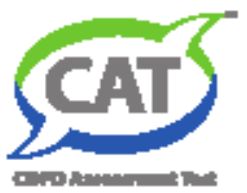

\section{How is your COPD? Take the COPD Assessment Test ${ }^{\mathrm{TM}}$ (CAT)}

This questionnaire will help you and your healthcare professional measure the impact COPD (Chronic Obstructive Pulmonary Disease) is having on your wellbeing and daily life. Your answers, and test score, can be used by you and your healthcare professional to help improve the management of your COPD and get the greatest benefit from treatment

For each item below, place a mark $(X)$ in the box that best describes you currently. Be sure to only select one response for each question.

Examplea I am very happy 0 (0) (3) (3) (3) (3) very sad

I never cough $\quad(0)(1)(2)(3)(4)(5)$ I cough all the time
SCORE

I have no phlegm (mucus) In my chest at all

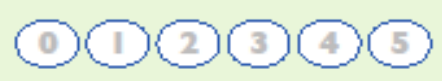

My chest is completely full of phlegm (mucus)

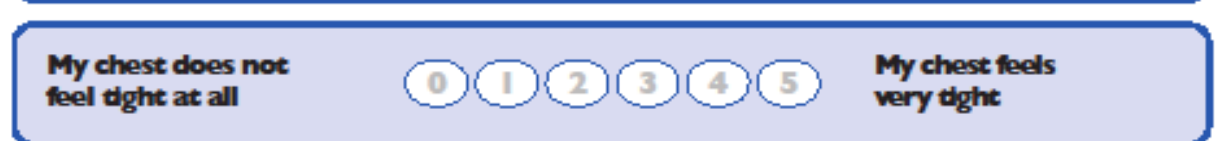

When I walk up a hill or one filght of stairs I am not breathless

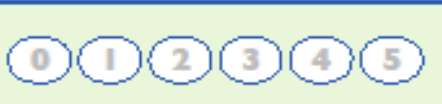

When I walk up a hill or one nilght of stairs I am very breathless

I am not llmited doing any activitles at home

\section{(0) (1) 2$)(3)(4)(5)$}

I am very limited doing acthulties at home

\begin{tabular}{|c|c|}
\hline $\begin{array}{l}\text { I am confident leaving } \\
\text { my home desplte } \mathbf{m y} \\
\text { lung condiltion }\end{array}$ & $\begin{array}{l}\text { I am not at all confident } \\
\text { leaning } \mathrm{my} \text { home because } \\
\text { of } \mathrm{my} \text { lung condition }\end{array}$ \\
\hline
\end{tabular}

I sleep soundly $(0)(1)(2)(3)(4)(5) \quad \begin{aligned} & \text { I don't sleep soundly } \\ & \text { because of my lung } \\ & \text { condition }\end{aligned}$

I have lots of energy

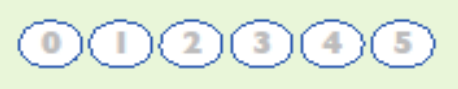

I have no energy at all

COPD Assessment Test and the CAT logo is a trade mark of the Glaxosmithiline group of companies. O 2009 GlaxoSmithKline group of companles. All nghts reserved. Last Updated: February 24, 2012
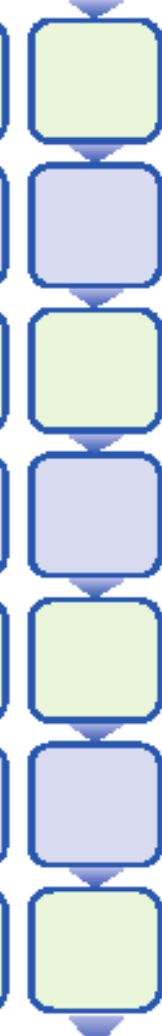


\section{FORM A: FOR SELF-ADMINISTRATION BY THE RESPONDENT (revised 4-2000) \\ DUKE HEAL TH PROFILE (The DUKE) \\ Duke University Medical Center, Durham, N.C.. U.S.A.}

Date Today:

Name:

Date of Birth:

Female

ID Number:

INSTRUCTIONS: Here are some questions about your health and feelings. Please read each question carefully and check $(\sqrt{ })$ your best answer. You should answer the questions in your own way. There are no right or wrong answers. (Please ignore the small scoring numbers next to each blank.)
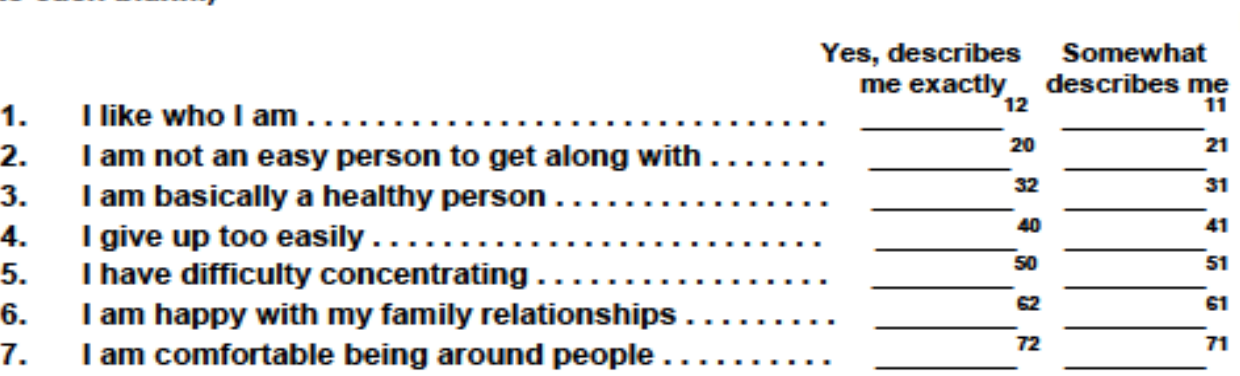

No, doesn't S, describes Somewhat describe me me exactly describes me at all at all

IODAY would you have any physical trouble or difficulty:

8. Walking up a flight of stairs .............

9. Running the length of a football field .........

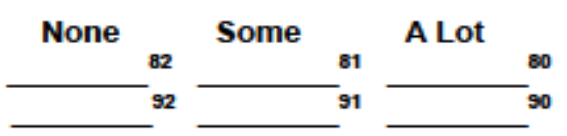

DURING THE PAST WEEK: How much trouble have you had with:

10. Sleeping. . . . . . . . . . . . . . . . . . .

11. Hurting or aching in any part of your body......

12. Getting tired easily . . . . . . . . . . . . . .

13. Feeling depressed or sad $\ldots \ldots \ldots \ldots \ldots \ldots$

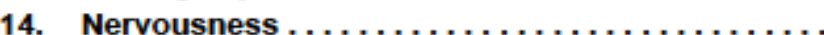

DURING THE RAST WEEK: How often did you:

15. Socialize with other people (talk or visit

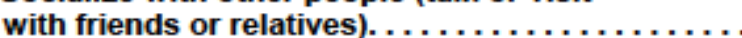

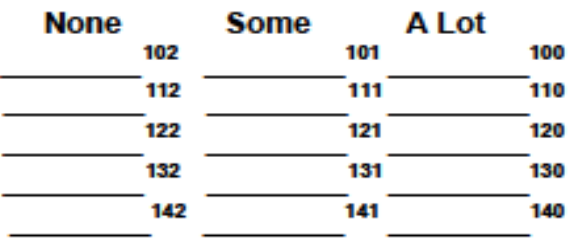

16. Take part in social, religious, or recreation activities (meetings, church, movies,

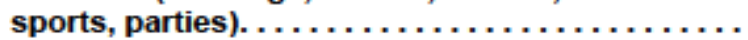

\section{None}

Some

A Lot 150 151 152

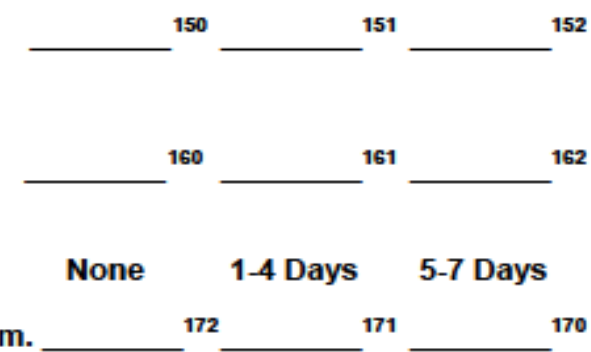




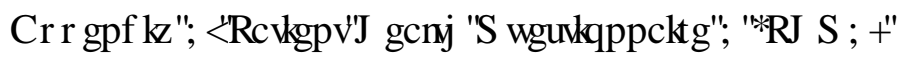

\section{PATIENT HEALTH QUESTIONNAIRE (PHQ-9)}

NAME:

DATE:

Over the last 2 weeks, how of ten have you been bothered by any of the following problems? (use " $\checkmark$ " to indicate your answer)

1. Little interest or pleasure in doing things

2. Feeling down, depressed, or hopeless

3. Trouble falling or staying asleep, or sleeping too much

4. Feeling tired or having little energy

5. Poor appetite or overeating

6. Feeling bad about yourself-or that you are a failure or have let yourself or your family down

7. Trouble concentrating on things, such as reading the newspaper or watching television

8. Moving or speaking so slowly that other people could have noticed. Or the opposite - being so figety or restless that you have been moving around a lot more than usual

9. Thoughts that you would be better of dead, or of hurting yourself

\begin{tabular}{l|c|c|c|c}
\cline { 2 - 5 } & Not at all & $\begin{array}{c}\text { Several } \\
\text { days }\end{array}$ & $\begin{array}{c}\text { More than } \\
\text { half the } \\
\text { days }\end{array}$ & $\begin{array}{c}\text { Nearly } \\
\text { every day }\end{array}$ \\
\cline { 2 - 5 } & 0 & 1 & 2 & 3 \\
\hline \multirow{2}{*}{ loo much } & 0 & 1 & 2 & 3 \\
\hline failure or & 0 & 1 & 2 & 3 \\
\hline & 0 & 1 & 2 & 3 \\
\hline
\end{tabular}

\begin{tabular}{lll|}
$\begin{array}{l}\text { (Healnhcare professional: For interpretation of TOTAL, TOTAL: } \\
\text { please refer to accompanying scoring card). }\end{array}$ & add columns \\
\hline you checked off any probiems, how difficut & Not diffic ult at all \\
\hline ve these problems made it for you to do & Somewhat difficult \\
\hline
\end{tabular}

Copyright $\$ 1999$ Pfizer Inc. All rights reserved. Reproduced with pemission. PRIME-MDO is a trademark of Pfizer Inc. A.2663B $10-04-2005$ 


\section{BERLIN QUESTIONNAIRE}

Height $(\mathrm{m}) \_$Weight $(\mathrm{kg}) \_$Age___ Male / Female

Please choose the correct response to each question.

\section{CATEgory 1}

1. Do you snore?

a. Yes

b. No

_c. Don't know

If you snore:

2. Your snoring is:

_ a. Slightly louder than breathing

_b. As loud as talking

_c. Louder than talking

_d. Very loud - can be heard in adjacent rooms

3. How often do you snore

_ a. Nearly every day

-b. 3-4 times a week

_c. 1-2 times a week

-d. 1-2 times a month

_e. Never or nearly never

4. Has your snoring ever bothered other people?

a. Yes

-b. No

c. Don't Know

$\overline{5}$. Has anyone noticed that you quit breathing during your sleep?

_ a. Nearly every day

_b. 3-4 times a week

_c. 1-2 times a week

_d. 1-2 times a month

_ e. Never or nearly never

\section{CATEgory 2}

6. How often do you feel tired or fatigued after your sleep?

_ a. Nearly every day

-b. 3-4 times a week

c. 1-2 times a week

_d. 1-2 times a month

_ e. Never or nearly never

7. During your waking time, do you feel tired, fatigued or not up to par?

_ a. Nearly every day

-b. 3-4 times a week

_c. 1-2 times a week

-d. 1-2 times a month

_e. Never or nearly never

8. Have you ever nodded off or fallen asleep while driving a vehicle?

- a. Yes

-b. No

If yes:

9. How often does this occur?

a. Nearly every day

b. 3-4 times a week

_c. 1-2 times a week

d. 1-2 times a month

_e. Never or nearly never

Category 3

10. Do you have high blood pressure?

- Yes

- No

_ Don't know 
Categories and scoring:

Category 1: items 1, 2, 3, 4, 5 .

Item 1: if 'Yes', assign 1 point

Item 2: if 'c' or ' $d$ ' is the response, assign 1 point

Item 3: if ' $a$ ' or ' $b$ ' is the response, assign 1 point

Item 4: if ' $a$ ' is the response, assign 1 point

Item 5: if ' $a$ ' or ' $b$ ' is the response, assign 2 points

Add points. Category $\mathbf{1}$ is positive if the total score is $\mathbf{2}$ or more points Category 2: items 6, 7, 8 (item 9 should be noted separately).

Item 6: if ' $a$ ' or ' $b$ ' is the response, assign 1 point

Item 7: if ' $a$ ' or ' $b$ ' is the response, assign 1 point

Item 8: if ' $a$ ' is the response, assign 1 point

Add points. Category 2 is positive if the total score is 2 or more points Category 3 is positive if the answer to item 10 is 'Yes' OR if the BMI of the patient is greater than $30 \mathrm{~kg} / \mathrm{m} 2$.

(BMI must be calculated. BMI is defined as weight $(\mathrm{kg})$ divided by height $(\mathrm{m})$ squared, i.e., $\mathrm{kg} / \mathrm{m}_{2}$ ).

High Risk: if there are 2 or more Categories where the score is positive

Low Risk: if there is only 1 or no Categories where the score is positive 


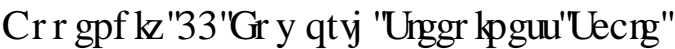

\section{Epworth Sleepiness Scale}

Name:

Date:

Your age: $(\mathrm{Yr})$

Your sex: $\square$ Male $\square$ Female

How likely are you to doze off or fall asleep in the situations described below, in contrast to feeling just tired?

This refers to your usual way of life in recent times.

Even if you haven't done some of these things recently try to work out how they would have affected you.

Use the following scale to choose the most appropriate number for each situation:-

$$
\begin{aligned}
& 0=\text { would never doze } \\
& 1=\text { Slight chance of dozing } \\
& 2=\text { Moderate chance of dozing } \\
& 3=\text { High chance of dozing }
\end{aligned}
$$

\section{Situation}

Chance of dozing

Sitting and reading

Watching TV

Sitting, inactive in a public place (e.g. a theatre or a meeting)

As a passenger in a car for an hour without a break

Lying down to rest in the afternoon when circumstances permit

Sitting and talking to someone

Sitting quietly after a lunch without alcohol

In a car, while stopped for a few minutes in the traffic

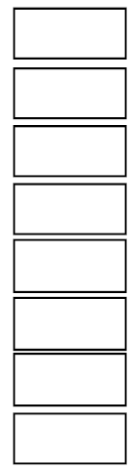

Total

Score:

0-10 Normal range

10-12 Borderline

12-24 Abnormal 


\section{\$ SSHDA[ प्य, 5 \%\$ SSLRYDO HMU]}

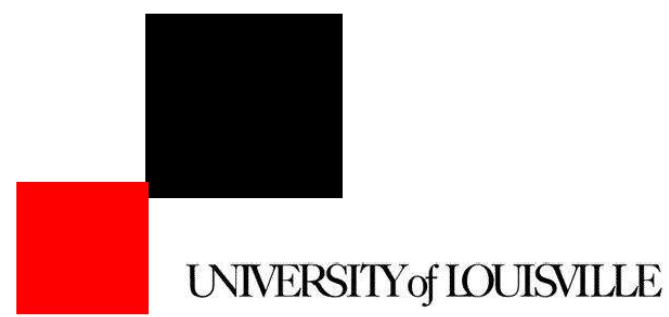

INSTITUTIONAL REVIEW BOARDS

University of Louisville

MedCenter One, Suite 200

501 E. Broadway

Louisville, Kentucky 40202-1798

Office: $\quad 502-852-5188$

Fax: $\quad 502-852-2164$

To: $\quad$ Folz, Rodney

From: $\quad$ The University of Louisville Institutional Review Board (IRB)

Date: $\quad$ Friday, August 16, 2013

Subject: Approval Letter

Tracking \#: 13.0428

Title: $\quad$ Effectiveness of COPD disease management program at University of Louisville

Approval $\quad 8 / 15 / 2013$ 12:00:00 AM

Date:

Expiration 8/14/2014 12:00:00 AM

Date:

This study was reviewed on $08 / 15 / 2013$ by the chair/vice chair of the Institutional Review Board and approved through the Expedited Review Procedure, according to 45 CFR 46.110(b), since this study falls under Expedited Category (5) Research involving materials (data, documents, records, or specimens) that have been collected, or will be collected solely for non-research purposes (such as medical treatment or diagnosis).

This study was also approved through 45 CFR 46.116 (D), which means that it has been granted a waiver of informed consent because it meets the following criteria:

${ }^{\circ}$ The research involves no more than minimal risk to the subjects.

- The waiver or alteration will not adversely affect the rights and welfare of the subjects.

- The research could not practicably be carried out without the waiver or alteration.

${ }^{\circ}$ Whenever appropriate, the subjects will be provided with the additional pertinent information after participation.

The following items have been approved:

- Research Protocol, not dated

- HIPAA Complete Waiver, not dated

This study now has final IRB approval from $08 / 15 / 2013$ through $08 / 14 / 2014$. You should complete and return the Progress Report/Continuation Request Form EIGHT 
weeks prior to this date in order to ensure that no lapse in approval occurs. The committee will be advised of this action at their next full board meeting.

Site Approval

If this study will take place at an affiliated research institution, such as Jewish Hospital/St Marys Hospital, Norton Healthcare, or University of Louisville Hospital, permission to use the site of the affiliated institution may be necessary before the research may begin. If this study will take place outside of the University of Louisville Campuses, permission from the organization should be obtained before the research may begin. Failure to obtain this permission may result in a delay in the start of your research.

\section{Privacy \& Encryption Statement}

The University of Louisville's Privacy and Encryption Policy requires such information as identifiable medical and health records: credit card, bank account and other personal financial information; social security numbers; proprietary research data; dates of birth (when combined with name, address and/or phone numbers) to be encrypted. For additional information: http://security.louisville.edu/PolStds/ISO/PS018.htm.

1099 Information (If Applicable)

As a reminder, in compliance with University policies and Internal Revenue Service code, all payments (including checks, gift cards, and gift certificates) to research subjects must be reported to the University Controller's Office. Petty Cash payments must also be monitored by the issuing department and reported to the Controller's Office. Before issuing compensation, each research subject must complete a W-9 form.

For additional information, please contact the Controller's Office at 852-8237 or contro II@louisville.edu.

The following is a link to an Instruction Sheet for BRAAN2 "How to Locate Stamped/Approved Documents in BRAAN2":

http://louisville.edu/research/braan2/help/ApprovedDocs.pdf/view

Please begin using your approved (stamped) document(s) at this time. The previous versions are no longer valid. If you need assistance in accessing any of the study documents, please feel free to contact our office at (502) 852-5188. You may also email our service account at hsppofc@louisville.edu for assistance.

Best wishes for a successful study. If you have any questions please contact the HSPPO at (502) 852-5188 or hsppofc@louisville.edu.

Thank you.

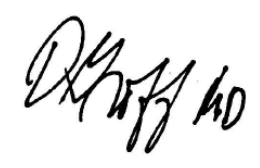


\&8 55,\&8/ $80[9,7 \$(\square$

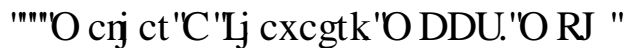

\section{QUALIFICATION SUMMARY:}

- A doctorate degree in epidemiology with special interest in epidemiological research, health economics and outcome research, pharmacoepidemiology, research methodology, comparative effectiveness research

- Strong background in epidemiology and biostatistics

- Trained in advanced statistical methods including Hierarchical Linear Modeling and propensity score analysis

- 2 years of experience in analyzing administrative claims data

- More than 5 years of experience in SAS

- Team player with strong communication, statistical and analytical skills

\section{EDUCATION:}

\section{Doctor of Philosophy (Ph.D.)}

Aug 2010 - April 2014

Concentration: Epidemiology with minor in Biostatistics

University of Louisville, Louisville, Kentucky

Dissertation: Clinical and Cost Effectiveness of Chronic Obstructive Pulmonary Disease management program at the University of Louisville

Committee: Dr. Frank Groves (chair), Dr. Rodney Folz (advisor), Dr. Richard Baumgartner, Dr. Susan Muldoon, Dr. Guy Brock

\section{Master of Public Health (M.P.H.)}

Aug 2005-May 2009

Concentration: Epidemiology with minor in Biostatistics

University of Kentucky, Lexington, KY

Thesis: Comparison of 3 versus 4 and Protease Inhibitors (PI) versus non-PI Combinations as Initial Highly Active Antiretroviral Therapy (HAART): Experience from 1998-2007 
Committee: Dr. Steven Browning (chair), Dr. Richard Greenberg (advisor), Dr. Heather

Bush

Bachelor of Medicine and Bachelor of Surgery (equivalent to MD)

September 1999 - March 2005

Sardar Patel University, Gujarat, India

\section{Professional EXPERIENCE}

Graduate Research Assistant August 2012-present

Department of Epidemiology, University of Louisville

Supervisor: Dr. Frank Groves, Dr. Rodney Folz

- Analyzed administrative claims data from United Healthcare retrospectively

- Prepared and submitted IRB documents

- Retrieved data from Electronic Medical Records

- Assisted supervisors in writing grant proposal

- Reviewed literature for research proposal

Graduate Fellow August 2010-July2012

Department of Epidemiology, University of Louisville

Supervisor: Dr. Richard Baumgartner

- Analyzed large data sets like NHANES, NHEFS using advanced statistical methods like logistic regression, linear regression, survival analysis

- Prepared manuscript for submission to peer review journals

Research Associate July 2008-April 2010

University of Kentucky

Supervisor: Dr. Juan Yepes

- Developed proposals under supervision of Principal Investigator

- Analyzed data from randomized controlled trial of Burning mouth disorder and dry mouth

- Assisted supervisor in grant writing, preparing IRB documents, recruiting subjects for trial and collected primary data.

- Prepared manuscript for peer review journal submission

- Provided Quality Assurance of analytic file

- Performed project related statistical analysis \& interpreted results

- Communicated \& disseminated study results effectively in the form of slide presentations

Research Assistant Aug 2006- June 2008

University of Kentucky

Supervisor: Dr. Richard Greenberg 
- Assisted supervisor in IRB submission and literature review

- Manipulated and analyzed data using SAS and Microsoft Excel

\section{Statistical MethodS}

- Ordinary Least Square regression

- General Linear Modeling

- Survey design adjusted multivariate analysis

- Longitudinal Data Analysis

- Survival Analysis and Cox Regression model

\section{STATISTICAL SOFTWARE}

- SAS

\section{AfFiliations}

- American Public Health Association

- American Federal Medical Research

- American Thoracic Society

\section{Publications}

- Myint T, Anderson AM, Sanchez A, Farabi A, Hage C, Baddley JW, Jhaveri M, Greenberg RN, Bamberger DM, Rodgers M, Crawford TN, Wheat LJ. Histoplasmosis in patients with human immunodeficiency virus/acquired immunodeficiency syndrome (HIV/AIDS): multicenter study of outcomes and factors associated with relapse. Medicine. Jan 2014;93(1):11-18

- Brimhall J, Jhaveri MA, Yepes JF. Efficacy of cevimeline vs. pilocarpine in the secretion of saliva: a pilot study. Special care in dentistry : official publication of the American Association of Hospital Dentists, the Academy of Dentistry for the Handicapped, and the American Society for Geriatric Dentistry. May-Jun 2013;33(3):123-127

- Luftman V, Martin CA, Guenthner G, Arnold SM, Mullett TW, Jhaveri M. The power of videotaped personal statements of patients with lung cancer: a recruitment strategy for smoking prevention and cessation programs. Oncology nursing forum. Jan 2011;38(1):11-14 
- Lommel K, Bamford J, Jhavari M, Martin C, Crofford L. A pilot study: pain, fatigue and stress in maternal relatives of adolescent female psychiatric inpatients assessed for juvenile primary fibromyalgia syndrome. International journal of adolescent medicine and health. 2011;23(1):59-63

- Jhaveri MA, Mawad HW, Thornton AC, Mullen NW, Greenberg RN. Tenofovirassociated severe bone pain: I cannot walk! Journal of the International Association of Physicians in AIDS Care. Sep-Oct 2010;9(5):328-334

- Jhaveri MA, Browning SR, Bush H, Thornton A, Greenberg RN. Comparison of 3-drug versus 4-drug and PI versus non-PI combinations as initial HAART: experience from 1998 to 2007. Journal of the International Association of Physicians in AIDS Care. Sep-Oct 2009;8(5):299-307

\section{Presentations}

\section{Poster Presentations}

- Malhar Jhaveri, Frank Groves, Bryan Beatty, Rodrigo Cavallazzi, MD, MPH, R. Folz, MD, PhD. Clinical Effectiveness of the University of Louisville Chronic Obstructive Pulmonary Disease Management Program Poster presented at American Thoracic Society; San Diego, CA (May 2014)

- Thein Myint, Albert M. Anderson, Alejandro Sanchez, Ali Farabi, Chadi Hage, John W. Baddley, Malhar Jhaveri, Richard N Greenberg. Outcomes after withdrawal of antifungal therapy for AIDS-associated histoplasmosis and factors associated with relapse Poster presented at Infectious Disease week (ID week); San Diego, CA (Oct 2012)

- Juan Yepes, Malhar Jhaveri, Andrew Hoellein. Knowledge and Attitudes of Dental Students towards HIV Infection and AIDS Poster presented at Annual Meeting of Hispanic Dental Association; Carefree, AZ (Nov 2008)

- Anand G. Vaishnav, Creed Pettigrew, Michael Dobbs, Stephan Ryan, Malhar Jhaveri, Lisa Bellamy. JCAHO Primary Stroke Center Core Measures: Influence of Stroke Care Unit Poster presented at American Academy of Neurology; Chicago, IL (May 2008)

- Kiyoung Lee, Elien Hahn, Malhar Jhaveri, Riker, R, Sara Head. Indoor Air Quality and Enforcement of Smoke-free Policies in public venues and schools 
Poster presented at International Conference on Environmental Epidemiology; Paris, France

(Aug 2006)

\section{Oral Presentation}

- Malhar Jhaveri, Heather Bush, Steven Browning, Alice Thornton, Richard Greenberg. Comparison of 3 versus 4 Drugs as Initial HAART: University of Kentucky Experience from 1998-2007

Presented at American Federal Medical Research Southern Regional Conference; New Orleans, LA (Feb 2009)

\section{HoNORS/AWARDS AND ACTIVITIES:}

- First Place Doctoral student award at Research Louisville conference (Sep 2013)

- Inducted into the University of Kentucky Delta Epsilon Iota society (Jan 2008)

- Student Facilitator in a "22nd Kentucky Governors Safety and Health Conference", Louisville, KY (May 2006)

- Certificate for excellent work on Tobacco Cessation Clinic, WHO conducted Pulse Polio Immunization program and Ministry of Health and Family Welfare (Jul 2004). 